Portland State University

PDXScholar

$1-1-2010$

\title{
American Belly Dance and the Invention of the New Exotic: Orientalism, Feminism, and Popular Culture
}

Jennifer Lynn Haynes-Clark

Portland State University

Follow this and additional works at: https://pdxscholar.library.pdx.edu/open_access_etds Let us know how access to this document benefits you.

\section{Recommended Citation}

Haynes-Clark, Jennifer Lynn, "American Belly Dance and the Invention of the New Exotic: Orientalism, Feminism, and Popular Culture" (2010). Dissertations and Theses. Paper 20.

https://doi.org/10.15760/etd.20

This Thesis is brought to you for free and open access. It has been accepted for inclusion in Dissertations and Theses by an authorized administrator of PDXScholar. Please contact us if we can make this document more accessible: pdxscholar@pdx.edu. 
American Belly Dance and the Invention of the New Exotic:

Orientalism, Feminism, and Popular Culture

by

Jennifer Lynn Haynes-Clark

A thesis submitted in partial fulfillment of the requirements for the degree of

\author{
Master of Arts \\ in \\ Anthropology
}

Thesis Committee:

Michele R. Gamburd, Chair

Sharon A. Carstens

Priya Kandaswamy

Portland State University

(C)2010 


\begin{abstract}
Belly dance classes have become increasingly popular in recent decades in the United States. Many of the predominantly white, middle-class American women who belly dance proclaim that it is a source of feminist identity and empowerment that brings deeper meaning to their lives. American practitioners of this art form commonly explain that it originated from ritual-based dances of ancient Middle Eastern cultures and regard their participation as a link in a continuous lineage of female dancers. In contrast to the stigmatization and marginalization of public dance performers in the Middle East today, the favorable meaning that American dancers attribute to belly dance may indicate an imagined history of this dance.

Based on ethnographic fieldwork conducted on the West Coast of the United States and Morocco in 2008-2009, I explore American belly dance utilizing theoretical contributions from feminism, Foucauldian discourse analysis, and postmodernism. I argue that an anthropological investigation of American belly dance reveals that its imagery and concepts draw from a larger discourse of Orientalism, connected to a colonial legacy that defines West against East, a process of othering that continues to inform global politics and perpetuates cultural imperialism. But the creative identity construction that American women explore through belly dance is a multi-layered and complex process. I disrupt the binary assumptions of Orientalist thinking, highlighting the heterogeneity and dynamic quality of this dance community and exploring emergent types of American belly dance. Rather than pretending to be the exotic Other, American belly dancers are inventing a new exotic Self. This cultural anthropological study contributes to a greater understanding of identity and
\end{abstract}


society by demonstrating ways that American belly dancers act as agents, creatively and strategically utilizing discursive motifs to accomplish social and personal goals. 


\section{Dedication}

This thesis is dedicated to my husband, Jason, for his abiding patience and support. 


\section{Acknowledgments}

I would like to thank all of the dancers who so generously shared their stories with me. I am greatly inspired by their passion and commitment to joyful dancing.

I would also like to thank my advisor, Michele R. Gamburd, whose enthusiasm for anthropology and teaching is an inspiration to me. I am ever grateful for her enormous support, guidance, and the many extra hours she dedicated to help in this endeavor. 


\section{Table of Contents}

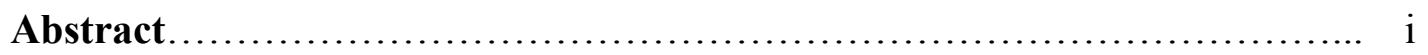

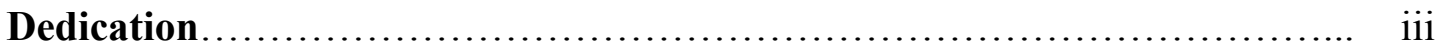

Acknowledgments.................................................... iv

List of Figures...................................................... vii

\section{Chapter 1}

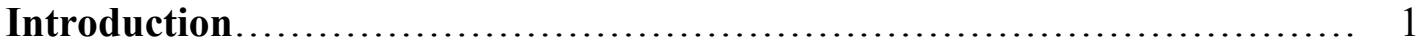

Theoretical Perspectives.................................................. 5

Orientalism/ Critique of Orientalism................................. 6

Postmodernism.................................................... 7

Invented Tradition................................................. 8

Alternative Western Feminism........................................ 10

Research Site and Methodology......................................... 11

Reflexive Approach: My Background and Perspective....................... 12

Overview of Chapters.................................................... 15

\section{Chapter 2}

\section{A History of Oriental Dance}

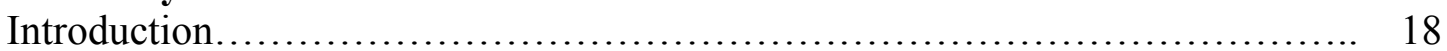

Theoretical Orientations................................................ 18

Geographical and Historical Overview of Oriental Dance..................... 20

Colonial Presence in the East................................................ 22

Oriental Travel Literature................................................ 25

Orientalist Painting, Photography, and Postcards.......................... 27

World's Fairs and Exhibitions.......................................... 30

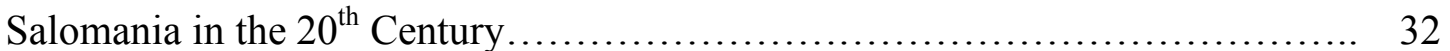

The "Scandalous" Descendants of Oriental Dance............................. 37

Conclusion.......................................................... 38

\section{Chapter 3}

Invented Tradition and Postmodernism: 1950's to Present in American

\section{Belly Dance}

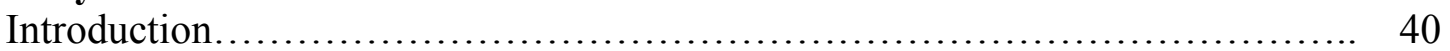

Theoretical Orientations.................................................. 41

Hollywood's Belly Dance............................................... 43

Arab Americans: Migration and Transnationalism, 1960s to Present............. 45

Modern Tourism.................................................... 47

My Observations in Morocco, Fall 2009.................................... 49

Modern Types in the West........................................... 54

The Imperial Privilege of Pastiche..................................... 60 
The American Cult of Invention and Revision of Tradition..................... 64

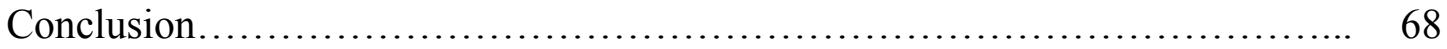

\section{Chapter 4}

American Belly Dance as Alternative Feminism

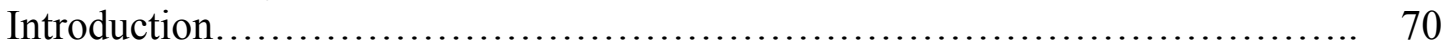

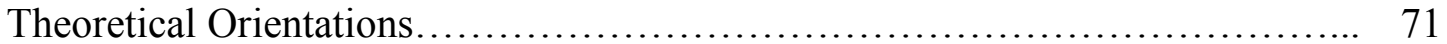

Inventing Alternative Feminisms Through Dance.............................. 74

Public Exposure.......................................................... 78

Fat Dancer, Skinny Dancer and Everyone In Between...................... 82

Belly Dance as Alternative Lifestyle and Community............................ 86

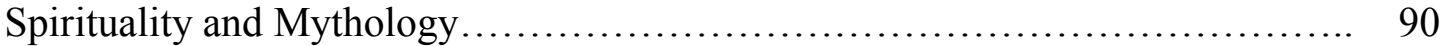

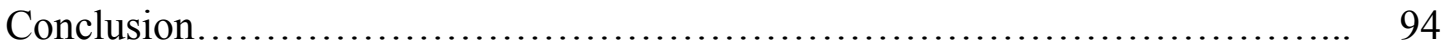

\section{Chapter 5}

\section{Dis-orienting American Belly Dance}

Introduction........................................................................... 96

Theoretical Orientations......................................................... 97

Belly Dance in the Modern Eastern Context.................................... 98

Imperial Dialogue: The East Gazing Upon the West........................... 101

Prejudice, Misunderstanding and Faux Pas Within the American Belly Dance

Community ........................................................... 102

Interstices............................................................. 104

Heterogeneity of the Belly Dance Community: Cultural Art v. Art Art............ 105

Internal Conflict Within the American Belly Dance Community................ 110

The Evolution of Occidental Dance: A Closer Look at Emergent Types.......... 117

Burlesque Belly Dance.......................................... 117

Gothic- The Modern Vamp...................................... 120

Cultural Fusions: Inventing New Exotics........................... 123

Conclusion.............................................................. 125

\section{Chapter 6}

\section{Conclusions}

Summary of Main Arguments............................................. 127

Implications of this Research............................................ 130

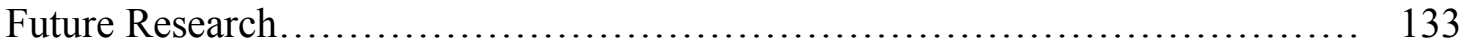

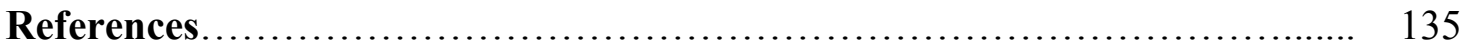




\section{List of Figures}

Figure 2.1- Palmolive Soap. Postcard purchased in Rabat, Morocco, October 2009.

Figure 3.1- Folies Bergere. Postcard purchased in Rabat, Morocco, October 2009.

Figure 3.2- Oriental dance class poster, Rabat Medina, Morocco, October 2009, Author's Photo......................................................... 5

Figure 3.3- Belly dance costumes for sale in Rabat souq, Morocco, October 2009, Author's Photo.

Figure 3.4- Male belly dancers, Marrakech, Morocco, November 2009, Author's Photo. 


\section{Chapter 1 \\ Introduction}

Joan $^{1}$ and I agreed to meet at her metaphysical store and dance studio for an interview one hot August afternoon in 2009. Her shop is located in an older building in a small Oregon downtown. As I opened the front door, the bells on the doorknob jingled. "Come in! You must be Jennifer," came a voice from the back of the room. As I walked back to greet Joan, my eyes scanned the brightly colored shelves. Available for purchase was incense, Egyptian statuary, Afghani jewelry, candles, perfume oils, fairy dolls, Egyptian coin and chiffon hip scarves, and glittery belt and halter tops sets.

In the course of our conversation, Joan confided that she had always been interested in Egyptian culture, even as a small child. She told me, "I had always been attracted to the Egyptian people, the mummies, the god and goddesses, the dancing and all." I asked Joan to explain more about her attraction to contemporary and ancient Egyptian cultures. Suddenly her lighthearted countenance became a bit more serious:

I am an ordained reverend. I have my own temple services. I teach how it used to be back in the day- it's a dying religion and there aren't many [of us] left. It's the Temple of Isis....Us Isians, we are trying to keep it alive- this ancient, ancient religion alive....It's the same thing with belly dancing. It's a spiritual connection for me. The goddess, her power, her strength, her beauty. When you are dancing it goes hand and hand.

I had never heard of the Temple of Isis. Because her dedication to Egyptian cultures, ancient and contemporary, was so strong, I asked Joan if she had ever traveled to Egypt. She replied:

I missed my time, I don't want to go now. I needed to go there in the forties, but I wasn't born yet. I talked to [another American belly dancer who had traveled to

\footnotetext{
${ }^{1}$ Pseudonyms are used to protect the identity of informants.
} 
Egypt] and she told me this stuff: trash out in the sand and human feces on top of the pyramids. I don't want to see that, because it's my place, it's my spirituality.

Joan's story is similar to those of the millions of American women who have taken belly dance classes or participated in the belly dance community since the 1970 s (Shay 2008:5). ${ }^{2}$ Interest in belly dance, especially American interpretations of Middle Eastern $^{3}$ dance, has spread internationally, with many dancers networking via hundreds of websites and online communities (Seller-Young 2005: 296). According to my research and that of others, many of these women are white, middle-class, well-educated professionals (Crosby 2000: 171). Although professional dancers in the Middle East are often stigmatized and marginalized, for many American practitioners of this dance their experiences have imbued their lives with a sense of deep meaning, supportive community and self-confidence. For these American women, belly dance is a particularly potent site for creative identity construction-a place where they can "become what they never

\footnotetext{
${ }^{2}$ I use the terms "belly dance" and "Oriental dance" interchangeably. Belly dance is a name that is derived from the French, danse du ventre, widely used when this dance was introduced to the U.S. in the late nineteenth century. For many practitioners, this name is considered an offensive misnomer because it evokes historical misunderstandings about the dance. Yet the term "belly dance" is the most common name used to describe this dance in the U.S. I use Oriental dance as well, because it evades some of the offensive connotations of the term "belly dance" and also reflects ways this dance is rooted in American and European Orientalist tropes.

${ }^{3}$ Throughout this thesis I use the terms Middle East, North Africa, the Orient and the East nearly interchangeably. I have done so because the terms North Africa and Middle East are the names familiar to most Americans and specifically American belly dancers to designate geographical and cultural regions. At the same time, I find these terms limiting. For example, Middle Eastern may mean just Arab peoples to one person, but may include Persians and some Central Asian and North African groups to another person. Furthermore, some belly dancers trace their dance roots also to Turkey, Greece, Pakistan, India and parts of West Africa including Niger, Mauritania, and Mali. Because of the broad expanse of the imagined Orient in the minds of many Americans, I choose to use the term East or Eastern, while also recognizing its inexactness.
} 
were" (Sellers- Young 2005: 298). It is this process of creative self-construction that I explore in this thesis.

I argue that American belly dance is an Occidental construction that unveils yearning for an exotic Self. I disrupt the notion that this dance genre, in its current manifestation, represents any credible link to "authentic" Middle Eastern dance traditions. My exegesis partly entails an unmasking of American belly dance as an "Oriental” dance; as Erdman states, “'Oriental dance' was an occidental invention” (1996: 288). Many of the characteristics associated with "authentic" belly dance are based on Hollywood fantasies of an exotic Eastern dance, particularly the two-piece costume, exported East via Hollywood films and then imported back West as an "exotic" dance tradition (Maira 2008: 322; Shay 2008; Shay and Sellers-Young 2005: 20-21). As I explain in detail in chapter 2, there is no Eastern belly dance that has not been colonized, hybridized or in some way influenced by the West (Karayanni 2004: 19; Savigliano 1995: 9). This realization forces an historicized and politicized view of this dance form and reinforces the notion that American belly dance is an invention.

This dance form is not merely invented, however, it is invented as a "tradition" in that its practitioners represent it as being connected to a distant past. American belly dance has the potential to link the ancient to the present in a profoundly personal yet politically fragmented way, as illustrated in Joan's story recounted above. Joan feels a

\footnotetext{
${ }^{4}$ I use the terms East/West and Orient/Occident, because they are powerful descriptors of an imagined geography that locates certain elements along a cultural continuum in opposition to one another. Although I intend to disrupt the dichotomous thinking that comprises Orientalist discourse, pursuing a dialectical study that supports an antiOrientalist perspective, these terms describe very real features in the cultural landscape, if but based on imaginings, that affect social realities.
} 
deep spiritual connection to ancient Egypt, but expresses repugnance towards modern Egyptian society, revealing that her link to a distant past is stronger than the present context. Rasmussen's experience as an American dancer living in the Middle East led her to conclude that, "Middle Eastern dance, once taken out of a community celebration, is always somewhat of a reconstruction," further supporting the notion of American belly dance as an invention (2005: 199). This invented American tradition is based on social needs and as these needs have been met, the tradition has gained power, meaning and legitimacy for its practitioners over the past few decades.

Orientalist tropes inherent in American belly dance permit the exploration of alternative identities for many of its practitioners. Yet individual and social identities are fluid and context-bound, therefore an analysis of this tradition must account for globalization, transnationalism and the rapidity of mass communications through revision. I demonstrate that not only is belly dance a reflection of Occidental fantasies, but as American belly dance evolves, it is turning away from the phantasmal linkage to Eastern women's traditions.

While I examine the ways American belly dance is transforming, I underscore the heterogeneity within this community, thus confronting the persistent binaries of Orientalist thinking. The American belly dance community consists of individuals with diverse opinions and intentions, which leads to internal conflicts and fragmentation. By highlighting the complexity of this community, I embark on an anti-Orientalist project, shattering the perceived polarities of West and East.

The study of belly dance has been widely undervalued or misunderstood by the larger academy and, I argue, by many belly dance scholars as well. I propose that the 
study of American belly dance represents a powerful intersection in discursive flows between East and West. ${ }^{5}$ Analysis unmasks truths about social needs and desires of the West, and the heterogeneous ways individual agents pursue those needs and desires. This topic intersects with issues of race, gender, class, and alterity, making its study important for understanding the complexities of resistance and complicity.

\section{Theoretical Perspectives}

In my examination of American belly dance, three main theoretical perspectives emerge: Orientalism; invented tradition and postmodernism; and feminism. In my analysis of this topic these theoretical orientations are mutually dependent and circularly intertwined, but I chose to approach each theory in a separate chapter for the sake of clarity. I began by using Orientalism to examine the colonial and early history of American belly dance to provide a context from which to discuss this dance as an Occidental construction. Having provided this basis for understanding the salience of Orientalist tropes in American belly dance, I explore this dance as an invented tradition. Impacted by the forces of postmodernity, American belly dance constitutes a pastiche of cultural references and artistic inspirations that continue to evolve into heterodox forms. Having explored the modern development of American belly dance, I then discuss gendered aspects of this community of practice. Discussion of belly dance allows practitioners to voice feminist concerns about body politics, community, lifestyle,

\footnotetext{
${ }^{5}$ At the time of this writing, the West continues to impose its political agenda upon the East, with minarets being outlawed in Switzerland and more American military forces being deployed to Afghanistan. Meanwhile, Eastern extremists answer back in the form of an attempted hijacking on December 25, 2009, and Al Qaeda infiltration of the U.S. military, killing soldiers in Afghanistan.
} 
economic power, and spirituality. Finally, I return to Orientalism, criticizing its binary assumptions by emphasizing the heterogeneity of the evolving American belly dance community, and intersection points between East and West.

\section{Orientalism}

The theory of Orientalism describes the West's discourse about the East, which establishes the East as an exotic Other against which the West defines its own identity. The motifs employed by American belly dance are deeply embedded in a larger discourse defining West against East, which Edward Said describes as characteristic of latent Orientalism (1978). This ideology seeks to repetitively represent the East as the exotic Other, characterized by particular stereotypes. Such stereotypes include notions of homogeneity, timelessness, spirituality, femininity, hedonism, and mysticism associated with a vaguely defined, anachronistic geography. The supposition of a natural dichotomy between "us" and "them" is an important element in all political strategy (Shay 2006: 52). What is harmful about Orientalism is that these representations amount to a selfreferential canonical discourse in the West, which leads to inaccuracies and is often used to justify political conquests, discrimination, and cultural appropriation.

Critics of Orientalism have suggested that Said reifies a binary structure, does not adequately challenge Western dominance or acknowledge Eastern agency, and thus lacks theoretical consistency. Said's analysis tends to privilege male-originated discourse, ignores the effects of class, and avoids the difficulties of agency (MacKenzie 1995: 11). Additionally, where the arts are concerned, Said's original theory neglects to recognize the ways art may actually run counter to the dominant mainstream, and when Said does 
discuss art, he relies almost exclusively on elite texts (MacKenzie 1995: 14). ${ }^{6}$ Said does address these shortcomings in his essay "Orientalism Reconsidered," in which he reasserts that Orientalist discourse draws an imaginary divide between the East and the West (2000). He also encourages a dialectical analysis that recognizes cultural pluralities and complexities in order to surmount the limitations of this imagined dichotomy. In this study, I utilize Orientalism to discuss the history of belly dance and the Orientalist motifs appropriated by the American belly dance community. I also challenge Orientalism in my analysis of the diversity of this community. Upon this historical background, I then turn to an exploration of American belly dance from the 1950s to the present, investigating the effects of postmodernism in the construction of this Occidental tradition.

\section{Postmodernism}

The theme of "us" versus "them" that Said explores in Orientalism reflects not reality but common perceptions of social groups. In the past, ideas about culture involved notions of distinct, static, isolated social groups that were generally unaffected by interactions with others. Modern cultural theory has recognized that this cultural concept is not only overly simplistic but also highly improbable. Social scientists now understand that people have always interacted with other social groups, absorbing and rejecting ideas from outside their native communities in creative, innovative and strategic ways. For example, Gupta and Ferguson state:

${ }^{6}$ Said does discuss his appreciation for legendary Egyptian belly dancer Tahia Carioca. He describes Carioca as subversive, sexy, and tasteful and says that his admiration for her dancing lasted throughout his lifetime (2000). 
Interstitiality and public culture has led to efforts to conceptualize cultural difference without invoking the orthodox ideas of 'culture'....We do, clearly, find the clustering of cultural practices that do not 'belong' to a particular 'people' or to a definite place (Gupta and Ferguson 1992: 19).

Cultural diffusion or the sharing of ideas and images is an inherent aspect of social experience.

I define postmodernism as a condition related to expanding globalization in the form of mass communications, technology, supra-national economic and political systems, transnationalism, and other cultural flows and discursive frames that defy territorial boundaries, blur the notion of discrete homogenous groupings, and disrupt historical notions of individual, local and global identities. For American belly dancers, the dance community is a vehicle for identity construction in the postmodern milieu, enabling women to feel intimately connected to others with similar interests in a tightknit community that simultaneously exists locally and globally. It is in the context of postmodern discursive flows and the imperialist privilege inherent in exploitation of the Other that I explore American belly dance as an invented tradition.

\section{Invented Tradition}

Eric Hobsbawm defines "invented tradition" as a constructed tradition that implies continuity with the past (1983: 1). As evident in Joan's story, many American belly dancers trace their practice to ancient origins. Yet modern American belly dance represents a hybridized form that has been transformed by political, social, and economic forces for centuries. I argue that practitioners have created and embraced this tradition to meet social needs and desires that are not being met by the larger society. 
The invented tradition of American belly dance not only provides an alternative to Western mainstream society by embracing what colonialists once regarded as the backwardness of the East, (for example, mysticism, femininity, sensuality) but it also provides an outlet for resistance and transgressive and transformational behaviors that defy normative categories (Dox 2006: 53 and Karayanni 2004: 171). I argue that women use belly dance's formulaic structure, fortified by the familiarity and emptiness of Orientalist discourse, as a means to voice resistance, similar to the poetic discourse of defiance Abu-Lughod describes as "veiled sentiments" in Bedouin society (1986 and 1990). The practiced tradition of American belly dance has provided a mouthpiece to speak truths about aspects of the Western feminine experience.

Much of the invented tradition of American belly dance relies on the appropriation of elements from other cultures perceived to be "exotic," based on a belief in a so-called American right to fuse fragmentary aspects of cultures. This perceived right is based on the legacy of a melting pot mythology that is part of the national narrative of the American nation as an imagined community. ${ }^{7}$ This piecemeal exploitation of the exotic allows for an exploration of identity that is not permissible in daily life (SellersYoung 2005: 285). This process demands an avoidance of specific connections made to any one location or people.

Shay and Seller-Young coin the term "empty location" to encompass the perception that the exotic Other is so distant and removed that it represents a vacant space

\footnotetext{
${ }^{7}$ In the context of the nation, homogeneity is instituted through "systems of cultural representation" with each nation affirming a narrative of unity and shared experience through arts, media, consumer products, and through the construction of a dominant history, constructing an "imagined community" (Anderson 1983 and 1991).
} 
in which to explore identity (2003: 14). The concept of empty location does not imply a lack of cultural content, but instead refers to the perception that the exotic Other represents an unoccupied space in which the practitioner may creatively investigate means of self-expression and social meaning. In my analysis, the concepts of invented tradition and empty location are intertwined. The perception of empty location, which the exotic Other seemingly presents, provides the space for many American women to construct this platform from which to voice their concerns. Within the framework of this invented tradition, I analyze how some American belly dancers explore an alternative feminist identity.

\section{Alternative Western Feminism}

Millions of American women's interest in belly dancing coincided with the second wave feminism of the 1970s (Shay 2008: 124). For many American women, belly dance offered an alternative expression of feminine power. This alternative feminism is similar to what Hollows describes as "folk feminism":

Feminine cultural forms and practices are privileged over commercially produced popular culture and an attempt is made to unearth a women's cultural tradition which has been hidden, marginalized or trivialized by masculine cultural tradition and/or an 'inauthentic' women's culture...[There is] a nostalgia for more 'traditional' 'preindustrial' forms of cultural production... [including] fetishization of an 'ethnic Other woman' whose cultural traditions are deemed to be more in tune with 'nature' (2000: 29).

Hollows' folk feminism exhibits a startling resonance with ideals common in the American belly dance community. American belly dance, as an invented tradition, celebrates alternative feminine empowerment while addressing the changing context of the feminist debate. In doing so, the dance community relies upon Orientalist motifs to 
employ an alterity that permits sentiments of resistance against normative social formations. This alterity is represented by the exotic feminine Other who is perceived to be a vestige of a romanticized past and a symbol of the potential present. I explore American belly dance as an alternative feminism that addresses issues of empowerment, lifestyle, community, and spirituality, building upon my argument that study of this invention unveils the needs and desires of its practitioners.

\section{Research Site and Methodology}

My research included the gathering of ethnographic materials through interview, participant observation, and the analysis of popular culture. I conducted twenty-eight semi-structured, qualitative interviews with specialized informants of varying backgrounds and levels of participation in the belly dance community including students, teachers, and performers in the Pacific Northwest and Southern California. My informants' experience levels ranged from beginning students to well-known professional dancers. These women came from diverse backgrounds that ranged from small town stay at home moms to big city lawyers, journalists and finance experts. Some of the professional dancers I spoke with report that their primary source of income comes from performing, teaching and selling their own instructional and performance DVDs. My sampling methods included purposive or judgment sampling (as I sought out informants from my network) and snowball sampling (as informants made suggestions of people to talk to about specific topics.) I asked informants questions about how they incorporate their belly dance experience into their identities as women; whether they relate to belly dance as an expression of feminism; their thoughts and opinions on the belly dance 
community; and how belly dance has (or has not) enhanced their understanding of Middle Eastern culture. I have had the opportunity to establish relationships with various members of the West Coast belly dance community through my participation in dance classes and events since 1997 throughout the Western United States. I currently live in Portland, Oregon and have attended weekly belly dance classes, and dozens of performances, workshops and festivals in the local area as a participant observer.

In October and November 2009, I spent a month traveling through Morocco with the purpose of detecting evidence of Orientalist motifs and auto-exotification in the tourist economy and to search for indications of belly dance tourism. This aspect of my research has been critical for examining how interaction between East and West facilitates understanding between cultures or perpetuates Orientalist stereotypes. I have also reviewed a history of Orientalist representations of the "exotic belly dancer" in popular writings, films, and other media to evaluate to what extent Orientalist imagery pervades the public consciousness. Through my interviews and observations at multiple sites along the West Coast, I have been able to gather the views of women from a broad spectrum of experiences in a variety of locations and have been able to triangulate these data with other information collected throughout my research.

\section{Reflexive Approach: My Background and Perspective}

I describe myself as a feminist, socio-cultural anthropologist and a currently inactive belly dancer. I discovered belly dance in 1997 and specifically American Tribal Style belly dance while living in Arizona. Over the years, I continued to study, eventually performing and teaching, and I expanded my belly dance interests to include the 
historical roots of the dance, folk dances of North Africa and the Arabian Peninsula, and the effects of belly dance classes on my students' lives.

As a belly dance teacher with a background in cultural anthropology, I began to question some of the stories shared by the belly dance community explaining the cultural origins of the dance, and I sought more information about the history and meaning of this dance in its Eastern context from a variety of sources. I found that there are many interpretations of the meaning and origins of belly dance, often anecdotal in nature, especially those having to do with the supposed spiritual origins of the dance. In the story of the ancient origins of Egyptian belly dance recounted by Joan above, key components of what I see as the quintessential belly dance narrative are included: ancient, but somewhat nebulous spiritual origins of the dance; a feeling of taking part in a lineage of dancers that stretches back to those ancient origins; a sense that although the dance is traced to "cultural" origins it also "belongs" to the individual dancer and she may alter elements of the dance to suit her creative whims; and a disconnection between the modern practice of belly dance and the lives of modern women from the East. As a member of the belly dance community and dance teacher, I felt I had in some ways absorbed the American belly dance narrative and passed that message onto my students, but as an anthropologist I also questioned the accuracy of this narrative and felt a scholarly obligation to unveil its truths and its fantasies.

The more I learned about American belly dance from the standpoint of an anthropologist, the less able I was to don the mask of a belly dancer and participate in what was beginning to feel to me like a charade. It fascinated me as a belly dance teacher that, regardless of the historical veracity of what practitioners say about belly dance, the 
dance does seem to have some kind of magical power over students. Students attest that dance classes have given them renewed sense of positive self-esteem, a feeling of love and support within their dance community, and a means to explore their creativity in ways perhaps not available to other American women. In other words, most students report that belly dance has had a profound and positive impact on their lives.

I want to make it clear that in the course of writing this thesis I have tried to be aware of my own judgments, prejudices, and loyalties towards the American belly dance community. There are many dancers whom I love and deeply respect, but I have been involved in this community long enough that I have also formed some negative opinions about aspects of the community. As an anthropologist, I feel that my closeness to this community has, on the one hand, given me an advantage to observe things that an outsider would not necessarily realize. On the other hand, I acknowledge that this closeness introduces a personal bias that I have tried to surmount using my anthropological training.

Edwards remarks that cultural anthropology always struggles with temporal distance; based on field notes taken in the past, anthropological writing perpetually locates Third World peoples in the past (2005: 262). I feel that the new era of cultural anthropology moves beyond descriptions of the exotic and immerses the ethnographer in the messy realities of the postmodern condition. I believe that it is still important and worthwhile to pursue cross-cultural understanding and bridge the perspectives between the anthropologist's home country and the Other people. But I also feel that study of the "home" culture's interaction with the Other- imagined, virtual, and real- is an equally 
important endeavor in an increasingly complex social world, and this is what I have strived towards here.

\section{Overview of Chapters}

I begin this study with a historical overview of Oriental Dance, examining its origins in the Eastern context as a ritual and social dance, its transformation as entertainment and spectacle in the colonial period, and its arrival to the U.S. in the late nineteenth century. This background chapter provides the framework for understanding how the performance and reception of this dance transformed due to contact with European colonialism and tourism and how representations of this dance and the exotic feminine Other in Orientalist discourse contributed to this transformation. By the time belly dance was established in the U.S., it had been altered by a plethora of political, economic and social forces and had become a hybrid dance that would continue to evolve in the hands of the American practitioner.

In chapter 3, I explore American belly dance as an invented tradition, from the 1950s to present. I argue that belly dance enacts an American longing for the exotic and a nostalgic yearning for a romanticized past that reflects uniquely Occidental needs and desires. In the postmodern context, belly dance is affected by such global influences as Internet communications, tourism and international markets and consumes exoticism from the global margins. I examine the imperial privilege that enables the American belly dance tradition to transform and revise in order to remain relevant to its practitioners. In this chapter I introduce the idea that the American belly dance community is inventing "new exotics" as a means to circumvent the stark realities of political turmoil and social 
upheaval in the East and the continued tensions between West and East. Emergent, heterodox forms of belly dance reflect dancers' growing interest in pure fantasy and historical preoccupations with American Orientalism.

I consider belly dance an expression of alternative feminism. In chapter 4, I investigate how belly dance permits many American women to address issues such as body image, community, and spirituality, and to resist aspects of modernity and capitalism. Participation in the dance community allows many women to feel they are resisting dominant social systems by enacting subversive and transgressive behaviors that materialize as expressions of an exoticized Other. Yet this oppositional position is fueled by the Western capitalist project masked as the inevitable forces of globalization. Additionally, many American belly dancers may be internalizing Western scopophilia by exposing themselves to the male gaze. ${ }^{8}$ I argue that for some American belly dancers, their perceptions of resistance are based on a false consciousness.

Chapter 5 provides a closer study of diverse perspectives of belly dance. This chapter offers comparative analysis of Western and Eastern perspectives, but also interrupts the binary thinking of Orientalist discourse by highlighting areas where these perspectives intersect. In this discussion, heterogeneity within the American belly dance community becomes evident in that dancers have different intentions for their dancing: some are interested in cross-cultural understanding; others use their dance primarily as a mode of artistic expression, occasionally offending others in the process. I also further investigate the emergent forms of belly dance, for example, burlesque belly dance, gothic belly dance, and cultural fusion or what dancers refer to as "Tribal Fusion" as examples

${ }^{8}$ Scopophilia refers to voyeurism or a desire to look at others for erotic pleasure. 
of inventing "new exotics" in American belly dance. I argue that rather than pretending to be an exotic Other, these American belly dancers are inventing an exotic Self.

This final topic further supports my main argument that belly dance is a uniquely Occidental invention and must be recognized for its internal complexity to be adequately understood. In the final analysis, emergent forms of belly dance provoke future research questions regarding the stability of this community, the continued efficacy of belly dance to convey subversive or oppositional sentiments, and the potential of practitioners to actualize cultural ownership over belly dance in its current American context, as an Occidental dance. 


\section{Chapter 2 \\ A History of Oriental Dance}

\section{Introduction}

The United States was first introduced to belly dance at the 1893 Chicago World's Fair, Midway Plaisance. When performers arrived from the Middle East to perform at the Midway, they brought a belly dance that had already been altered by the influences of European colonialism, foreign tourism, and Orientalist discourse. The belly dance at the World's Fair was received in an atmosphere of great social change in the United States. American Orientalists interpreted the dancing women from the East as nostalgic symbols of an imagined past, evidence of Western cultural superiority, and a scintillating promise of feminine sensuality. For many American women, the Midway dancers and the hybridized belly dance they enacted sparked new possibilities for expression in a time of changing gender roles.

In this chapter I analyze the early history of American belly dance, exploring the origins of belly dance in the East, the effects of colonialism on this dance, and the arrival of belly dance in the U.S. via the World's Fair. I investigate finally how the dance performed by the Midway Plaisance dancers was consumed and transformed by American dance innovators who created a unique American form of Oriental dance. I ground my analysis of this early history in the theory of Orientalism, as I emphasize the recurring motifs that typified representation of early American belly dance and continue to inform its practice today.

\section{Theoretical Orientations}


The theory of Orientalism describes a discourse by which the West defines itself in comparison to an imagined, exoticized Eastern Other. This self-referential, canonical discourse implements a variety of recurring stereotypical motifs to represent the East (Said 1978). The West's representation of the East takes the form of a "panoramic gaze," citing scripture, mythology, literature, arts, and history, and assuring the West of its mastery over the East through knowledge and description (Karayanni 2005: 137). American Orientalism builds upon the European imaginings of the Orient that characterize this discourse.

The U.S. has a long history of ongoing covert interventions to assert its political interests in the Middle East and North Africa. The American Orientalism of the 1870 to 1930s was particularly formative as the nation was recovering from the Civil War and looking forward to expansion of its frontiers, affecting relationships with Native American nations, European nations and the Orient. In the face of rapid industrialization, urbanization, territorial expansion, economic change and the erosion of Victorian social norms, the Oriental Other provided a basis for cultural comparison and a nostalgic emblem of the past. For example, antebellum reformers cited the practice of keeping slaves in the Orient as an example of tyranny and backwardness. At this time in American history, an abundance of Orientalist motifs appeared in art, film, fashion, and consumer culture. Increased travel opportunities supported interest in the East (Edwards 2000: 16, 20). "Ultimately, it would appear that American Orientalism was essentially a therapeutic mechanism as well as a creative process whereby people might construct models of behavior and society and then move into spaces that they had constructed," Edwards writes (2000: 17). Interest in the exotic East in the late nineteenth and early 
twentieth century provided a framework in which Americans contacted, embraced, and then manipulated images of the Oriental female dancer.

The alterity of the exotic feminine Other presented a vacant space in which to contend with rapid social shifts during the late nineteenth century in American history. She became a cultural myth symbolizing mysticism, sensuality, and a romanticized past. Cultural myths present an empty reality that may be filled with meaning relevant to the particular social milieu. Jarmakani posits that Western society uses cultural myths as emblems of nostalgia to contend with "collective concerns about the disorientations of power and progress" (2008: 9). In essence, Jarmakani’s “Orientalist apparatus” grapples with chaotic social processes by evoking the myth of a simpler past. In particular, images of Arab womanhood are invoked during times of intense social flux related to consumerism, capitalism, imperialism, and globalization (Jarmakani 2008: 4-26). These specific gendered motifs of the exotic, which constitutes an American cultural mythology, have influenced the development of American belly dance since its inception. To understand American perceptions of the Oriental dancer more fully, I first investigate belly dance in its Eastern context.

\section{Geographical and Historical Overview of Oriental Dance}

The dance known as belly dance, Oriental dance and Middle Eastern dance draws from multiple origins. Belly dance may be described as a female, ${ }^{9}$ solo improvised dance originating from such regions as the Middle East, North Africa and Central Asia. The absence of a classical tradition, named movement vocabulary or formalized training

\footnotetext{
${ }^{9}$ Historically men also performed belly dance throughout the Middle East and North
} Africa (Karayanni 2004; Shay 2005). 
characterizes this dance complex. Across these broad regions, a common movement lexicon typical of belly dance consists of pelvic and torso movements, undulations, shimmies, and patterns denoting variations of circles and spirals (Al-Faruqi 1976:45; Shay and Seller-Young 2005: 1-2). The abstract dance figures explore variations of themes and expound upon leit motifs typical of Middle Eastern musical traditions. The dancer's movements are said to be a visual representation of the music, often emphasizing rhythmic complexities. The connection between dancer, musicians, and audience incites a state of tarab or collective ecstasy (Al-Faruqi 1976: 46; Lorius 1990: 12; Shay 2003: 15; Wood and Shay 1976: 18). Belly dance in the Eastern tradition does not convey a story line, although this differs somewhat in its Western context.

Evidence suggests that this dance existed in ancient times, as figures resembling belly dancers appear in paintings on Egyptian tombs and in Persian miniatures. Descriptions of the Phoenician dancers of Cadiz in ancient Roman poetry resemble modern day belly dancers, as well (Al-Rawi 1999: 38; Shay and Sellers-Young 2005: 3). Many authors, both American and Arab, suggest that ancient forms of this dance are associated with ritual, ${ }^{10}$ although it is impossible to reconstruct fully the dances represented in numerous cultures of the past and directly relate these to a larger dance complex in modern times (Shay and Sellers-Young 2003: 21; Shay and Sellers-Young 2005: 4). Firm evidence suggests that early Muslim and Christian groups took an oppositional position towards the practice of belly dance, defining themselves against others who combined dance with worship (Shay and Sellers-Young 2005: 4). Belly dance

\footnotetext{
${ }^{10}$ For example, Moroccan sociologist Fatema Mernissi traces a lineage of belly dancers that reaches from ancient Babylonian temple dances to present-day Moroccan practitioners (2001: 69-72).
} 
practices have certainly varied in intention and meaning for many centuries and across myriad cultural geographies, yet its practice encompasses a recognizable genre even today.

There are generally two types of female dancing in the Middle East today: regional folk dancing and solo improvised dance performed in urban settings and in private homes (Al-Faruqi 1976: 46; Shay 2005a: 101). Women dance in the private sphere in the Middle East for leisure and play. Dancers often incorporate humor into their performances, for example teasing audience members (Najwa 2005: 41- 45). Middle Eastern women have also long used dance as a means to express a variety of moods and emotions, including the desire to surmount oppressive circumstances (Villa 2006: 124125). In fact, belly dance in the private realm, in which women dance in front of other women or intimate family members, has been described as the only authentic representation of the dance (Rasmussen 2005: 199). Belly dance was traditionally a social and ritual dance in the Eastern world. Not until the historical time period that coincides with the advent of European colonialism in the late nineteenth and early twentieth centuries did belly dance transform into a dance form associated with sensuous and exotic entertainment performed largely for the erotic amusement of men.

\section{Colonial Presence in the East}

Colonial states were organized to cull resources from the colonized in the form of goods and labor. Another commodity materialized in the interaction between colonizers and the subjugated: "emotional capital" encoded as the "Exotic" (Savigliano 1995: 2). Savigliano describes the commodification of the cultures of the colonized: 
The exotic is the passionate haunting past at the margins of the imperial civilized world. For the Other to become an Exotic, this threat needs to be tamed, tilted toward the side of the pleasurable, the disturbingly enjoyable: the erotic. The dangerousness, however should be retained, evoked again and again, as proof of the necessity of colonial civilized domination (1995: 81).

One outcome of the colonial encounter was the collision between Western and Eastern worldviews. The West interpreted the cultures of the East as innately different and perceived this alterity as both threatening and alluring. The "threat" of the "uncivilized" East justified colonial presence, but this presence provided the means by which the colonizers could indulge in the imagined passion and sensuality of exotic lands.

Travel to the East was largely connected to the colonial presence in the region. For example, the French controlled Morocco from 1912 to 1956, Algeria from 1830 to 1962 and Tunisia from 1881 to 1956 . Colonial administration in these countries established an infrastructure that would support the economy of tourism. Karayanni suggests that each traveler plays a part in the colonial domination of a region and "each itinerary is a feature of expansionism" (2004: 24). Travel to the Orient became associated with higher education, search for personal identity and the quest for mystical wisdom. The advent of steamboat travel made these journeys more accessible for European and Americans in the last decades of the nineteenth century (Edwards 2000: 21). For Americans in particular, the European colonial presence accentuated the foreignness of travel experience in the East; "Americans who traveled to the Maghreb ${ }^{11}$...traveled through French frames" (Edwards 2005: 2-3). Perez explains, "The feeling of loss and the romantic yearning for the Orient were more important than the place itself" (1988: 50). Nineteenth century tourists journeyed to the Orient with expectations based on Orientalist

${ }^{11}$ Arabic word denoting Northwest Africa. 
stereotypes of how their experiences would affect them and these expectations undoubtedly clouded their perceptions once there.

Karayanni states, as "travelers inscribed the land, they also inscribed the dancing body, interpreting it for the Empire but also reinterpreting it to the native as well" (2004: 24). The dancer and the foreign spectator engaged in an economy of mutual needs, one providing a service for payment and the other consuming an exoticism that defined personal identity and gave voice to secret desires. The contact between the Eastern dancer and the colonial agent forever changed the female dance traditions of the East, permanently imprinting the Oriental dance with Occidental fantasies.

Only after contact with colonial rulers did belly dance transform from a dance performed only for women into almost exclusively a spectacle for male entertainment (Lorius 1990: 10; Shay 2008: 132-134; Van Nieuwkerk 2001: 136-137). Some reports indicate that the French colonists in North African nations made the professional dancers perform naked and encouraged hyper-sexualized presentations of the dance (Najwa 2005: 47 and personal interviews). At French military bases established near oases, local women, such as the Ouled Nail of Algeria, performed for soldiers. These oases eventually became tourist attractions for travelers (Villa 2006: 34). Arab American dancer Julie ${ }^{12}$ acknowledged the historical factors that affected the presentation and reception of belly dance in once colonized North African states. Julie suggested that colonialism caused much of the poverty and exploitation troubling the East today. She explained that it is

${ }^{12}$ For this project, I interviewed four women of Arab descent from North African nations. I do not specify their countries of origin because to do so may uncover their identities to others in the belly dance community. 
because women in poverty are more willing to show their bodies, in order to buy food for their household, that the face of belly dance had been transformed into a sexualized form.

Additionally the performances lauded by colonial male spectators discouraged the male belly dancers traditionally found throughout the Middle East, Central Asia and North Africa (Shay 2005b: 54-62). The Orientalist attitudes of the male colonists asserted that males only participated in certain types of movements, and belly dance was relegated to a strictly feminine domain associated with the colonists' fantasies about the sensual and exotic bodies of Eastern women. These attitudes directly translated to the travel literature of this time period.

\section{Oriental Travel Literature}

Oriental travel literature from this historic period contributed to the mythologization of the Eastern dancer. Foreign authors such as George William Curtis from America and Gustave Flaubert from France visited Egypt in the mid-1800s and wrote about the local belly dancers performing in public venues. In descriptive accounts

of the dancer's body, these authors emphasize her sensuousness and erotic magnetism but neglect the possibility of the dancer as agent (Villa 2006: 31). Curtis witnessed the courtesan dancer Kuchek Hanem, famously calling her performance "a curious and wonderful gymnastic" (Karayanni 2005: 121). Flaubert also described Kuchek Hanem's dancing and his personal relationship with her in his writings.

In his musings, Flaubert depicts Hanem as both a mystical figure and what Flaubert imagines as a typical Oriental woman, "no more than a machine" when it comes to sex and love (Karayanni 2005: 133). Karayanni makes the argument that Flaubert faces 
a conundrum. For him, access to Hanem's body is a means to commune with the mystical East. At the same time, Flaubert is remiss if he is "to leave an impression upon the whore" (Flaubert's words), for Flaubert is just another client (Karayanni 2005: 129). Flaubert has traveled to Egypt in search of extraordinary experience; "Indeed, the Orient does not need Flaubert as much as he needs it" (Karayanni 2005: 130). This sentiment of longing and desire to extract passion from the East, based on Orientalist stereotypes of the Eastern feminine, characterizes travel literature from this period and informs Western perceptions of belly dancers today.

Other recurring motifs in this literature include descriptions of veils, cosmetics, jewelry and speculations about the inner workings of the harem. What Americans and Europeans write, photograph, and paint in the mid-nineteenth century reveals the fantasies and hidden desires of specifically male colonial interests (Karayanni 2004: 166). According to my research, these same images attract belly dancers to this dance form today (Dox 2006: 53 and personal interviews). Opulent jewelry, sumptuous costuming, and lavish aesthetics are a major draw to and preoccupation of the American belly dance community. As American belly dancers search for creative inspiration, they selectively employ historical elements in costuming and presentation.

Karayanni points out a gap between American women's celebration of the history of the dance and their failure to acknowledge the colonial presence that allowed Westerners to gain access to this expressive form in the first place (2004: 71). Nancy, an older woman from North Africa, has a lifetime of experience studying, performing, and teaching the dances of her native homeland. Nancy expressed her dismay at American dancers' glorification of Oriental dance in the colonial era: 
Being a performer what matters to me because of my background and what mattered to me because of Orientalism is how [North African] women were used. If you see these paintings and colonial postcards...I am sorry when I see American women [belly dancers] having these pictures [historical photographs] all over the place and actually they don't know anything about them. They say, 'Oh, they look fantastic to me. Why can't I perform their dance with a cigarette [referencing historical photographs of dancers featured on colonial postcards and National Geographic magazine]?' I'm sorry but you cannot do that, because that cigarette was brought by a soldier. They spoiled their dance, they spoiled everything. They can't understand it. That is my blood. It's my soul. It's why I need to show the dance with respect.

This informant conveyed to me that she felt many American belly dancers lack historical knowledge about the colonial context that fostered the modern, highly sexualized presentation of belly dance. Furthermore, she expresses sadness over this history and a sense of being robbed of the dignity of the dance by colonial forces. Before the colonial presence, belly dance was a social and ritual dance performed by women for women. As Orientalist fantasies about the exotic feminine played out in cultural collisions between colonists and colonized, belly dance transformed into an erotic spectacle. Images of this bastardized form of the dance were replicated in the Western imagination up to modern times. I next explore these persistent images in the Orientalist painting, photography and colonial postcards that continue to influence modern American belly dancers.

\section{Orientalist Painting, Photography, and Postcards}

In the nineteenth century, men dominated the world of painting and fine arts and both painters and buyers exhibited great interest in Orientalist subject matter that reflected sensuality and eroticism that Western nineteenth century conservativism lacked (Davies 2005: 247). Not all Orientalist painters depicted their subjects in a manner that betrayed the artists' own sexual fantasies. Works such as Frederick Arthur Bridgman's 
(1847-1928) Portrait of a Kabylie Woman shows a realistic image of a strong, stoic woman (Davies 2005: 249). In contrast, many European Orientalist artists of the late nineteenth century focused on imagined scenes of harems, slave markets and public baths.

Eugene Delacroix traveled throughout Algeria and Morocco for six months in 1832 to find inspiration for his painting. Critics claim that despite his travels and direct contact with the East, the limits of his own fantasies of the East ensnared images he painted. Similarly, Jean-Auguste Dominique Ingres painted the women's baths or hammam. Being a man, he could not enter the baths, so he based his images on the travel diaries of Mary Wortley Montague. Jean-Leon Gerome sought to paint realist images of the East, but also relied on Orientalist fantasies, depicting harems and belly dancers as in Dance of the Almeh (1875) and women's baths, places he never had the opportunity to experience firsthand. Gerome was an influential force in the Orientalist art movement and trained many of his contemporaries while teaching at the Ecole des Beaux-Arts in Paris (Jarmakani 2008: 39-49).

These artists share the choice of Orientalist subject matter to justify eroticism. This may be true of American painters as well. John Singer Sargent, trained by Gerome, created Study of an Egyptian Girl in the tradition of the classical nude subject. Jarmakani suggests that her ethnicity lessened the awkwardness for an American audience gazing upon the nude female form (2008: 55). For many Orientalist artists their subjects "like a Freudian relief," allowed them to voice fantasies about violence and sex (Perez 1988: 65). It is possible that artists utilized Orientalist imagery to speak of the forbidden in nineteenth century European polite society. 
Photographic representation of the East was a popular pastime of mid-nineteenth century tourists and artists alike. In 1851 Francis Wey called the photographic images garnered from Westerners' travels to the East "les conquetes pacifiques" or the peaceful conquests (Perez 1988: 100-102). Photographic studios, such as the Bonfils and Dumas studios, were launched to depict fantasies of Oriental life. These studios and others created pictures of supposed harem life, as well as "freaks," circus characters, and people with physical deformities for sale as postcard images to Western consumers.

Because social rules and religious taboos prohibit photography of most women in the Arab world, the women featured in these photographs were probably prostitutes (Perez 1988: 105-107). These "harem" women were sometimes shown as dancers. Their depictions suggest that "the feast of the body is, first of all, a show only for one individual: the viewer-voyeur, namely the photographer" (Alloula 1986: 86). In his analysis of French Orientalist postcards, Malek Alloula compares the dancers to "butterflies and insects" pinned for "vivisector's gaze." Many North Africans of the colonial period believed that a photograph could capture the soul of its subject (Perez 1988: 100-102). Similarly, Alloula astutely observes, "Photography is a stealer of souls; the 'savages' knew this intuitively; and they were yet to suffer a more ferocious and less symbolic spoilation" (1986: 92).

While I conducted fieldwork in southern Morocco, October 2009, a local man explained to me that rural women did not like having their photograph taken by tourists for fear that it would appear on a postcard or in a magazine. Photographs displayed in a museum exhibit in the mountain town of Chefchaouen in northern Morocco, featured women dressed in examples of colorful local dress and discordant facial expressions. The 
women peered into the camera lens with looks of anger, fear and sadness. The "bogus exoticism," as Alloula puts it, of Orientalist representation of the East during the mid- to late nineteenth century was a precursor to the West's representation of the East in the twentieth century; Orientalist depictions of Eastern life provided rationale for political actions as well as the inspiration for thousands of Western women who sought community and identity through belly dancing. Having described belly dance in its colonial context in the East, I now turn to the introduction of the belly dance in the West.

\section{World's Fairs and Exhibitions}

The colonization of the Middle East by European nations employed an Orientalist discourse in the process of asserting dominance over these regions and in defining a Western identity as different from the East. This process involved ethnography and constructing descriptions of the East; compiling information about the region through census and mapping; and the collection of artifacts for museums (Bahrani 1998:159; Meskell 1998: 3). The Western scientific community of the nineteenth century took part in this process of discovery, analysis and classification of Eastern culture. Knowledge of cultures outside of the West was packaged, displayed and sold to European and American audiences in the form of fairs and exhibits of the late nineteenth century. Rosemarie Garland Thomson describes the construction of spectacle by which the audience may assess the exotic Other as a "social process of enfreakment" (Jarmakani 2006: 148).

I argue that the fair exhibition provided a site of condensation, where large crowds gathered to enact an artificial binary reinforced by the perpetuation of Orientalist discourse and where the "primitives" on display and in performance interfaced with the 
"civilized" who gazed upon them. Belly dance performers were first brought to the West after the French campaign in Egypt facilitated the export of the dance to the 1889 Paris International Exhibition and the 1876 Philadelphia Centennial Exhibit. Belly dance made it first formal appearance in the United States in Chicago at the 1893 World's Fair, which featured performers from Algeria and Syria on the Midway Plaisance (Sellers-Young 1992: 142). Middle class and working class men and women of the Victorian era came to witness the notorious Little Egypt dance "the hootchy-kootchy" at the Persian Palace of Eros (Carlton 1994:74; Desmond 1991: 36). The Chicago World's Fair introduced many Americans to a social construct of the exotic that would continue to influence American culture in the twentieth century in the form of entertainment, consumerism and in the quest for personal identity.

I argue that the belly dance that audiences witnessed at the Midway Plaisance directly influenced American dance innovators of the early twentieth century as well as belly dancers today. In contrast, Shay argues that the American belly dance of the fin de siecle fundamentally differed from that of the 1970s. Shay's use of the concept of "parallel tradition" to describe the current practice of American belly dance that references its past incarnations, but constitutes a wholly new inception of the genre (2008: 128). In some ways modern American belly dance marks a conceptual break with the Eastern dances witnessed on the Chicago Fair's Midway Plaisance (Al-Faruqi 1976: 46). ${ }^{13}$ For example, dancers' performances in the past contained not only dance, but also

${ }^{13}$ This conceptual break is not necessarily recognized by modern practitioners of American belly dancer. Many dancers instead trace their practice along a continuous lineage of dancers into ancient times. 
singing, acting and sometimes acrobatic feats. Additionally, belly dancers were not always female (Shay 2005b: 65-66; Shay 2008: 136).

I disagree with Shay that contemporary American belly dance has almost nothing to do with nineteenth century incarnations of the dance as modern dancers experiment with the vaudevillian aesthetics that are a direct product of the Chicago World's Fair exhibits. I also disagree with Shay that many American women were wholly "repelled" by the dances they saw in 1893 (Shay 2008: 131). It is apparent that exposure to the East and Oriental representations of the East inspired American women's taste for art and creative self-explorations as I discuss in the section below. Furthermore, Shay neglects to acknowledge that the Eastern dancers who came West to perform at fairs and exhibitions demonstrated a dance already corrupted by colonial contact, as discussed above.

Although modern American belly dance does not always contain all of the elements listed above, historical images of turn of the century dancers from the East continue to transfix modern dancers; therefore modern dance is not a total breach with earlier forms. U.S. dancers perform an Occidental version of an Oriental dance, but this dance was based on a colonized form. I now turn to an examination of how the image of the exotic feminine Other, transcribed by historical forces and Orientalist discourse, influenced the identity construction of American women in the early twentieth century.

\section{Salomania in the $20^{\text {th }}$ Century}

Many authors have epitomized Salome as the quintessential representation of the exotic feminine (Erdman 1996: 289). She dances barefoot and bedecked in veils and jewels, as do many modern American belly dancers. The Bible portrays Salome as a 
passive, young girl. But the Salome of Oscar Wilde's 1891 play is lustful, assertive, and decadent (Finney 1998: 182-183; Karayanni 2004: 106). In Wilde’s play, Salome is obsessed with John the Baptist, composing verses that compare him to fruit and wine. Her sexuality resembles more a masculinized, assertive mode, especially for the time period. Wilde's play seems to comment on the decadence of society and gender norms in flux at the end of the Victorian era (Finney1998: 184-186; Karayanni 2004: 117; Studlar 1997: 99-102). At that time, many American women donned an emergent feminine identity known as the New Woman, a woman who freely and boldly embraced romance, consumerism and self-expression.

The image of the New Woman strongly correlates with Orientalism evident in American culture in the early twentieth century. For example, Hollywood produced numerous romantic films with Orientalist themes such as The Sheik in 1921; flapper girls were called shebas and their boyfriends sheiks in the popular vernacular; and consumer goods marketed specifically to women were packaged with Orientalist imagery (Studlar 1997: 100-105). ${ }^{14}$

\footnotetext{
${ }^{14}$ See Figure 2.1.
} 


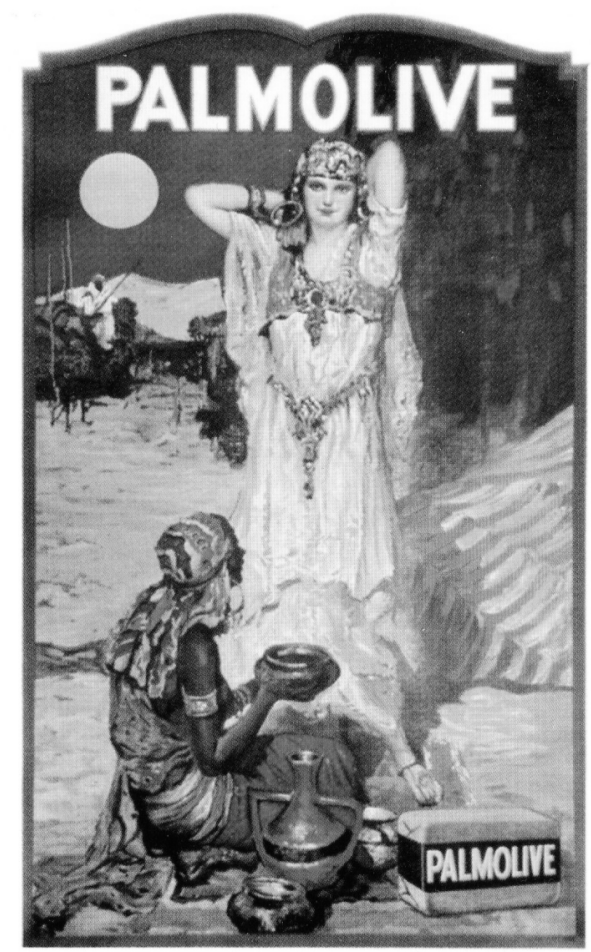

Postcard purchased in Rabat, Morocco, October 2009

[Figure 2.1]

A phenomenon referred to as Salomania, ${ }^{15}$ connoting the widespread, fervent interest in Salome-inspired Orientalist imagery, was usurped by a generation of young American women experimenting with gender identity and social norms. For many American women, this experimentation included donning the persona of Salome and dancing on stage and in private homes. With Salomania, a dance movement was born, a process by which American women could explore their creativity, gain a sense of community, and express their inner most desires. Several pioneering American dancers and

${ }^{15}$ Salomania was thought to present a real threat to the general public. For example, Richard Strauss' opera, Salome scheduled to play at the Metropolitan Opera in 1907, was cancelled to avoid a Salomania outbreak (Studlar 1997: 105). 
choreographers headed this movement, inventing spiritual dances from the "East" that would later inspire American belly dance.

In the nineteenth century, American female dance performers were strongly associated with prostitution (Shay 2008: 140). Many innovative dancers and choreographers referenced exotic cultures and esoteric spiritual practices in order to anchor their productions in the respectable realm of "high" art meant for the theater stage (Monty 1986: 89). ${ }^{16}$ Such early twentieth century dancers as Ruth St. Denis, Maud Allen ${ }^{17}$ and La Meri all experimented with the use of Orientalist motifs signifying exotic connections to mysticism and spirituality in portrayals of Oriental dance.

In 1904, American dancer Ruth St. Denis saw an advertisement for cigarettes featuring the Egyptian goddess Isis. St. Denis had never formally studied any dance traditions of the East and relied exclusively on images from popular media that reflected the orientalia at the turn of the century for inspiration (Desmond 1991: 30-32, 39). She credits the cigarette ad as influence for choreographies such as "Radha," which portrayed themes of mysterious spirituality and Oriental aesthetics (Desmond 1991: 38; Shay and Sellers-Young 2005: 7).

\footnotetext{
${ }^{16}$ Spiritual narratives have formed a common motif in Western interpretations of Eastern dances since the early twentieth century. Orientalist music, operas, and ballets such as "Scheherazde" proliferate during this period (Shay and Sellers-Young 2005: 8).

${ }^{17}$ Maud Allen and Ruth St. Denis both performed their own versions of Salome, inspiring generations of women to follow them in Oriental dance, conflicting Shay's theory of parallel tradition discussed above (Deagon 2005: 251; Studlar 1997: 107-108).
} 
Interestingly, before St. Denis' "Radha" hit the elite theaters, she got her start as an entertainer in the vaudeville ${ }^{18}$ circuit. St. Denis performed "Radha" in a vaudeville theater for working class audiences alongside other acts such trained animals and magicians. Not until St. Denis performed the same dance for members of the upper class in theaters did the performance slip into the category of "high" art. The class affiliation of the audience determines how the performance is perceived, evaluated and assigned a position in an imaginary hierarchy, simultaneously determining refined or coarse entertainment and good or bad taste. Upper class and working class audiences alike enthusiastically received St. Denis' "Radha", indicating the enduring ubiquity of gendered exoticism in American cultural mythology.

La Meri, a contemporary of St. Denis, was one of the first American dancers of the twentieth century to actively pursue a study of foreign dance traditions. Born Russell Meriwether Hughes in 1898, La Meri eventually traveled to Morocco to study North African dance with a teacher known as Fatima (Rutyer 2005: 208-215). But early in La Meri's career she presented dances that may easily be interpreted as relying on familiar Orientalist tropes with names such as "Persian Slave Dance" and "Egyptian Frieze Dance" (Rutyer 2005: 210). Rutyer suggests, "It is clear that La Meri's entire life work is based on what today some might criticize as a questionable appropriation of dance material from cultures not her own" (2005: 219). American interest in exotic themes continues into the present. Modern American belly dancers continue to exploit the stories, symbols, and presentation styles of these early dancers. Many of the stereotypical motifs

${ }^{18}$ It is interesting to note that many famous American belly dancers who performed in the 1970s had connections to vaudeville. For example, Serena Wilson's parents were vaudeville performers (Monty 1986: 261). 
of the exotic feminine Other explored in American Oriental dance were also exploited by burgeoning genres of American erotic dance.

\section{The "Scandalous" Descendants of Oriental Dance}

The mysticism, sensuality, and exoticism of Oriental dance continued to draw early twentieth century American audiences. Many dancers, who went by the name "Little Egypt," exploiting the mystique of the original dancer who went by that name at the Chicago World's Fair, amplified the erotic aspects of the dance in order to book jobs in burlesque shows (Al-Faruqi 1976: 46; Sellers-Young 1992: 142). Ibrahim Farrah, dancer and publisher of Arabesque magazine stated, "The whole misconception of belly dance as being similar to strip tease dance may have been initiated by dancers who had limited talent, or by those who were looking for a gimmick and imitated Little Egypt and her contemporaries. Many may have been former Salome dancers. There is a definite need to unravel the authentic belly dancers with [sic] those who selected the burlesque route as professional dancers" (Monty 1986: 396). Because belly dance came to the United States as an exotic spectacle that was packaged and sold to the consumer in such venues as the Chicago World's Fair and the Coney Island Amusement Park, belly dance

graduated naturally into burlesque and strip tease as American dancers competed for jobs (Jarmakani 2006: 148-149).

The developing striptease and burlesque industries of the 1920s credit the hootchy-koochy as the antecedent of all American erotic dance forms. For example, strip tease promoter Paul Alt specifically links belly dance to the origins of striptease (Deagon 2005: 266). The first American school of belly dance, the Stairway to Stardom that 
opened in 1964, taught classes in both belly dance and strip tease (Monty 1986: 241). Both belly dance and striptease or burlesque are connected to notions of female sexuality. Both dance genres feature gyrating and shimmying movements: one style links these movements to reproduction, ancient ritual and feminine power (belly dance) and the other to sexuality and eroticism (striptease and burlesque) (Jarmakani 2006: 152). Yet most modern American belly dance narratives do not acknowledge any kinship between belly dance and other erotic dance forms.

Many dancers I interviewed adamantly distinguished their belly dance practice from other erotic dance forms. One dancer declared, "Belly dance is not stripping. I did not spend this much money to drop my costume on the floor." Another interviewee expressed her concerns upon seeing belly dancers who experimented with burlesque elements: "It is scary and it is uncomfortable and you feel that something precious could unravel when belly dance is not held to a standard of dignity. There is a prudishness to belly dance." Although many modern American belly dancers may deny the close historical connections between belly dance and other erotic dance forms, ${ }^{19}$ Oriental dance has long abetted the exploitation and mythologization of the exotic feminine Other in the West.

\section{Conclusion}

American belly dancers practice a hybridized dance form that has been transformed through colonial contact, Orientalist representation, and the commodification

\footnotetext{
${ }^{19}$ It is interesting to note that striptease is often referred to as "exotic dance" in American culture.
} 
processes inherent in cultural exhibitions and exploitation of the exotic feminine Other. American belly dancers continue to be influenced by the Orientalist images of Eastern women of the late nineteenth and early twentieth century in painting, photographs, literature and postcards. As I will further discuss in the following chapter, in the first half of the twentieth century, highly sexualized versions of Oriental dance were exported back to the Middle East and featured in nightclub venues marketed towards tourists and presented as the local dance. ${ }^{20}$ This version of the dance was then imported back West. Based on this historical analysis, revealing the Orientalist tropes that form part of the foundations of American belly dance, I investigate in the following chapter how belly dance continued to transform in the latter half of the twentieth century to the present.

${ }^{20}$ This aspect of the tourist economy continues today. 


\section{Chapter 3 \\ Invented Tradition and Postmodernism: 1950s to Present in American Belly Dance}

\section{Introduction}

From the mid-twentieth century to the present, discursive flows between East and West have affected American belly dance, as have the increasing globalization, transnationalism, mass communications and diffusion of cultural elements that exemplify the postmodern world. Many modern American belly dancers see their participation as linked to an ancient practice. The Orientalist tropes that have historically been associated with American belly dance impart an anachronistic exoticism to this practice, permitting many women to feel that they are occupying an empty location when exploring identity through belly dance. In this exploration, many American belly dancers exercise an imperialist privilege in creatively combining cultural fragments in their dancing.

In the following chapter I investigate the recent history of American belly dance, from the 1950 s to present. I examine the effects of Hollywood, tourism, technology and global markets on this dance community. I posit that the perceived alterity attributed to this dance form provides the empty location from which American woman invent this Occidental tradition as I discuss its unique modern types. I examine how modern forms of American belly dance are composed of cultural fragments, collected under the auspices of imperialism. I argue that in order for this invented tradition to maintain relevance, in the context of postmodernity, it must undergo revision leading to emergent, heterodox forms of American belly dance and the creation of "new exotics." I base my discussion in an understanding of postmodernism, in order to make visible the aggregative quality of this dance form. 


\section{Theoretical Orientations}

The concept of a discrete, stable individual identity is disrupted in a postmodern world. Stuart Hall explains that the modern individual no longer perceives himself/herself as a unified subject, which constitutes a "crisis of identity" for the displaced and decentered individual (1992: 274-275). In Hall's view, identity becomes a “moveable feast" and perception of a coherent unity is but a fantasy of the postmodern subject (1992: 277). Gupta and Ferguson state that people are actually in a state of flux rather than adhering to imagined naturalisms of stability and solidity; "displaced and decentered identities...mark what is often called the postmodern condition" (1992: 12). The modern individual is free from the expectation of tradition; instead this entity focuses on personal needs and desires, exhibiting the entrepreneurial individuality fundamental to capitalist systems (Hall 1992: 281-283). Hall further explains that in the modern context, identity is a process, not a state of being; therefore the subject is always searching for identity (1992: 287).

Postmodern technology and mass communications play a major role in disrupting the possibility of a unified identity as social interaction on a global scale modifies intimate and personal aspects of daily life (Brubaker and Cooper 2000: 8; Hall 1992: 278). Furthermore, globalization amplifies the importance of local identities and particular communities that are inhabited by modern individuals in constant search of a meaningful personal identity. For American belly dancers, the postmodern dilemmas of increasing access to the global and the seeming fluidity of personal identity are both the cause for social and individual instability and the remedy for unstable meaning and 
perceptions. For many American women, belly dance is a dynamic means to explore identity and meaning based on culturally viable tropes.

Holland suggests that identity is temporal and subject to refinement based on the discursive practices that are available in late modernity (2004: 29). In other words, the social structure predetermines what types of identity are available. The white, American woman who chooses to belly dance must rely upon the West's colonial and Orientalist heritage to conceptualize what it means to be a belly dancer. For the American woman who identifies as a "belly dancer," this image is informed by historiography, discursive structures, normative formations and personal beliefs.

Based on the alterity and malleability of Orientalist motifs associated with belly dance, many American women are able to construct a "white woman mythology," inventing a tradition that responds to and articulates with the anxieties and needs of many American women (Maira 2008: 332). ${ }^{21}$ A supposed linkage to a distant past legitimizes this tradition (Hobsbawm 1983:1). As one informant eloquently stated, "It's just conjecture and desire. We really want it to be that, so that is what it becomes." The functionality of the exotic Other and the evocation of motifs that are salient in the American context depend on a notion of empty location (Shay and Seller-Young 2003: 14). Because Westerners feel that they are delving into a world of alterity, they feel their creative exploration occupies a culturally vacant space. It is from this space that the American belly dance is constructed. Additionally, just as postmodern identities are fluctuating and context-dependent, the invented tradition of American belly dance must

${ }^{21}$ In this chapter I examine American belly dance as an invented tradition and in the chapter that follows I address why this tradition was invented by investigating which anxieties and needs it addresses. 
also respond to social flux through revision to support the dynamic needs and desires of its practitioners.

Bourdieu's concepts of orthodoxy and heterodoxy help to explain how common Orientalist tropes utilized by the American belly dance community are being challenged (1994: 164). The styles of belly dance popular from the 1970s to the 90s are now falling out of fashion but demand respect as originators; these may be viewed as orthodoxy. A proliferation of new movement and presentation styles are currently being introduced into the community, challenging the definitive parameters of this dance form. I assert that this is an example of heterodoxy in the belly dance community. In Gramsci's analysis of hegemony, he says that narratives must be constantly renewed to adapt to contradictions (Jarmakani 2008: 6). I argue that the invented tradition of belly dance must be renewed and revised if it is to remain relevant to American woman. To illustrate the transformative processes affecting modern American belly dance, I begin with a discussion of Hollywood representations of the mythological figure of the exotic feminine Other as belly dancer in the mid-twentieth century.

\section{Hollywood's Belly Dance}

Following the American public's introduction to belly dance at the World's Fair in 1893, American dance pioneers translated Oriental dance into an Occidentalized form through the implementation of mystical references and emphasis on the spectacular and marketable elements. These early pioneers of American belly dance influenced the emergent cinematic industry. Denishawn, the dance company that Ruth St. Denis directed alongside her husband Ted Shawn, provided a model of Oriental entertainment soon 
embraced by Hollywood (Shay 2008: 130). Hollywood created an array of films with Orientalist themes throughout the twentieth century, beginning with Intolerance in 1916. Production studios referred to these films as "T and S movies," meaning "tits and sand" (Friedlander 2009; Kamal-Eldin 1999). Films such as Cleopatra 1963, Baghdad 1949, Kismet 1955, and Sons of Sinbad 1955 often portrayed Eastern women as barely-clothed, exotic belly dancers who provide entertainment in the harem or at royal feasts for the pleasure of men. For example, the trailer for the film Baghdad promised an ideal Oriental fantasy: "Against this exotic background the screen brings you a story of love on hot desert sands...what is your pleasure? Dancing girls perhaps? Why certainly" (KamalEldin 1999). The dances in these films rarely bear any resemblance to Middle Eastern or North African dances, but instead are an amalgamation of Arab, Persian, Chinese, Indian and American erotic dances. The American Orientalism celebrated, perpetuated and reinvented by the Hollywood film industry continues to influence the commodificaton of exotic culture; film, television and Internet on a global scale; and the presentation and reception of Oriental dance in the United States and beyond.

Meanwhile in the early to mid-twentieth century East, new dance venues such as nightclubs and music halls opened in Egypt's urban centers. Tourists and members of the Egyptian upper class were the main customers at these establishments. As dancers and musicians vied for an opportunity to make a living in these venues, traditional standards of professional conduct deteriorated. Dancers and musicians were able to make more money from tips from patrons and many dancers supplemented their performance by fraternizing with customers and wearing scanty costumes. Many dancers also engaged in prostitution (Shay 2008: 133-137; Van Nieuwkerk 2001: 139-140). Tourism and an 
expanding Egyptian upper class that patronized these clubs are linked to dancers' loss of social esteem during this time period.

Modern belly dancers are part of a legacy traced back to Syrian actress Badia Masabni’s Casino Opera House which opened in Cairo in 1926. Masabni hired dancers such as Tahia Carioca and Samia Gamal who later became icons of Egyptian dance and popular Egyptian film stars. This nightclub show emulated Western choreographic elements and incorporated Hollywood-inspired fantasies of an exotic Eastern dance costume: a bare, bikini-like costume with sheer skirt and high-heeled shoes (Shay 2008: 129-130; Shay and Sellers-Young 2005: 20-21). Masabni "eagerly embraced these westernized creations of a romantic Orient" (Shay 2008: 130). Egyptian club owners and dancers adopted western aesthetics largely as a business strategy to draw tourists and well-to-do Egyptians as patrons. This Westernized form of belly dance in the East was then imported back West as an exotic tradition. Postmodernity increased accessibility to the global circulation of Orientalist tropes, permitting American dancers to appropriate images that had been filtered through Hollywood's American Orientalism, to the East, and back to the West again in the construction of tradition. Similarly, the strategies of many Arab American business owners also contributed to modern understandings of belly dance.

\section{Arab Americans: Migration and Transnationalism, 1960s to Present}

The rise of American interest in belly dance in the 1960s and 1970s coincides with an emerging awareness of cultural plurality in the U.S., and the growth of the Arab American community (Maira 2008: 323-325). From the late 1800s to the early twentieth 
century, large numbers of Muslims, Christians, and Jews immigrated from Lebanon, Palestine, Egypt, and Syria. These immigrants were typically uneducated, single men who came to find work and escape political unrest associated with the fall of the Ottoman Empire. Some of these immigrants saved money as peddlers or factory workers and decided to stay in the U.S. After the 1960's, most Muslims immigrated from Egypt, Iraq and Yemen. The majority of this wave of immigrants fled tensions due to the IsraeliPalestinian conflict and Lebanese civil war (Shay 2006: 126-131; Shay and SellersYoung 2005: 12). Many of this later wave of immigrants identified with the label "ArabAmerican" as a means to consolidate the interests of these related social groups and create a sense of community.

As more Arab immigrants arrived in the U.S. and Arab American populations increased in the 1960s and 1970s, a profusion of Middle Eastern and Mediterranean nightclubs and restaurants popped up in American metropolitan centers (Rasmussen 2005; Shay 2006: 133). ${ }^{22}$ These businesses offered an amalgamation of various ethnic influences in food, music, and dance, strategically marketed utilizing Orientalist images familiar to American consumers such as camels, sexy harem dancers, pyramids and musicians wearing Turkish fez (Rasmussen 2005: 176-187) ${ }^{23}$ Today's most influential American belly dancers, such as Jamila Salimpour and Morocco (Carolina Varga

${ }^{22}$ The music and dance styles offered in the nightclubs of the 1960s and 1970s differed greatly from music performed and enjoyed by earlier immigrant communities. For example, the 1920s era Syrian, Palestinian and Lebanese communities arranged musical events in churches or community centers, where evidence of Orientalist motifs was decidedly missing (Rasmussen 2005: 173-174).

${ }^{23}$ This business strategy constitutes a form of "self-exoticism" or "auto-exotification" (Rasmussen 2005: 176-193; Savigliano 1995: 2; Shay and Sellers-Young 2003: 18). 
Dinicu), attended these clubs to study the movements of the Middle Eastern performers working there.

American dancers also watched Egyptian films ${ }^{24}$ and looked to Orientalist paintings and photography to find inspiration for their version of belly dance (SellersYoung 2005: 279-284; Shay 2006:133; Shay 2008: 138-139; Shay and Sellers-Young 2003: 17; Shay and Sellers-Young 2005: 15;). Dancers in those films, such as Samia Gamal and Tahia Carioca mentioned above, performed a reinvented, hybrid style of belly dance heavily influenced by Hollywood representations of the Orient and then presented to foreign tourists as the local style (Maira 2008: 322). This version of the dance was also what American dancers observed in the Arab American nightclubs in the 1960s: a more sexualized, romanticized, Occidentalized form of the dance that stems from a history of Western colonial and postcolonial influence in the Middle East and was then exported back to the U.S. as an authentic dance tradition.

Having explored the ways Hollywood influenced belly dance in Eastern and Western contexts, I now take a closer look at the effects of modern tourism on the development of this dance East and West. In the following section I will focus on Morocco as a case study for modern tourism in the East, relating my observations from my fieldwork in this northwest African nation.

\section{Modern Tourism}

${ }^{24}$ Even today's top Middle Eastern dancers, such as Egyptian star Fifi Abdou, claim they taught themselves to dance by imitating dancers in Egyptian films (Lorius 1996b: 287). 
In the modern tourist economy, belly dancers, "free-spirits" and adventure seekers arrive in a foreign place in search of extraordinary experience, greater knowledge and diversion. Often tourists are presented with an idealized and/or dehistorized version of the local culture. "What was once proudly displayed as imperialist 'booty' at the turn of the last century is now presented as the last hope for conservation and education," explains Desmond (1999: 255). Similar to the late nineteenth century traveler whose presence facilitated colonial domination, modern tourism encourages an artificial representation of local lifeways. ${ }^{25}$ In this interactive tourist economy, the tourist arrives with expectations of the exotic and the local meets those expectations in order to satisfy the customer, provide a positive image of the culture, and also benefit financially. The dancing female body is often an iconic aspect of the tourist destination, for example, the hula of Hawaii, the flamenco of Spain, the can-can of Paris, the geisha of Japan, and the belly dancers of the Orient (Shay 2006: 47). Nostalgic images of a harmonious reality, enacted through dance performance detached from history or social stigma, are presented for the entertainment and feel-good factor of the tourist.

Many nightclubs that offer belly dance in the Middle East and North Africa are marketed solely to tourists (Rasmussen 2005:200-201; Shay and Sellers-Young 2005: 24). North African born informant Beth explained to me, "There are clubs for tourists; those [clubs] are different. Sometimes they have a belly dancer that performs. [Locals] rarely attend them." I spoke with Arab American belly dancer Julie about the affects of tourism on the integrity of dance traditions. She said, "I'll support your demand [imaging

${ }^{25}$ The European colonial period of the late nineteenth century to the mid-twentieth century in the Middle East and North Africa helped to establish an infrastructure that now supports neo-liberal economies, military-industrial ventures, and modern tourism. 
herself to be in the position of the local performer dancing for tourists], it's a business transaction, it's not personal." Tourists in search of the cultural roots of belly dance are often presented with the image of the solo cabaret dancer, decked in resplendent and revealing costuming, performing a dance utterly similar to the dances performed at Masabni's Casino Opera House. It is interesting to note that this is true even in the Moroccan context, even though solo cabaret belly dance is not considered indigenous to this region.

Many American belly dancers travel to the Middle East or North Africa as part of their dance education and to immerse themselves in what they perceive to be the cultural roots of belly dance tradition. Some of these women travel independently, while many others joined one of hundreds of belly dance tours that are offered each year to locations such as Egypt, Turkey and Morocco (Shay 2008: 147; Shay and Sellers-Young 2005: 16; Sellers-Young 1992: 144 and personal interviews). As one informant who had traveled to Egypt aptly stated, "What's good is the Americans going over to Egypt and bringing money...Through dance tourism, the costuming, the music-all those things have helped." Overall, much of the tourist economy in the East is inundated with Orientalist motifs regarding culture and specifically belly dance, as was my observation in Morocco discussed below. This act of auto-exotification (process by which locals fashion their image to meet Orientalist expectations) and commodification allow native communities to reap the benefits of tourist dollars.

\section{My Observations in Morocco, Fall 2009}


In October and November 2009, my husband and I spent a month traveling through Morocco to detect evidence of Orientalist motifs and auto-exotification in the tourist economy and to search for indications of belly dance tourism. I observed abundant Orientalist imagery almost everywhere we traveled. In restaurants, tapestries showed harem scenes and belly dancers, and postcards featured such images as Oriental-themed packaging of consumer goods ${ }^{26}$ and belly dancers that performed at the Folies-Bergere.

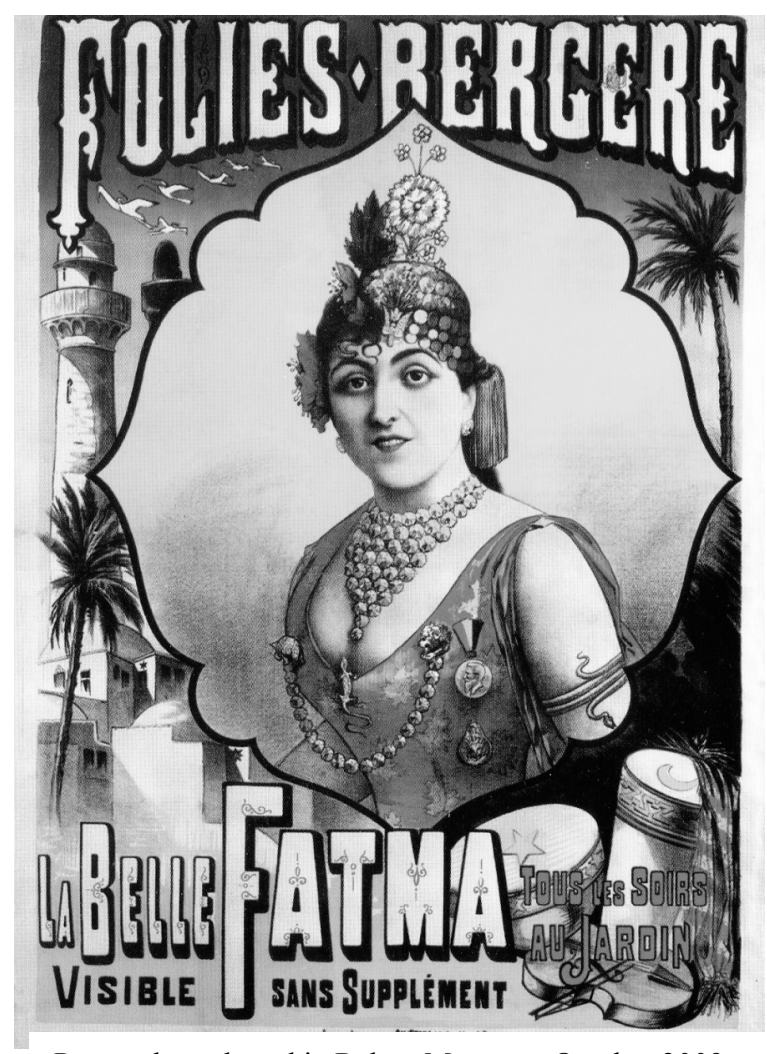

Postcard purchased in Rabat, Morocco, October 2009 [Figure 3.1ๆ

Throughout the country I saw flyers for belly dance tours, specifically a belly dance retreat in the Sahara organized by teachers from the United Kingdom. A gym I saw in the Rabat medina or old town offered belly dance classes. Beth, born in North Africa,

${ }^{26}$ See Palmolive soap advertisement on page 31 . 
told me she used to teach belly dance classes in Morocco and mostly tourists attended her classes and performances.

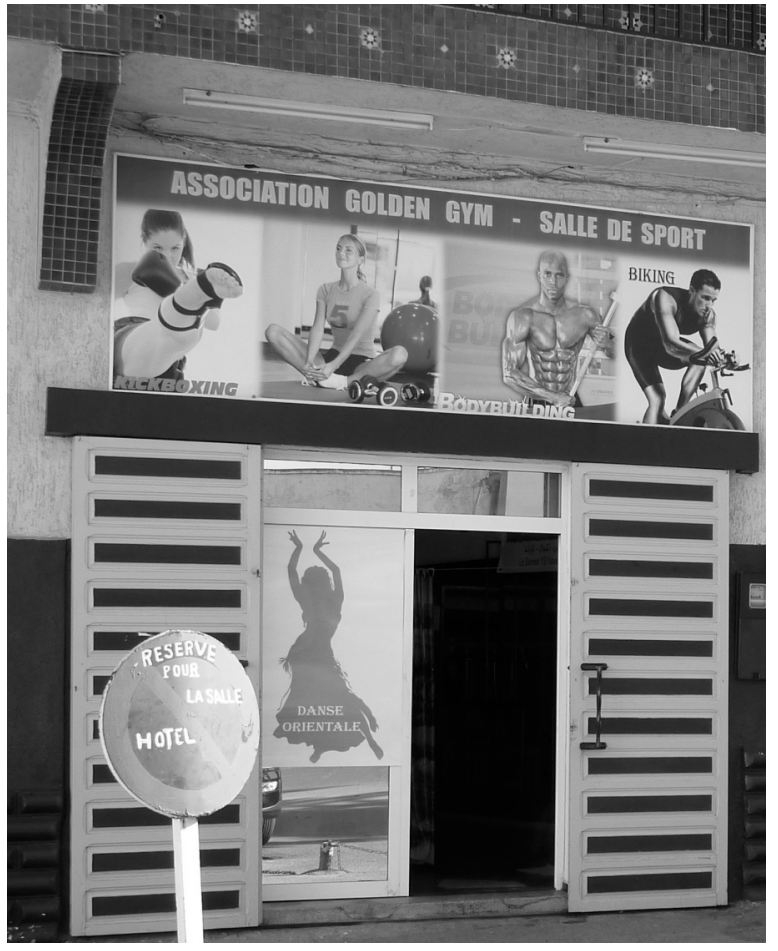

Oriental dance classes, Rabat Medina, Morocco, October 2009

[Figure 3.2]

Almost every souq or marketplace I visited sold belly dance costumes. The brightly colored belly dance bra and belt sets, fashioned with lots of gold beads and coins were nearly always in close proximity to shops that sold lingerie. I wondered if this was because belly dance was considered a private affair; if it was categorized as sexualized accoutrement marketed towards those interested in such things; or if it was put out front primarily for tourists to purchase as souvenirs (or all of the above). I never saw any Moroccan women frequenting those shops, while I did often see groups of European and American women perusing the wares. 


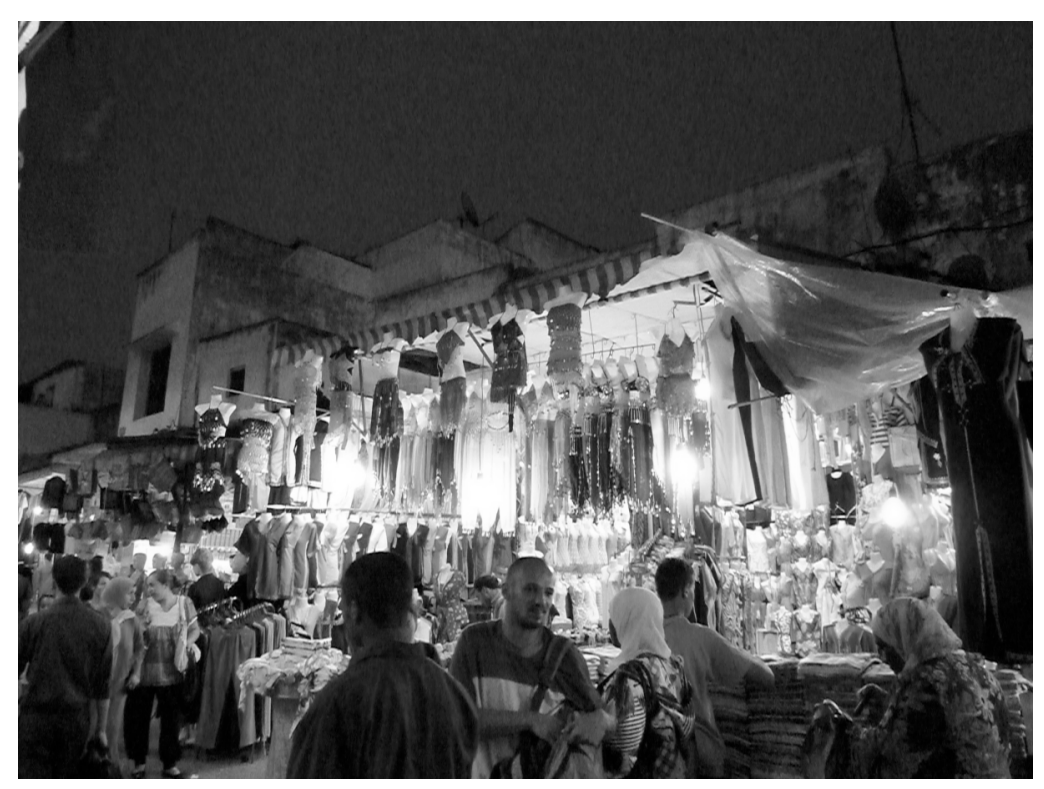

Belly dance costumes for sale in the Rabat souq, Morocco, October 2009

[Figure 3.3]

A few bars in Rabat, Essaouria and Marrakech offered belly dance performances, although my husband and I hesitated to go to these places. Before leaving on our trip, a friend had told us that he and wife had visited Marrakech and were reprimanded by a local Moroccan man for going into a bar. The Moroccan man made it clear to them that the bar was not an appropriate place for a woman and that a caring husband should not bring his wife there. In the end the only public belly dancing I witnessed was the crossdressing male dancers in the Djemma al-Fna or main square in Marrakech. 


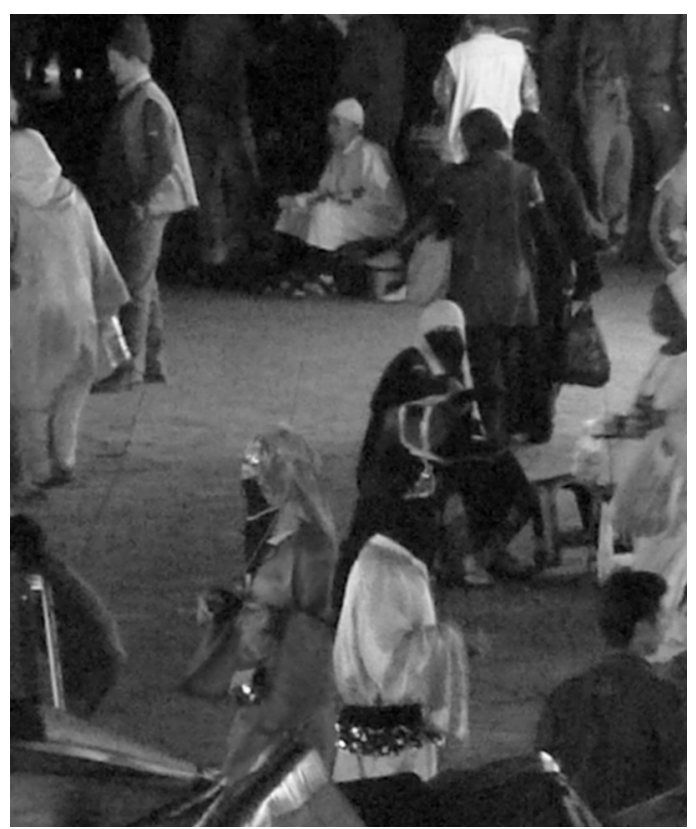

Male belly dancers Marrakech, Morocco, November 2009

[Figure 3.4]

Overall, the performance of belly dance or similar women's dances was largely hidden from view during my travels through Morocco. The dance that was available occurred in bars deemed inappropriate for respectable married women to patronize or constituted a parody of the dance, as with the cross-dressing male dancers. Of course, belly dance or similar women's dances may have been occurring in private homes. Nevertheless the message was that Moroccan belly dance in the public realm happens in licentious places.

Women on belly dance tours have access to Moroccan belly dance through the foreign women who organize these tours. The belly dance tours occurring in the area featured dancers from the Western world. Foreign women, not Moroccans, organized these tours, taught the classes and performed at related events. Belly dance tourism is filtered through an Orientalist lens. For example, tourists are not shown the possible 
ridicule that local dancers may receive from the stigmatization of their profession or the harsh poverty that compels their public dancing in the first place. Tourists may not be shown an authentic version of the local dance, but an Oriental bastardization. These women experience a fabrication of Moroccan culture and may only witness what is permitted to them by the dictates of the tour itinerary.

In the modern context, belly dance has been altered by the influences of Hollywood images and international tourism, and the processes of auto-exotification within Eastern economies and by Arab American business owners. The belly dance that exists in the U.S. is imbued with Occidental interpretation and alteration, making it more a relic of American Orientalism than an example of Eastern cultural heritage.

In the following section, I shift focus to ways this dance has been adopted and absorbed into the white, middle-class ethos of the American women who practice it as part of a tradition invented to satisfy their unique needs and desires. Modern subgenres of American belly dance evolve within the context of postmodernity, drawing inspiration from the global margins to construct local meanings.

\section{Modern Types in the West}

In the 1960s and 70s, many American belly dancers performed a style that became known as American Cabaret. American women learned this dance from teachers who generally fell into three categories: those trained in the East; Arab American immigrants who learned from informal gatherings; and (most likely) American women who learned about this dance by observing Egyptian films and nightclub dancers (SellersYoung 1992: 143). The cabaret versions of belly dance typically feature a solo dancer 
who performs an approximately twenty minute set consisting of a lively entrance, veil dance, folk song, floor dance, slow dance with a balanced prop such as a sword or tray, rapid drum solo, and concluding lively section (Sellers-Young 1992: 145). To this day, American dancers performing in this style rarely deviate from this formula.

Jamila Salimpour is considered one of the pioneers of modern American belly dance. Although Salimpour never traveled to the East, she invented a format for teaching belly dance based on dances she learned from Middle Easterners performing in American clubs and gained inspiration from Orientalist paintings, National Geographic magazines, a Moroccan cookbook and films (Sellers-Young 2005: 284). In 1968, Salimpour create a variety show in the model of a circus or vaudeville show based on her fantasy of an Arabian souq. ${ }^{27}$ Her artistry and vision inspired generations of American belly dancers and various sub-genres of the dance that emerged in coming decades. For example, in 1987, the first American Tribal Style (ATS) dance troupe formed under the direction of Carolina Nericcio, who was a student of Masha Archer, who was a student of Salimpour (Sellers-Young 2005: 286-287). Based on improvisational group performance, ATS provides an alternative aesthetic to the glitzy, sparkling costume typical of the solo cabaret dancer. ATS dancers gravitate towards multi-layered costumes, turbans and lots of heavy jewelry. I discuss ATS in greater detail at the end of this chapter.

Many varieties of American belly dance draw from spiritual references. ${ }^{28}$

Priestess dancing, snake dancing, birth dancing and meditation dancing are all varieties of belly dance that strive to use belly dance movement as a vehicle for transcendent

${ }^{27}$ Arabic word for marketplace or commercial center of a town or city.

${ }^{28}$ Modern American belly dancers celebrate the possible spiritual and ancient origins of the dance form, as did American Oriental dancers of the early twentieth century. 
experience (Dox 2005: 317-330). According to my observations and interviews, an efflorescence of belly dance types are recognizable to the belly dance community today. The dancers I interviewed list no fewer than the following seventeen types: American Cabaret, Raqs Sharqi, Egyptian Cabaret, Turkish Cabaret, Lebanese Cabaret, American Tribal Style, Tribal Fusion, Neo-Tribal, International Tribal Style, Folkloric, Gyspy/Romany, Fantasy, Theater, Gothic, Burlesque, and Historical.

The Internet and technology help proliferate the global spread of belly dance in various forms. Hundreds of websites, blogs, social networking sites, online magazines, podcasts, chat rooms and YouTube video posts are dedicated to belly dance topics; the advertisement of dance classes, events and workshops; the dispersion of information; and the marketing of innumerable dance related products (Sellers-Young 2005: 287, 296; Shay 2003: 17 and personal research). For many performers, "Online space becomes an extension of the performance space" (Ferreday 2008: 48). More and more dancers realize the impact that mass media, technology and the Internet has had on the belly dance community. There is a correlation between the worldwide explosion of women's and sometimes men's interest in belly dance and the eruption of new belly dance styles as dancers- East, West, North, and South- are able to gaze at each other through a computer screen. Some American dancers I interviewed offered the following insights:

By the time we do it here in the United States it's pretty watered down. There is now more blending and melding. We are watching each other on YouTube. They are imitating us and we are imitating them. It's more and more difficult to find a pure style of dance (Kristie).

People will see something an Egyptian dancer learned off of MTV and they will say it's Egyptian style, but it's not (Mary). 
In the Internet age, cultures are losing identity. Globalization is leading to lower quality (Karen).

We aren't just seeing fusion here, we are seeing it over there (Sarah).

The phenomenon of fusion, a result of the forces of postmodernity, has spurned questions about the authenticity and purity of belly dance as a cultural art form and has aggravated issues about belly dance as an art versus belly dance as a vehicle for personal exploration and self-promotion. Yet, some dancers question the attainability of cultural authenticity in this dance form:

It's all belly dance, because belly dance comes from all feminine movement. You can't pinpoint where it comes from... We as Americans, it's way more true to us because we are all fusion. Most of us aren't just one thing... it just suits our culture more. I have a bone to pick with people who call themselves purists. Because there is nothing pure. It's all mixed up. You can't say you are doing something correctly. You can do what one person or one era did and call it that era and be doing their stylization correctly. Those dancers were pulling from other dancers and the universal movement. Anyone who says that one way is wrong, is wrong. It's all belly dance, it's all creation. Someone who calls themselves a pure Egyptian stylist- well then what era? Are you a modern Egyptian dancer? It's complicated (Carrie).

Many dancers I interviewed had mixed feelings about the effects the Internet has on the belly dance community and the dance as an art form. Carrie, a young, ambitious belly dance teacher and performer I spoke with, said she felt Internet communication interfered with her ability to sell her instructional DVDs because other dancers were selling used copies via Internet channels. She also expressed concern that dancers were learning to dance by watching videos online, thereby missing out on the opportunity to receive feedback from a teacher and fellow students. Carrie said, "Belly dance is person to person, it's not cable to cable. You don't get healed by looking at the Internet." Some dancers I interviewed felt that Internet sites such as YouTube encourage a narcissistic 
tendency within the dance community, directing focus on individuality rather than artistry and competent technique. Simultaneously, informants expressed concern that the globalization of belly dance was diluting the quality of the dance, a symptom of the cultural porosity that is characteristic of postmodernity.

More dancers have become aware of global interest in this art form. They network with other dancers, teachers, performers, and students, and many people have had greater opportunity to travel internationally to participate in belly dance festivals and other events. For example, in 2000 Raqia Hassan, a well-known Egyptian dancer, organized the Ahlan Wa Sahalan ${ }^{29}$ festival. Reportedly, over 170 dancers from around the world attended this event, which is now held annually in Egypt (Sellers-Young and Shay 2005: 23). Interestingly, these festival attendees are predominantly white, middle-class women (Beck 1991: 26; Karayanni 2004: 160). For example Marta Schill, organizer of the Glendale Cairo Carnival in southern California, estimates that eighty-five percent of attendees are not Middle Eastern (American Bellydancer 2005, bonus footage). At festivals, dancers are able to meet, share ideas, watch each other dance, and buy and sell goods. Orientalist motifs abound on DVD and CD covers, in costuming and sets, and on festival print materials. For example, such motifs include images of harems, pyramids and date palms (Beck 1991: 26 and my observations at a West Coast dance festival attended April 26, 2009). The ubiquity of these recurring motifs indicates an enduring tradition that draws from varied and imagined cultural sources.

In general, dancers I interviewed could also discern positive benefits from the global dissemination of belly dance through the Internet, such as the ability to share

${ }^{29}$ Arabic for "welcome." 
information and ideas, and buy and sell belly dance products. A North African dancer in the U.S., Beth remarked, "For me as an Arab, I am kind of proud. It's like wow- look how far and how deeply my culture has gone all over the world. ${ }^{, 30}$ Other dancers I spoke with expressed excitement about the idea of connecting with other women internationally through dance and the implications that this may have for greater cross-cultural understanding. One older belly dance teacher, performer, author, and business owner Mary told me, "Belly dance community is like a family reunion; whenever I travel I see people I know....This community reaches all over the world...it's becoming the world's dance. That is part of the joy of belly dance to me." Mary continued:

Not only are we in this time continuum of belly dancers going through these generations, but we are in this space continuum where all over the planet women are doing these same movements, from thousands of years throughout time and millions of women all over the planet. I really feel that this dance is a key to peace. There are no borders and no boundaries when it comes to dance and music.

Women are gaining a sense of connection and community on a global scale through belly dance. This dance may have the power to dissolves barriers, stimulate communication, and give practitioners the hopeful sense of being acknowledged by others. For many American women, their sense of participation in a long-standing tradition is facilitated by the emptiness of Orientalist tropes and the entitlement inherent in a "melting pot" mythology. I now turn to an examination of the imperialist privilege that imparts American belly dancers with a sense of freedom and right to choose cultural fragments to suit their interests.

${ }^{30}$ This informant's views are in direct opposition to the perspectives of other Arab Americans who view belly dance as a negative, inaccurate representation of Arab culture (Shay 2008: 146). 


\section{The Imperial Privilege of Pastiche}

bell hooks suggests that American society has long been interested in consuming

Otherness because "ethnicity becomes spice, seasoning that can liven up the dull dish that is mainstream white culture" (quoted by Jarmakani 2006: 163). In what Savigliano describes as the "political economy of passion," the hegemonic forces of imperialism and globalization indiscriminately and disrespectfully combine fragments of cultures to suit their tastes (1995: 169). American belly dancers are involved in a process of borrowing (perhaps co-opting) influence from the margin (in this case the exotic Other) and calling it multicultural and cosmopolitan. The market commodifies and absorbs this influence, diluting the transgressive and subversive power that was the impetus for seeking alternative identity construction and alternative community through belly dance in the first place (Villa 2006: 310-311). The attraction of the exotic consumable reflects the search for intense or meaningful personal experience in the language of modern, capitalist culture (Studlar 1997: 124). Here I share an interaction I had with an informant, to further explore why belly dance appears so uniquely consumable.

I was excited to meet with Rebecca because I was interested in learning more about the burgeoning "Tribal Fusion" craze. As we began the interview, I learned that Rebecca also has an extensive background in Hawaiian hula. When I asked her to compare her impressions of hula and belly dance, she explained that hula is different because it's a "cultural thing." She said tribal style is a "bastardization," "a free gypsy style, woman camaraderie thing;" "it's the American melting pot." "In a nutshell we are borrowing moves from other cultures." I asked if she had combined hula with belly dance into a fusion form, and Rebecca replied, "I could have added some Hawaiian, but I was 
very hesitant because of the culture....Out of respect, if you are learning from a hula master you don't want to take this move and do it in your belly dance."

What I find most interesting in my conversation with Rebecca was that she felt free to play and experiment with elements of belly dance, but felt that hula was off limits because it is a "cultural thing." As Rebecca points out, it is the cultural myth of the American melting pot that contributes to this perception of accessibility in belly dance. Dancers feel free to integrate other dance styles into belly dance, but this is a delicate process: it may not be appropriate to "borrow" movements from traditions deemed too "cultural," but those traditions, such as Bollywood ${ }^{31}$ for example, that have been relegated to the realm of popular culture are fair game.

Eclectism, mixed references, and creative configurations of cultural fragments abound in the costuming, movement vocabulary, performance, presentation, venue, music and origin stories of American belly dance. Part of the impetus for this amalgamation is a desire to create new styles of dance (Maira 2008: 331). Much of this cultural pastiche is due to an infatuation with the exotic coupled with a disregard for the exotic's origins. One informant I spoke with related a time when her ATS troupe encountered a Middle Eastern man while performing at an Asian art festival. He demanded to known what kind of belly dance they were doing, appearing very confused about their eclectic costuming and movement style. After the troupe attempted to explain ATS to him, his annoyed reply was, "This is America; I guess you can do anything you want."

American belly dancers combine exotic elements in innumerable ways, donning a first layer of alterity in their costuming (Dox 2005: 314). A dancer might also acquire an

${ }^{31}$ A Hindi film genre replete with music and dancing. 
Arabic or exotic sounding name as a stage name such as, Serena, Aziza, or Layla. A dancer may choose to mix music from different regions or genres into one performance; may incorporate movement vocabularies from dance traditions as varied as Indian classical to hip hop; and may incorporate a variety of moods and messages in a single performance- from the mystical to the kitsch. This process of reconfiguration is not limited to belly dance, as is evident in Maira's analysis Indo-Chic and Rubidge's review of experimentation in Indian dance theater (Maira 2000; Rubidge 1993). The exchange and appropriation of cultural fragments, particularly in an era of globalization, transnationalism, mass communications and postmodernity, disrupts notions of cultural authenticity.

Maira argues that American belly dance is a site for performing "imperial feelings" and then "Americanness" and "Liberal Orientalism" are enacted in the process (2008: 319). In the way that white American belly dancers adopt Arabic names and eclectic exotic costuming, for example, Maira suggests they are masquerading in "Arabface" partially in an effort to appear multi-ethnically aware (2008: 334). Nancy, a North African born performer and instructor, told me that she felt she was often invited to belly dance events in the U.S. because of her ethnicity. She said, "It's nice to have somebody [a North African person], 'oh yes she is from that country.' It's good for them to be connected with me because it makes them more important. But I am not stupid. It's sad, it's really sad." Based on my research, I agree with Maira that some white, American belly dancers may perform a "liberal Orientalism" through their affiliation with the dance community, attempting to associate themselves with multiculturalism. 
Maira also suggested that belly dance has become so much a part of the white, middle-class American women's domain, that non-white women who participate in the belly dance community end up conforming to a popular, white trend. In essence, nonwhite women are donning "Arab-face" to appear more white. When I asked Rebecca, an Asian American belly dancer, why she felt the dance community was predominantly white she responded:

I joke around about being stuck in an Asian body. I look in the mirror like- whoa! I don't like that person...Sometime I get invited to do private parties because of the way I look. Or people want me in their troupe because of the way I look. I see groups that have at least one Asian person in it. It makes it look more authentic, I guess...not that I'm authentic, but people associate Asian with Oriental dance.

It appears that some non-white belly dancers may relate to belly dance as part of a white, American milieu. In Rebecca's case, she immediately confessed her discomfort with her ethnicity to me. But I strongly disagree that this assessment represents the whole of the belly dance community.

I am concerned that Maira is essentializing the experiences of white Western belly dancers. I agree that many of the cultural elements exploited in American belly dance are misrepresented and denied historicity in an effort to bestow a sense of meaningful tradition to belly dance practice. But I am also concerned that the voices and needs of white women become muffled in this debate. I argue that white, middle-class American women strategically participate in belly dance as a form of resistance to aspects of mainstream American society, not just to appear more multi-ethnically aware. Additionally, this invented tradition is internally critiqued and evolving. In the following section, I utilize the theoretical concepts of orthodoxy and heterodoxy to explore ways 
the American belly dance community is developing new dance forms to remain relevant to its practitioners.

\section{The American Cult of Invention and Revision of Tradition}

In May 2009, I attended a Tribal Fusion belly dance show. The dancers used distinctively "belly dance" movements. All dances appeared choreographed. The dancers' costumes, which they change, frequently, resembled something from Vaudeville meets Moulin Rouge meets ATS. Costuming elements included: black and white striped stockings, antique white lacey petticoats, coin bras, elaborate metal headdresses, large tribal earrings for stretched lobes, black knee high lace-up boots, metallic lacey shawls, some particularly gorgeous beaded dresses that looked like authentic antique flapper dresses with long petal-like panels, brightly colored Rajasthani-looking tiered skirts and tribal hip belts with big beaded Afghani medallions featured on the women's hips. The women's eyes, heavy and dark, reminded me of old silent film stars. Their looks evoked images of Maude Allen, Ruth St. Denis, Chicago World's Fair, Moulin Rouge, and Folies Bergere. Acts included a burlesque dance with ostrich feather fans, where the dancer never quite revealing herself; a Flamenco-inspired dance in which the dancer pretended to drink between verses and got progressively more drunk until she was tripping (skillfully) all over the stage; and a trio with all the dancers taking shots of liquor, finally one balancing the shot glass on her forehead as she executed a deep backbend and then dropped to the floor on her back, without dropping the shot glass! The show contained lots of comedy. 
My thoughts about this performance: This is truly American belly dance. Is the idea for this show a conscious representation of American's fascination with the "Orient" and belly dance? This show incorporates so many influences and seems to interpret a piece of American history. The music styles included Appalachian, ragtime, and African jazz influences. There were movement influences from belly dance, hootchy-kootchy, burlesque, and vaudeville. All these elements are transmutations of global influences that had time to be absorbed and reconfigured into uniquely American forms (Field Notes, May 5, 2009).

This Tribal Fusion represents a new subgenre of American belly dance that is gaining popularity and challenging the parameters of this dance form. Before the recent inception of Tribal Fusion, most American belly dancers subscribed to one of two basic camps: Cabaret and ATS. A comparison can be made between cabaret solo dance and ATS. American Tribal Style subsumes individuality and emphasizes the co-creative process of the group, relying on subtle visual and aural cues that facilitate group improvisation. It is a self-proclaimed hybrid style that was created in response to the hyperbolized femininity and coquettish aesthetic of solo cabaret dance. ATS takes inspiration from nineteenth century presentations of the East, and responds to and rejects the 1960s glorification of the Hollywood images reflected on the stages of Arab American nightclubs and restaurants. "American Tribal, like many popular forms, is contradictory in its incorporation of some stereotypes while challenging others" (SellersYoung 2005: 295). I posit that ATS originated as a heterodox style of belly dance, in opposition to the more glitzy, orthodox solo cabaret from. 
In the last few years, interest in ATS has waned, and American belly dancers are once again experimenting with new forms of expression generally based on standard belly dance movements but incorporating new presentation styles. This new style is loosely labeled “Tribal Fusion.” Rebecca explained, "A lot of people are getting bored with the tribal improv [ATS] because they are constantly wanting something more. That is where the fusion comes in." Jarmakani describes the seemingly insatiable appetite for something new as an aspect of the hegemonic structures of Orientalism and imperialism. These structures contain "narratives that must constantly be renewed and revised as they adapt to resistant and contradictory narratives" (2008: 6). As the exoticism of the exotic becomes depleted, "the escape is to discover 'new exotics' (Savigliano 1995: 90). ATS, ten years ago the heterodox rebellious response to an older version of belly dance, has now lost some of its relevance. I suggest that the social experiment of ATS has failed, its communalism not able to withstand the American desire for individualism. Tribal fusion places focus back on the individual dancer and introduces new exotic roles for American women to explore.

Tribal Fusion is an emergent phenomenon that is still being debated, discussed and defined by the American belly dance community. A 2008 DVD entitled "Tribal Revolution: Tribal Fusion Bellydance Performance" describes Tribal Fusion as "a catchall label for the various representations of this evolving style." Its current incarnation may incorporate diverse aesthetic modes, from burlesque and vaudeville to gothic and postindustrial punk. The DVD explains that music can range from "authentic" to modern DJ mixes; the costume can be layers of "authentic textiles" to "sleek club wear... or anything in between"; movement can be improvisational or choreographed, utilizing modern hip 
hop or diverse dances of the world. In the final analysis Tribal Fusion is "in its infancy as an art form, its rules not yet firmly established....Its relation to ATS grows more distant and controversial" (2008). The loose definitions of Tribal Fusion make it difficult to assess what would not be subsumed under its rubric.

The new exotic of Tribal fusion presents a peculiar mixture of exotic East, historical West, and pure fantasy. One dancer featured in the "Tribal Fusion: Fundamentals" DVD stated, "I like the Voodoo aesthetic...my look is a cross between Mad Max Beyond Thunderdome and Barbarella" (2009). It is interesting that the new exotic of Tribal Fusion commemorates historical encounters with the East in the American milieu, as in vaudeville and burlesque. ${ }^{32}$ An aspect of this new exotic is in fact American culture. The emerging genre of Tribal Fusion shows that the invented tradition of American belly dance "has less to do with the Middle East than with women's ongoing dialogue with western culture and the value of the individual, specifically the female self" (Dox 2005: 333-334).

I propose that the tradition of American belly dance is facing revision because many American women's roles, needs and perspectives are in flux. Dancers who are exploring the new world of Tribal Fusion are drifting away from associations with Middle Eastern culture that other belly dancers adamantly embrace. Perhaps for some Americans, the modern Middle East has become too "real" for it to be confused with the exotic Orient of the Western imagination. The interest in vaudeville and burlesque evoke a time in American history when the Orientalist fantasy seemed less cluttered. Does this

\footnotetext{
${ }^{32}$ The celebration of burlesque within the Tribal Fusion movement is contained within historical signifiers, perhaps in an effort to distinguish this erotic form of belly dance from other modern erotic dances.
} 
aspect of the emergent Tribal Fusion represent an invented cultural memory for a more innocent time as far as world politics were concerned?

I also propose that Tribal Fusion accepts a subversive sexuality that other American belly dancers have tried to obscure. Many Tribal Fusion dancers are incorporating overtly erotic elements such as burlesque in their dancing, reflecting a postfeminist trend especially among younger dancers. Many of my younger informants decidedly rejected the label of feminist with such statements as "I am not a big fan of feminism" and "the word feminism has such a butch, man-hating, negative kind of thing" but see their dancing as empowering and liberating. Tribal Fusion may represent an emerging "post-feminism" felt among some American women. One informant recounted a time when her troupe performed at a women's rally to promote women as police officers and firefighters. She recalled that women in the audience heckled them while they danced. The amplified femininity of all belly dancing may be a powerful challenge not only to patriarchy, but also to mainstream Western feminists.

\section{Conclusion}

In the process of inventing linkage to an exotic dance tradition, American belly dancers are constructing a unique Occidental mode of expression that obscures connections to the social concerns of modern Eastern women, while providing a source of meaning and social identity for its practitioners. It is critical that this construction be continually revised to maintain relevance for the American women involved in the belly dance community, leading to the emergence of new heterodox forms of American belly dance that challenge previous notions of the exotic. The permanence of some aspects of 
American belly dance indicates that as an invented tradition its survival is likely. The formulaic nature of many aspects of this dance community, such as movement vocabulary, predominantly women's involvement, and two-piece costuming, facilitates its efficacy as a vehicle for resistance, transgression and transformation. In the following chapter, I investigate what social needs and desires this tradition satisfies, analyzing American belly dance as alternative feminism, acknowledging that many practitioners do not necessarily label themselves as "feminist." 


\section{Chapter 4 \\ American Belly Dance as Alternative Feminism}

\section{Introduction}

Belly dance has empowered many American women, addressing their personal concerns and providing a sense of supportive community. Although belly dance has been "the object of cultural appropriation, manipulated into complicity by an Orientalist agenda...this same art form incorporates a rare and unyielding potential for various forms of resistance: social, cultural and sexual" (Karayanni 2004: xii). Belly dance, though informed by global power dynamics that privilege the Western dancer under the banner of imperialism, still creates potential for positive transformation. Many American women use belly dance as a mouthpiece to express concerns about power, sexuality, and the hegemony of Western capitalism. But does their dancing truly free them from the binds of patriarchal and imperialist constraints?

Having explored how elements of postmodernity, such as global communications, transnationalism, and technology, have affected the invented tradition of American belly dance, I now turn to an investigation of what purposes this invention fulfills. Here I take a closer look at specific aspects of identity construction and meaning formation that belly dance facilitates. I examine how practitioners utilize the perceived empty location of the exotic Other to express concerns difficult to voice through normative social structures. I investigate ways belly dance has permitted women to explore alternative modes of femininity through transformative encounters with perceptions of body image, community, lifestyle, mythological narrative, and notions of spirituality. I also underscore its significance as a site of resistance to modernity, capitalism, and industrialization. 
Other scholars have largely neglected this particular aspect of belly dance. I base these arguments on an understanding of the alternative feminisms that sprung from the second wave feminism of the 1960s.

\section{Theoretical Orientations}

American belly dance represents a type of folk feminism that arose in reaction to the second wave feminisms of the 1960s. This alternative feminism evokes a nostalgia for an imagined women's tradition thought to be buried by the Western patriarchy. Dancers seek to access vestiges of this tradition by "festishization of an 'ethnic Other woman' (Hollows 2000: 29). Furthermore, the concept of invented tradition is integral to an understanding of belly dance as an alternative feminism. Through the empty location of Orientalist motifs, participants are able to envision their connections to an exotic Other and an ancient practice. From this position, practitioners construct a folk feminist tradition.

Belly dance, as a modern spiritual practice rooted in ancient tradition, illustrates how many American women construct tradition and seek feminine empowerment that runs counter to the mainstream Western feminism. I conclude this chapter with an indepth look at spirituality in American belly dance. As Crosby writes in the book Daughters of the Goddess: Studies of Healing Identity and Empowerment, "While some feminists object to Goddess spirituality for what they see as biologically reductionist viewpoint, there is little doubt that when women see their bodies as divine they get a taste of the power which has been the traditional province of men for millennia" (2000: 169 and 175). American women adopted imagined reconstructions about ancient, matriarchal 
Middle Eastern cultures as alternative models to Western patriarchy (Dox 2005: 304). Many belly dancers believe that the primordiality of this dance affirms a universalized femininity. Yet the concept of universalized feminism has been greatly criticized by many modern feminist scholars.

Mohanty refers to non-Western feminism as Third World feminism in order to distinguish women who live in specific locations and share a similar historical background, which includes minority women in the United States (2003: 44). Mohanty asserts that a global feminist epistemology must include not only discursive categories but also materialist definitions of class. She argues that one of the biggest differences between Western and non-Western feminisms is the focus on gender and sexual rights as compared to understanding ways gender is crosscut by race, class and liberation issues, respectively (Mohanty 2003: 53-54). Mohanty emphasizes that issues of race, class, nation and sexuality must be addressed alongside gender, conveying a "dynamic oppositional agency," in order for Third Women feminisms to be efficacious (2003: 55). I argue that many American women are using belly dance as means to transcend some of the constraints of class and race categories, but not necessarily in ways that fundamentally challenge the power structures that perpetuate inequalities.

For many American belly dancers, the desire for new identity is related to the constraints of ethnicity and class affiliation. For example, in the early twentieth century, upper class women explored dance as a means to transcend the limitations of bourgeois domesticity (Desmond 1991: 41; Studlar 1997: 105). Similarly, participation in belly dance allows white, middle-class women to explore other ethnicities, performing "a measure of 'blackness' without paying the social penalty" (Shay 2008: 140). I argue that 
middle-class, white American belly dancers continue to utilize dance as a means to escape the perceived alienation and meaninglessness of social constraints. Yet being steeped in the institutionalized norms of the American society, the othering process of this invented tradition often glosses over race, class, and ideological concerns that trouble relations between East and West, with the dance instead construed as a form of personal expression (Dox 2006: 55). Additionally, it is mainly economically comfortable white women from the middle-class who can afford to participate in the belly dance community. Ironically, the discursive frames meant to transcend these limits often avoid the realities of modern social concerns.

Similarly, many American belly dancers may succumb to a false consciousness in terms of how their sensual dancing is perceived by the larger society. There is an interesting tension between the innately seductive qualities of the dance and its liberating power, what Karayanni describes as "compliant resistance" (2004: 109). Dancing constitutes a form of resistance to societal norms in that women's sexual power has often been demonized by general society, even by Western feminists (Crosby 2000: 177) ${ }^{33}$ But this resistance is context dependent. American women strive to become the subject of their dance experience, as opposed to the object of male gaze, in the protective atmosphere of a semi-public classroom or recital attended by mainly other dancers. But in a public restaurant or club setting the gaze changes, as does the potential for objectification (Dox 2006: 54-55; Karayanni 2004: 171; Shay 2008: 125). In belly dance, there is a constant risk of discrepancy between intent and gaze.

${ }^{33}$ This resistance may be in part a reaction to the masculinized feminism of the $1980 \mathrm{~s}$ as women competed in the corporate world. 
The criterion for performance also differs in the semi-public and public realms. In the classroom, women of all shapes, ages, and fitness levels are welcomed to participate and thus enact a resistance against the internalized obedience to what Mernissi calls "Size 6: the Western women's harem" (2001:208-219). Yet on the public stage this ideal of inclusiveness and resistance against societal norms disintegrates as competition ensues and thin, young dancers rise to the top.

Ultimately, I argue that some American belly dancers deny their own political power by focusing on improved self-image as a means to attain liberation and internalizing a patriarchal male fantasy disguised as sexual autonomy motivated by feminist ideals. To better understand this alternative feminism, I now investigate perspectives of personal empowerment, sexual liberation, public exposure, and body image in the American belly dance community.

\section{Inventing Alternative Feminism Through Dance}

For many American women, belly dance offers empowerment by tapping into women's presumed "natural" feminine attributes. Many dancers describe a sense of greater control over their bodies, increased self-confidence, and more connection with others that they credit to the practice and community of belly dance. For most American dancers, this perspective refuses to acknowledge the low social status of modern dancers in the Middle East and instead emphasizes an ancient context for the dance (Dox 2006: 55). Part of the confidence that American women gain through public dancing and bodily exposure arises from the connection made between the "naturalness" of womanhood and 
reproductive sexuality detached from pure eroticism. Kristine, a Southern Californian

performer of many different genres of belly dance, clearly illustrates this concept:

The earlier feminism was, 'we need to be equal.' But nowadays we are finding that well we still need to be women. The belly dance is strong and feminine at the same time. It is ultra empowering in that way. You are using your natural feminine abilities [emphasis mine] to have power and create beauty and enjoyment for yourself .... and other people are watching.

Dancers must tussle with a precarious alliance between seductive dancing and personal liberation (Deagon 2005: 256). The common narrative of American belly dance highlights its connections with ancient spirituality, thus dampening its erotic connotations. In this way, the discourse of American belly dance "Does not question the opposition of licentious sexuality with generative sexuality" thus reifying the mother/whore dichotomy (Jarmakani 2006: 156). American belly dancers seek empowerment and liberation by celebrating a notion of the vital nature of women, a universalized view of womanhood that denies the significance of race and class.

Almost all the women I interviewed for this project agreed that their participation in the American belly dance community had improved their lives in some way. Nearly all my informants described a feeling of "falling in love" with the dance and "embracing their femininity" in the process. All women interviewed stated that the dance was empowering, but not all related to the label "feminist." Many women also described feelings of being sexually liberated because of their dance experiences, in private and public ways. One informant shared, "It made me uncomfortable for a while, because then I became aware of my sexuality as a woman...then I got through that and then it was all the wonder of my body...just the joy of being a woman." Another dancer stated, "My 
male domestic unit is a gynecologist- half of our bread and butter is men who bring their women in- like 'she has no libido, fix her.' I don't hear that from belly dancers. I hear healthy conversations about women's orgasms and how excited they are to see their mate, and their husbands just beam."

The personal empowerment and sexual liberation associated with second wave feminism and 1960s hippie counterculture made it desirable for many American women to explore and display their bodies in public venues such as the belly dance performance. Professional dancer Ansuya stated in a 2005 documentary about the international touring group Bellydance Superstars that she learned the dance from her mother, who learned it in the 1960s and 70s and therefore her dance approach was from the standpoint of female sexual liberation, not an ethnographic study of dance. What divided the belly dance community's view of female empowerment from the larger Western feminist project was a concentrated focus on the empowerment garnered through sexual liberation, control of the male gaze and especially public exposure of the body. This perspective on female empowerment is what Deagon calls "Cosmo-girl feminism" (2005: 253). This notion of feminine power is strategically positioned in between resistance against oppressive patriarchy and transgressive attitudes towards the mainstream feminism.

The view that American belly dance embodies, as one informant put it, "feminine empowerment to the extreme" has largely excluded men from participation in the art form. Historically, male belly dancers were once popular in the Middle East and Central Asia. Male and female dancers were often viewed as interchangeable in these societies. Male dancing was not viewed as an effeminate parody of female belly dancing in these contexts. Instead, notions of exclusively female professional belly dancers are essentially 
a product of colonialism and the imposition of European gender constructs on Eastern subjects (Karayanni 2004: 77-79; Shay 2005: 52; Shay and Sellers-Young 2005: 6). The virtual absence of male dancers from the narrative about the origins of this dance form further supports the notion that American belly dance is an invented tradition.

The American belly dance community welcomes the family and friends of dancers, but the core of the community is essentially female. The female community of American belly dance, a semi-public realm where the dancer becomes the subject of her experience, may be likened to a Western harem. The belly dance class, troupe, and occasionally performance site is a place of women, who sometimes opt to prevent male presence. ${ }^{34}$ But as Dox contends, this is the harem of the Western imagination (2006: 55). Built upon Orientalist fantasy, the harem is an exotic feminine realm all the more intriguing because of its perceived limits and restrictions. In this way the "harem" also reifies the patriarchal social system (Dox 2006: 60). Because practitioners feel that they are engaging a tradition rooted in ancient and universal feminine principles- empty, available and lacking specificity- that they are able to mold their motivations and experiences as belly dancers to fit under the rubric of feminism (albeit, an alternative feminism). I now take a closer look at the ways many American women experience empowerment through belly dance by first examining my observations at a local belly dance show that took place in the protected realm of the dance studio.

${ }^{34}$ Belly dance classes generally discourage men's observation or participation. Class advertisements, instructional format and setting promote the dance as uniquely suited for a woman's body in a community of female practitioners. 


\section{Public Exposure}

I attended a local belly dance show that was a fundraiser for a program promoting confidence and self-awareness for teenage girls through belly dance. This program taught young girls self-respect and fostered mutual support through participation in dance classes and performances. Turkish and American Tribal Style forms of dance were represented. Music varied from Romanian Gypsy to techno club music; costuming included items as varied as rhinestones, African pendants, Indian bindis or forehead jewels. Dancers wore full, multi- tiered skirts, coin belts and bras, flowers in their hair and temporary facial "tattoos" applied with eyeliner. The small audience consisted of women, men and small children, many of who appeared to be family or friends of the performers. At the beginning of the show the audience was presented with instructions on how to participate in the performance by making noises, such as ululating (zhagareet,) hissing like snakes, yelling affirmative exclamations in Arabic and clapping. The audience was also given a short history of belly dance, tracing its origins to ancient cultures.

The last performance featured two teenage graduates from the program. They entered the stage wearing veils over their heads and shoulders, reminiscent of Afghani burqas. ${ }^{35}$ Their entrance music repeated the lyric, "it's a man's world" again and again. The young women eventually discarded their veils, revealing a two-piece belly dance costume and improvised a duet, each taking turns "leading" the other dancer by standing slightly in front of the other and cueing changes in movement through eye contact, verbal cues and hand gestures. Their dance eventually incorporated swords and concluded with

${ }^{35}$ An enveloping outer garment meant to conceal the entire body. 
the dancers facing each other on their knees, swords balanced on their heads, describing symbols and gestures in the air that each followed as if looking in a mirror.

After their dance performance, the young women offered short statements about how belly dance had improved their lives, their friendships and their self-esteem. Some audience members interjected comments of praise and compliments on their improvement and effort. An older woman in the audience, closely associated with the program, stated that she felt the young women were like family to her- daughters or granddaughters. The atmosphere of sisterhood, support, and encouragement was touching. It was evident at this performance that the dance has great meaning and power in the lives of the dancers and was a source of community support and personal development (Field notes, November 15, 2008).

The act of displaying the body in the two-piece costume associated with Hollywood fantasies of the exotic Oriental female has become emblematic of a belly dance student's personal transformation and initiation into the community. The belly dance studio becomes a sanctuary, shielded from the male gaze. ${ }^{36}$ Many women feel that this context for display gives them control over their own sexual power and the male gaze, an image that differs from the popular cultural stereotype of the belly dance being for men's erotic entertainment (Shay 2008: 125). Several of my informants have expressed the significance of the transformative moment when female students bare their midriffs for the first time in the dance classes they teach:

\footnotetext{
${ }^{36}$ Belly classes generally discourage men's observation or participation. Class advertisements, instructional format and setting promote the dance as uniquely suited for a woman's body in a community of female practitioners.
} 
I love it when people come to the first class and they are covered from head to toe in a big baggy sweatshirt and sweat pants and they are afraid to shake their jiggly stuff. Then three weeks and their shirts are off, the tummies are out and everyone is free and uninhibited. I love watching that happen and I think that for some people that's their only chance to do that. I love that! (Emma).

It is inspiring to see this group of women really covered up and thinking there is no way in hell that I am lifting my shirt up to show my belly and then... all of a sudden they are wearing the coin scarves and the half top and to me that is amazing (Denise).

Through the act of removing clothing, some women in some contexts experience empowerment. This process is clearly illustrated in the description of the teenage belly dancers' performance described above. The dancers enter, fully covered, to music about a "man's world" evoking notions of patriarchy (and specifically Eastern patriarchy) and then ceremoniously discard the outer layer to reveal two piece costumes and bare midriffs. The potential liberating and transformative power of belly dance is enacted in the fine grain of a single performance.

Western belly dancers may derive a very different sense of empowerment through public dancing and bodily exposure than do their Eastern counterparts, because the distinction between the public and private realm is much less pronounced in the West where dancing is concerned. In the American belly dance community, the distinction between the semi-public realm of the classroom or belly dance event and public dancing in restaurants or clubs for non-belly dancers is paramount because in the American belly dancer's harem the gaze can be controlled. In the East, the implications of belly dance in the private context contrasts greatly with public belly dancing. It is not unusual for professional, public belly dancers in the East to be suspected of moral transgressions such as prostitution (Dougherty 2005: 150-152; Fraser 1993: 60; Lorius 1996a: 514; Lorius 
1996b: 286; Van Nieuwkerk 1995). This private/public divide for belly dancing is not applicable in the West and thus most American belly dancers do not question the appropriateness of dancing in public the way that Eastern women do. Rachel, who spent extensive time in the Middle East, explained, "There is greater focus on decency in the East and your appearances reflect on your family, neighbors and friends. Middle Eastern women don't display themselves in public." Sarah further elucidates this point: “Europeans and Americans, we don't have those same associations and our families aren't giving us that negative feedback and so we don't have that problem [with public dancing]."

The question of why many American women feel empowered by public bodily exposure begs further investigation. I suggest that exposure, such as that in a skimpy, two-piece belly dance costume, is empowering because it represents resistance to and transgression of societal norms. By exposing skin, women are purposefully disobeying the societal rules about "showing too much." Supposed fashion experts counsel women to avoid "over-exposure," such as showing both cleavage and upper legs at the same time. On the other hand, the fashion elite in the West may consider the low-neck line of an expensive evening dress classy. There is an intriguing class element involved in this distinction. A revealing dress designed by a famous fashion designer, may mitigate excessive skin exposure by its categorization as a luxury item. On the other hand, if a woman chooses to wear a cut-off t-shirt and cut-off jeans, exposing proportionately the same amount of flesh as does the expensive dress, her bodily exposure is deemed tacky and "low-class." Terms such as "low-class" and "not classy" reveal social attitudes that connect socio-economic class with appearance (Ortner 2006). White, American, middle- 
class, belly dancers who appear in public with exposed midriffs, cleavage, and legs

purposefully break the social rules about appearance. Buffered by an air of exoticism and their privileged status as white and middle-class, they show skin while maintaining that its exposure signifies personal empowerment. A sense of empowerment gained through public exposure is directly related to concerns with body image for many practitioners.

\section{Fat Dancer, Skinny Dancer and Everyone in Between}

The discourse of the American belly dance community encourages physical health, self-improvement and self-acceptance. The American belly dance community has a sense of body image that is inclusive of all body types. It ideally rejects the image of the ideal women as young, skinny, blond and rather Barbie-like, as presented by the mainstream media. This open invitation to all female body types is posited in opposition to not only patriarchal oppression but also aspects of Western feminism that devalue the sensuality of the voluptuous female body (Jarmakani 2006: 147, 161). Natalie, an experienced performer and larger-bodied dancer stated:

I think that women are tired of having to compete against women. For myself, I still buy Vogue and In Style magazine and all that, but I really resent the fact that I don't fit into any of those boxes and I am tired of them telling me that I have to. Belly dance gives another avenue to feel good about yourself and feel like you don't have to fit inside a box.

Because many women feel immersed in a culture that demands conformity to certain body types and appearances, participation in belly dance offers a respite from these pressures, albeit based on a notion of empty location that allows them to enact these alternative identities and oppositional perspectives. 
Many American belly dancers assume that Eastern cultures accept fuller figured women, supporting notions that belly dance practice is uniquely positioned to celebrate larger women. For example, American belly dancers have participated in events such as the National Association to Advance Fat Acceptance convention. Many Western dancers do not recognize that the Western ideal of the anorexic body type and oversized breasts have become globalized (Maira 2008: 333). Sarah confided with me that on a recent trip to Egypt, that local Egyptians loved her larger bodied belly dancer travel companion. She stated, "People went insane for her there. Just insane! And I was just not that interesting to them. Dancing here in the States we get the opposite reaction." In contrast, Cynthia told me that the big women supposedly favored by Egyptians do not appear on Egyptian television and furthermore, Arabic poetry traditionally describes the ideal woman as slender. This disparity in reports about the reception of large women in the East may reflect changing preferences in the East regarding the ideal female body type. Although the American belly dance narrative celebrates the idea of inclusion of all body types, in practice the belly dance community sometimes ostracizes larger women, especially where belly dance performances and competitions are concerned.

Many of the dancers I interviewed questioned whether the all-inclusive rhetoric of American belly dance reflected reality in that community. These women explained that although dancers of all body types are welcome to classes, this sentiment changes when dancers perform on stage. Furthermore, the idea of all inclusiveness may be unique to American belly dance traditions in particular. Beth, a fitness instructor as well as a belly dance teacher, stated 'It's the Dance of the Fat Chicks. If you can't do ballet you belly dance. In other countries it's like, 'if you want to be a belly dancer you have to be a 
dancer." Jill speculated, "Is tribal for old and out of shape ladies? Is fusion for all the hot skinny, young chicks?" And many women I interviewed insinuated that although the belly dance community embraces an ideal of all-inclusiveness, there is a lot of competition, gossip and non-acceptance "behind the scenes." The belly dance competition crystallizes much of this irony. The belly dance competition, in which some women participate, is often a locus for individuality, antagonism and body size judgment that may be unique to Western approaches to this dance form. North African-born dancer Nancy told me:

Unfortunately the Western way is competition and with that is ignorance, and with ignorance is insecurity and with insecurity is arrogance... Women learn Middle Eastern or Oriental dance but they don't learn about the culture, the spirit, they don't learn about how women are honoring each other.

Natalie described her experience dancing at competitions as a large-bodied belly dancer:

My very presence on stage with the rest of those women is really pushing buttons and it has been very polarizing. It has been either, 'woman power' or 'you need to cover up.' One judge always scores low on appearance [specifically for her]. This judge said, 'I would rather see you in a dress.' [She is saying that this judge was offended by her large belly exposed in her two-piece dance costume.] She said, 'I couldn't even watch her dance,' because she was distracted by my belly. Really. A belly, in belly dancing!? And why is this person allowed to judge?

I assert that the emphasis on individuality so central to the American cultural mythos undermines American belly dance practitioners' ability to fully understand the native context of belly dance in the historical East. Just as interest in the communally centered ATS has dissipated and American belly dancers are shifting greater attention to the soloist, the belly dance competition also encourages contention between dancers, buttressed by the entrepreneurial nature of the belly dance marketplace and the 
individualistic ideals of the larger society. When belly dance is intended for a stage production, rather the semi-public realm, resistance against society's body ideals fades.

It should be noted that many dancers I interviewed cite the international phenomenon of the Belly Dance Superstars (BDSS) as instrumental in encouraging Americans and dancers around the globe to idealize the youthful, skinny belly dancer. In the American Bellydancer documentary, Suhaila Salimpour argues with BDSS producer Miles Copeland about his interest in creating a dance troupe composed only of sexy, young, thin dancers (2005). Copeland complains that the belly dance community was appalled that he first featured young, thin women in the BDSS shows. Some dancers I interviewed attribute the BDSS's international success to the widespread perception that "people think they [belly dancers] are all 5'4" to 5'8" and wear a size 4 to 6 . If you look

at the mass marketing it seems that dancers should be pretty and thin as compared to what is actually out there." The belly dance community includes women of all body types, ages and levels of ability, but in in-group discussions of performances, dancers criticize those who do not meet the ideal type, as promoted by such companies as the BDSS. Although many belly dancers celebrate the beauty of all women in dance, it is certain that those dancers who rise to fame do so because they fulfill the demands of consumers. I question whether all American belly dancers realize true freedom from the constraints of patriarchy, popular culture, and mainstream feminisms that deny the power of feminine sexuality.

In order to obtain a sense of empowered femininity, the belly dance community encourages a form of liberation attained through elevated self-image. Jarmakani calls this trend "New Liberation." New Liberation focuses on inner personal thoughts about body 
image, rather than questioning the power structures that suppress women's access to equal rights (Jarmakani 2006: 159-160). With emphasis on surmounting negative thoughts about the self, political action is "displaced by the rhetoric of empowerment and inner freedom, which is buttressed and normalized by a booming self-help industry" of which arguably American belly dance, with its emphasis on physical fitness and selfacceptance, is very much a part (Jarmakani 2006: 160). Belly dancing has a presence in many of its practitioners' lives that is relatively unusual for an exercise activity (Crosby 2000: 171). I argue that American belly dancers who claim to pursue an alternative feminism through their dance practice and dance community are actually internalizing some aspects of the Western patriarchy by relinquishing a greater awareness of their political agency. Based on this investigation of American belly dance as an alternative feminism, I now look at ways this gynocentric community addresses concerns about lifestyle and community.

\section{Belly Dance as Alternative Lifestyle and Community}

The ways that American belly dance provides a sense of community and offers alternative lifestyle choices in response to consumer capitalism and modernity is a topic that has been widely neglected by other scholars. Sellers-Young suggests that American

women's increased economic freedom and spare time related to their employment outside the home during World War II and the improvement of modern household conveniences contributed to their desire to "to seek diversion outside the home" by taking belly dance classes (1992: 142-143). I argue that feelings of alienation and isolation associated with modernization, late capitalism, post-industrialization and urbanization also played a 
often- overlooked but significant role in American women's participation in the belly dance community. One belly dance performer, teacher, and former anthropology student Natalie stated:

For American women, obviously the lifestyle is different. Our idea of a nuclear family is different from the extended family that exists in the Middle East. If you look at most ancient cultures, the extended family model is really important- to their spiritual lives, to their child-rearing, a cornerstone of how societies work. And we don't have that. I feel like there is a big chunk missing in the European/American model. There are integral connections that cultures with more extended families generate by their own existence. Within the world of belly dance, I think that is why tribal really took off- especially in the Western world. There is a network that is formed that replaced that ancient thing...We need these networks and connections.

Savigliano indicates that exoticism is necessary for keeping Westerners in touch with a naturalness and humanness that has been eclipsed by capitalist life (1995: 89). According to Natalie's statements, it appears that belly dance is associated with a nostalgic ideal, an imagined model for a better way of life. In fact, many of the dancers I interviewed expressed a sense of loss, alienation, isolation or even nihilism in the face of modern life. Many American belly dancers report that the community life of belly dance has abated these feelings. Dancers feel they are tapping into a more "wholesome," ancient way of relating to others, remembering and recouping a "culture" that has become lost. One Native American informant, Megan, shared that sense of lost culture because her tribe had suffered near annihilation. She said that belly dance had helped her regain a sense of culture.

Many American women have been attracted to the American Tribal Style (ATS) belly dance specifically because of its emphasis on group performance, the strength of unified female presence, and the bonding that takes place between "sisters" of the "tribe." 
Tribal-style dancer Jill expressed the importance of community in belly dance experience, saying: "We didn't do this because we loved performing, we did this because we loved to go out to dinner after we performed." In ATS's group improvisational format, dancers pay attention not so much to the audience but to the interdependence of the tribe (Sellers-Young 2005: 291) ${ }^{37}$ Carolena Nericcio, the director of the original ATS troupe, Fat Chance Belly Dance, partly credits her interest in intentional communities as the inspiration for the community-based model that is the foundation of ATS (SellersYoung 2005: 286-287). The communitas and social bonding of belly dance appears to promise an alternative way of life that contrasts with the alienation and individualism of modern, Western capitalism.

One dancer I interviewed explained that involvement in belly dance coincided with certain lifestyle choices that may be described as anti-establishment, counterculture, or a challenge to mainstream consumer culture. Many dancers, particularly those who practice American Tribal Style belly dance, celebrate modern primitivism, the DIY ${ }^{38}$ movement, tattoos, the craft movement, an appreciation for repurposed objects, an eclectic aesthetic and the avant-garde (Beck 1991: 29; Ferreday 2008: 57 and personal interviews). For example, many dancers take pride and delight in making their own costumes. They place great emphasis on the creativity and resourcefulness of a dancer in sourcing, designing, and crafting her own costume and other presentational elements. For example, a large portion of the 2009 Bellydance Superstars produced "Tribal Fusion: Fundamentals" DVD shows featured dancers describing the process of putting together

${ }^{37}$ One informant I interviewed stressed that ATS is less about performance than about connection between the dancers.

${ }^{38}$ DIY- Do it yourself 
their complex and intriguing costumes. I purport that this represents a subversive aspect of belly dance in that it is a rejection of mainstream consumerism and conventional ideals of beauty through the celebration of the handmade and personal creativity.

The yearning for community, the admiration for the handmade, and the value placed on female bonding intersect in my analysis of American belly dance. Resistance against Western capitalism and modernity and advocacy for an alternative feminism are both engaged in nostalgic yearnings for a distant past that strengthens the notion of American belly dance as an invented tradition. The concepts valued by this dance community, such as the wisdom of an ancient past, communal living, and feminine power, and their associated Orientalist tropes such as harems and tribal village life, may be described as "nostalgic foils for a progress-bound society" (Jarmakani 2008: 53). Dox makes the insightful observation that "there is a complex reciprocity between the authority of the ancient archetype and a women's experience in a contemporary industrialized culture" (2005: 316$)$. The alternative feminism of American belly dance is a folk feminism that seeks to overcome modern concerns by privileging an imagined Other of the past.

The tradition of American belly dance fills a social need: a felt need for greater social connections and more meaningful materialism. Administering to those needs may imply an imperialist imposition upon the exotic Other that relates to the mass consumption of cultural fragments possible in the postmodern reality. "Capitalism did in fact massively alienate the workers, but the existence of the sensual exotics.... 'reminded' them of what they had lost and now could buy" (Savigliano 1995: 89). Participation in this dance community presents opportunities for social bonding and 
alternatives to modern capitalist culture, to economically comfortable women who can afford the costs of costuming, classes and related products and activities. American women are expressing economic power through affiliation with this dance community. Although practitioners claim that belly dance is a means to connect with a universalized essence of womanhood, it is largely middle-class women who have the financial resources who participate the most actively in this community. As an alternative feminism, American belly dance addresses issues of sexual agency, body politics, community and lifestyle. I now investigate how this practice is framed and legitimized by a mythos of ancient, feminine-centered spirituality.

\section{Spirituality and Mythology}

Most, if not all, popular writings on American belly dance include a section tracing the ancient origins of belly dance and establishing the dance form as the oldest dance known to humanity (Al-Rawi 1999; AlZayer 2004; Buonaventura 1983, 1998; Copeland 2000; Djoumahna 2000; Hobin 2003; Mishkin and Schill 1973; Mourat 2000; Stewart 2000; Wilson 1972). In Earth Dancing: Mother Nature's Oldest Rite, Gioseffi traces dance origins in a timeline that begins with Upper Paleolithic Venus figurines in 25,000 B.C. (1980). This story of ancient origins was even recounted by the emcee at the beginning of the teenage dance performance that I described above. Descriptions of ritual dance convey a sense of timeless tradition affiliated with the worship of a variety of ancient goddesses from a variety of ancient matriarchal cultures in the East (Buonaventura 1983, 1998; Copeland 2000: 72; Hobin 2003: 41-42; Mishkin and Schill 1973: 15-17; Mourat 2000: 42-45; Stewart 2000:112-113). These authors cite 
archaeological research as evidence for this claim, particularly in non-academic belly dance literature. Authors who seek to link modern belly dance to primeval origins cite reliefs, tomb paintings and pottery depicting dancers as evidence of ancient belly dance in ritual contexts (Djoumahna 2000: 10; Hobin 2003: 41-42; Mourat 2000: 42). In contrast to these claims, re-evaluations of archaeological evidence, by such professional archaeologists as Ian Hodder, Lynn Meskell and Cynthia Eller in 1993, have disputed the existence of ancient matriarchal cultures in the Middle East (Dox 2005:335). Likewise contemporary Middle Eastern cultures, especially Islamic peoples, deny any such connection with belly dance. North African informant Beth told me "If you go to the Arab world and tell someone that you dance for the goddess, they will laugh at you. What goddess? Most Arab countries have the one God!” Therefore, I would argue that the perpetuation of the myth about the ancient, matriarchal origins of American belly dance constitutes an invented tradition.

I concur with authors such as Jarmakani, Shay, Sellers-Young and Dox in their critique of a blind adherence to a weakly supported narrative of the ancient origins of belly dance that relies on Orientalist stereotypes of ancient Eastern wisdom (Dox 2005; Jarmakani 2008; Shay 2008; Shay and Sellers-Young 2005). Jarmakani refers to this history as a desire to seek a "lost" past, "[tracing] belly dance far back to an origin that seems to have no cultural specificity," this myth being "in the service of a universalized, hegemonic white feminist narrative" (2008: 4, 84-85). The mythology of belly dance does not recognize specific cultural origins and or a specific historical period. This ambiguity allows the privileged West to pick and choose pieces of the story, constructing a narrative with little regard for accuracy. 
The myth of the ancient tradition of belly dance permeates popular writings about the dance, performances that I observed, and the interviews I conducted:

The roots are really, really ancient. It has been passed down through the generations of women for thousands of years. So now in this time and place, we are doing the same movements that women did thousands of years ago. We are teaching the movements to younger generations who will be teaching those movements way into the future. We are in this time continuum (Mary).

I like thinking about the thousands of years of women before me. I work that way with my students- to let them know the ways I think this dance is special (Kristie).

The sense of connection with an ancient lineage constitutes American belly dance as an invented tradition, but one felt on a deep personal level by many dance practitioners. Joan's story (recounted in the introductory chapter) shows her love of ancient Egyptian culture. Her understanding of how dance performance was a link to that ancient world has become a part of her religious practice.

Many American belly dancers view dance performance as spiritual practice. One sociological survey found that many women belly dancers perceive their dance experience as an alternative to church attendance (Briggs 2008). The interest in ancient goddesses and matriarchal cultures is characteristic of a revisionist history associated with modern day goddess spirituality (Deagon 2005: 258; Karayanni 2004: 71). In fact, members of Western-based goddess spirituality draw from the same demographics as the American belly dance community. They are typically white, well-educated, economically comfortable women in their thirties and forties (Sellers-Young 2005: 333). Non-academic belly dance literature contains many examples of women suggesting ways dancers can make their practice more spiritual. For example, Iris Stewart recommends that dancers 
design and implement new versions of birth rituals ${ }^{39}$ associated with belly dance (2000:97). Another dancer and writer, "Shahrazad" C. Diallo-Huisman, suggests a new kind of belly dance academy that would emphasize training not only in dance technique but also in yoga and meditation; the holy scriptures of the world; the study of ritual, ceremony and prayer; and sacred drama (2002: 55). Dancer and writer Z-Helen Christopher, in an article entitled "The Emergence of the New Sacred Temple Priestess," makes recommendations to dancers who perceive their dance practice as a sacred calling (2000). Many of the suggestions offered in the popular writings of the belly dance community encourage the creative development of ritual dance, evoking the idea of reclaiming a lost heritage of female-centered ritual in a modern context.

Belly dance ritual and the revisionist history linked with the practice of spiritual belly dance are also thought to be a source of healing in response to damage incurred due to patriarchal oppression. Why this tradition has not been more effective in alleviating aspects of patriarchy remains unanswered (Dox 2005: 319). It is possible that American belly dancers experience an incongruity between the motivations and outcomes of their dancing, instead internalizing the male gaze and imposing the male fantasy upon themselves. This false consciousness is the center of much feminist debate about belly dance (Dox 2006: 54-55; Karayanni 2004: 171; Shay 2008: 125). Yet much of the belly dance literature and the remarks of the dancers I interviewed suggest that Western dancers are engaged in a process of renouncing degrading and disempowering views of

${ }^{39}$ Birth rituals that involve belly dance-like movements are historically linked to rural peoples of Morocco (Dox 2005: 324). 
feminine sexuality, especially those specifically associated with belly dance, through the creation of new dance traditions and identities.

The perception of the healing potential and ancient origins of belly dance is biased towards a middle-class, Western ethos. Deagon expresses concern about the imperial implications of belly dance associated with spirituality under the rubric of feminism. She states:

Perhaps most problematic are the gendering of Oriental dance as feminine and the wholesale projection of spiritual significance into its original culture; both readings may interfere with Western dancers' accurate appreciation of the dance and its primary milieu (quoted by Karayanni 2004: 165).

As American belly dancers address issues of gender inequality and search for deep meaning, imperialist agendas and patriarchy are reified, in that social complexities and cultural histories are disregarded or appropriated. Yet women derived great benefit from their dance experiences as they gain a positive sense of self and empowerment through involvement in a community fortified by its own invented constructions. This Occidental dance is the invented tradition of an alternative feminist project.

\section{Conclusion}

It is through invented linkage to a distant past that modern American women construct present truths. The American belly dance community employs Orientalist tropes in order to occupy the empty location of the exotic Other. From this position and sanctioned by claims to a mystical past, American belly dancers are able to voice unique concerns, needs and desires that are difficult to express by other means. These concerns involve spirituality, empowerment, feminine identity, community, lifestyle, and the effects of modern capitalism. But practitioners' position of social and political privilege 
may obscure their ability to acknowledge the capillary power of patriarchal structures, the heterogeneity of global feminisms, or the discombobulations of history. Next I examine the heterogeneity within the American belly dance community, to explore how this subculture contends with contradiction and seeks new sources of meaning. 


\section{Chapter 5 \\ Dis-orienting American Belly Dance}

\section{Introduction}

In this chapter I investigate the diversity within the belly dance community. I examine the meaning women have derived from participation in belly dance in both Eastern and Western milieus, highlighting contrasts and similarities. Acknowledging the intervening spaces between Eastern and Western perceptions of belly dance interrupts the Orientalist binaries that have prevented past studies from realizing the full complexity of this topic. I also counter this dichotomous logic as I examine another issue not widely recognized by other scholars: the heterogeneity of the American belly dance community and what the changes in this community imply about emergent epistemes in American society.

In the following analysis, I draw out the complexity of the issues and internal conflicts that dancers think about to demonstrate that this community is struggling, transforming, and in many ways fragmenting. In order to delve deeper into this heterogeneity, I explore such issues as standardization, public expectation, and the concept of belly dance as a cultural art v. art art or artistic expression without regard to cultural tradition. I also take an in-depth look at some burgeoning trends in belly dance that are likely to influence future dancers: burlesque, gothic and cultural fusion. In discussing these emergent trends, I revisit the notion of the "new exotic" to investigate ways that belly dancers reject Eastern cultural traditions and develop a completely homegrown, American exoticism: a process of self-realization in this Occidental dance tradition. 


\section{Theoretical Orientations}

In my analytical approach towards the study of American belly dance, I resist polarities as well as essentializing and generalizing the subject matter. I therefore employ an anti-Orientalist perspective. In Said's exposition, “Orientalism Reconsidered," he advocates an anti-Orientalist approach that deconstructs canonicity in scholarly methodology and analysis; embraces plurality; and moves beyond binary structures. This approach, Said suggests, entails a dialectical perspective that engages the intellectual "both in the defining of a context and in changing it" (2000: 211-215). With Said's suggestion in mind, I underscore the heterogeneity of the belly dance community as a means to deconstruct the homogeneous logic of Orientalist discourse. I also highlight the interstitial spaces between Eastern and Western perspectives to further dissolve their imagined boundaries.

Orientalist thinking also privileges the Western position by denying agency to the East. Especially in the context of postmodernity, East and West are in a discursive exchange that may be described as an imperial dialogue. Karayanni explains, "The colony also shares a form of kinesthetic power in this economy of penetration and control, as its dance traditions respond to the emerging global order of cultural knowledge" (2004: 34). The notion of imperial dialogue permits agency to both sides of the Orient/Occident continuum and is an issue I address in this study. I argue that belly dancers in the East and the West accept or reject elements associated with this dance form due to personal taste, social strategy, or economic impetus. I demonstrate that these 
dancers share many common intentions in their pursuit of Oriental dance. In order to do so, I begin with a discussion of belly dance in the modern East.

\section{Belly Dance in the Modern Eastern Context}

Many of the Arab American or foreign-born dancers whom I spoke with in the course of my research expressed perspectives on belly dance that contrasted markedly with the views of the white, American women whom I interviewed. In general, most Eastern women view belly dance simply as a diversion ideally confined to the private realm. They consider belly dancing in public for pay a transgressive act. Yet belly dance forms an important component in family celebrations, such as weddings, although the professional entertainers engaged are perceived as morally suspect. Type of entertainment provided and class status of audience factor into Eastern perceptions of the dance. For example, singers and musicians are viewed as less stigmatized than dancers for their profession. Higher class Egyptians may be more likely to view dancing as an art form whereas middle class audiences generally perceive dancers as being shameless. Lower class audiences tend to view dance as simply a way to make a living or escape undesirable domestic circumstances. It is not unusual for all classes to suspect professional belly dancers in the East of prostitution (Dougherty 2005: 150-152; Fraser 1993: 60; Lorius 1996a: 514; Lorius 1996b: 286; Van Nieuwkerk 1995). Although many Eastern peoples do not view belly dance as a serious art form, the discussion of the belly dancer's role is society is a serious topic in many Eastern nations, especially where religion is concerned. 
According to Islamic tradition, the Prophet Muhammad never spoke negatively about music or dance and additionally the Qur'an does not specifically mention music or dance. Surah 31, verse 6 in the Qur'an states, "And of men is he who takes instead frivolous discourse to lead astray from Allah's path without knowledge and to take it for a mockery; these shall have an abasing chastisement." This verse has led religious scholars to interpret dance and music as frivolous acts (Shay 2005a: 96-97). Some interpretations of the Hadiths, which are accounts of the life of the Prophet Muhammad, suggest that the Prophet actually approved of music and dance. The issue may be not so much about dancing as an activity in general, but the context of dancing in particular (Shay 2005b: 98-104). Dancing in private homes does not pose the same threat of fitna ${ }^{40}$ as does dancing in public, especially when the unveiled female body moves sensually in front of strangers.

Historically, female belly dance performers have had the opportunity to attain greater economic independence and exercise extensive public mobility, as compared to other women in predominantly Islamic, Eastern nations. In her analysis of the Schikhat, female dancers who perform movements similar to those in Oriental dance in Moroccan society, Kapchan postulates that the commodification of women's talents forms the basis for their stigmatization and marginalization in Moroccan society. She explains that "her sin is her unmediated affiliation with the marketplace" (1994: 101). She also advances that the Schikhat help define what it means to be a "good" woman in Moroccan society, because by occupying the margins they also clarify the center (Kapchan 1994: 95). In

${ }^{40}$ Fitna is an Arabic term meaning both chaos and a beautiful woman (Mernissi 1987: 27-31). 
essence, belly dancers fill a vital role in society in that they demonstrate how a woman should not behave.

In the Eastern context, most women enjoy participating in belly dance in the protected space of the private realm. At a private women's party, the host plays music and women may choose to get up and dance in front of other women. Women assess each other's skill based on such criteria as level of coordination, modesty in her dancing (small movements, downcast eyes), flirtatiousness of facial expression and marital status. Women take a married woman's dancing more seriously than that of a non-married woman. Dancers will generally never touch each other or other women in the audience during dance. Even within the home, class status may determine a dancer's willingness to perform and magnitude of movement, with higher class women generally observing greater restraint. Some upper class or very conservative families may not approve of belly dance at all. Overall, all dancers are expected to show control and reserve in their dancing (Deaver 1978: 14-17; Najwa 2005: 31-35, 46; Shay and Sellers-Young 2005: 21).

In contrast, Western women are more likely to touch each other or audience members ${ }^{41}$ and show larger unrestrained movements. Because the dance in the Western context originated from dancers who performed in public, it is unlikely that Western women understand the appropriate behavior or proper form associated with the dance in its domestic context in the East (Najwa 2005: 37). The belly dance most American women know is one severed from its original context, the Eastern woman's home. Upon

${ }^{41}$ For example, many American cabaret style dancers may approach a male audience member and drape her veil around his neck during the course of a performance. 
this background understanding of modern Eastern belly dance, I now explore ways the East actively participates in a discursive exchange with the West through belly dance.

\section{Imperial Dialogue: The East Gazing Upon the West}

The East's fascination with the perceived “exoticism" of the West manifests in modern Eastern belly dance. In contrast to auto-exotification, the East sometimes employ Occidental motifs in its construction of belly dance. For example, some Egyptian dancers use Western-sounding stage names such as Fifi, Dina or Lucy; state-supported dance companies employ Western choreographic strategies or Orientalist images in their shows; and some Eastern dancers mimic Western belly dancers' images to market their own dance businesses (Shay 2008: 129; Shay and Sellers-Young 2003: 27-31; Shay and Sellers-Young 2005: 24). Eastern dancers sometimes add Western elements to belly dance presentations as a way to appeal to elite audiences (Karayanni 2004: 172; Shay and Sellers-Young 2003: 27; Shay and Sellers-Young 2005: 19). ${ }^{42}$ Because many upper-class audiences in the East generally embrace what is perceived to be most modern, they regard traditional belly dance and folk dances as embarrassingly retrograde. ${ }^{43}$

Many Eastern belly dancers include Western movements in their performances due to exposure to Western dance styles through the Internet, mass communications, and an influx of foreign dancers competing for jobs in Middle Eastern and North African

\footnotetext{
${ }^{42}$ Karayanni suggests that this preference for Western-styled dance presentations is an example of internalized colonization (2004: 172).

${ }^{43}$ Shay offers the insight that Middle Easterners do not seem to have the same "choreophobic" feelings about Western dance as they do about Eastern dances (2005a:112, note 9).
} 
venues (Lorius 1990: 12; Maira 2008: 333; Najwa 2005: 47). Many of the American belly dancers I interviewed were aware that Eastern dancers look West for inspiration:

People are dancing in mini skirts in Cairo right now. It's all about lips, fake breasts and the male gaze (Cynthia).

If you look at the American history of belly dance, they just saw what other people were doing and smashing it together. The Egyptians now are taking their basic social steps and fusing it with ballet, samba, whatever. It's all fusion (Ellen).

Just as Badia Masabni adopted the Hollywood version of the two-piece belly dance costume for her nightclub shows in 1920s Cairo, modern Eastern dancers borrow movement techniques and presentation styles from the West today. Although some believe that many aspects of Oriental dance have been bastardized by external influences, I posit that some Eastern dancers adopt Western elements simply because they find those elements fresh, modern, novel, exotic and "cool." What is disturbing is the unidirectional nature of Western influence on Eastern dance: the East incorporates Occidental elements to enliven its indigenous dances and the West makes Oriental dance more palatable by infusing Western aesthetics, as well. Furthermore, Eastern and Arab American audience members sometimes view alterations made to this dance form by Western practitioners as offensive.

\section{Prejudice, Misunderstanding, and Faux Pas Within the American Belly Dance Community}

Critics outside and inside the American belly dance community complain that many dancers do not understand the cultural context of belly dance and therefore misrepresent the dance outwardly to the general public and also inwardly to the belly 
dance community. A professional performer Natalie lamented, "They [uninformed belly dancers] just hear something that sounds exotic, throw on a costume and call it belly dance. That makes me hiss!” Some dancers blame belly dance teachers and performers for spreading misinformation about Eastern cultures to their students and audiences. North African born dance teacher Beth stated her message to those hypothetical culprits: "Just don't come in public and say this means something in this country and that country when you have never been there."

Misunderstandings or absence of information about Eastern cultures can lead some belly dancers to take missteps, knowingly or unknowingly, when representing this cultural art form to the general public. Ellen related a story about a local group of dancers who performed in a city park in "full hijab." 44 "There were some Middle Eastern people who were like, 'what are you doing? That is really offensive!' She also told me she saw a dancer writhing erotically on the floor while performing to the Israeli national anthem. Some American dancers have espoused images having to do with travel or nomadic cultures to promote themselves, such as using the word "gypsy" in their troupe names or show titles. A romanticized image of "gypsy" culture denies the realities of nomads who often contend with political strife, such as refugee status (Maira 2008: 330). Nancy, a North African born dancer, performer and teacher, revealed that these misunderstandings can give not only offense but also traumatic emotional wounds to the misrepresented or exploited:

Someone asked me to be a model for Arabic dresses. Syrian, Palestinian dresses, beautiful dresses with a lot of embroideries. All the dresses I was wearing were

${ }^{44} \mathrm{Hijab}$ is an Arabic term that generally refers to modest dress and especially head coverings. 
sold. Then at the end, the organizer asked me to dance. For her, her concept wasif you dance you have to dance with [exposed midriff]. I didn't even have really a costume- I just had pants, I didn't even have a black bra. So in a few seconds, a woman in the audience gave me her bra, for me to wear. I felt like I was a doll and they were putting all these things on me. Then she said, 'Here, go!' I was dancing and I felt sick, I felt terrible after that. I felt that I had been raped. I got sick after that. It was like I was selling my culture so cheaply. That is the reason why I am not doing cabaret. That is reason why I want to dance with dignity, with respect to my culture. I am not a Western woman who is doing it for fun. I am somebody who is bringing my culture to other people. That is the reason why I am very particular about how I do what I want to do.

Nancy decided never to perform again with her belly exposed because she felt it was a misrepresentation of her culture.

When American belly dancers do utilize class or performance opportunities to educate others about Eastern culture, they rarely acknowledge, for example, the effects of imperialism in the Middle East (Maira 2008: 337). The American belly dance narrative generally provides an incomplete view of Eastern cultures. It cloaks the political context of the modern lives of Eastern women and men, suspending them in an imagined timelessness reinforced by Orientalist discourse. This partiality inadvertently reinforces imperial and neoliberal values. But the perspectives of Eastern and Western dancers meet at points that defy their seeming opposition.

\section{Interstices}

In my aim to investigate American belly dance through anti-Orientalist lens, I emphasize that there are numerous points of articulation where the perspectives of Eastern and Western practitioners meet. These interstices are the concepts of empowerment, spirituality and community. For example, both Eastern and Western belly dancers feel their dance imparts a sense of empowerment. Eastern women describe this 
empowerment as having fun, communing with others and feeling confident. Western women associate this sense of empowerment with spirituality, feminist ideals and personal liberation. But both Eastern and Western dancers link spirituality to belly dance. Easterners experience this as tarab or the collective ecstasy that may occur during musical performance. Additionally, some Eastern women perform rituals in rural areas that involve belly dance movements. Western dancers' spirituality may take the form of devotional dance to a goddess or other newly invented Western rituals. Both Eastern and Western dancers acknowledge the potential for communitas through belly dancing. The community that forms around the dance, be it in the private home or the dance studio, provides opportunity for cooperative creativity, social networks, and conviviality. Having explored Eastern and Western belly dances through an anti-Orientalist lens, looking beyond dichotomies, I now apply the same analysis towards understanding the diversity within the American belly dance community.

\section{Heterogeneity of Belly Dance Community: Cultural Art v. Art Art}

In the course of my ethnographic research, two distinctive camps emerged within the West Coast American belly dance community: those who viewed belly dance as a cultural art who take an almost ethnographic approach to their study of this art form and those who viewed belly dance as a personalized, individualized exploration of their creative and spiritual selves and see belly dance as a foundation for free-form artistic expression. Beck noticed this split within the dance community during her investigation 
of the Rakkasah belly dance festival in Northern California in the early 1990 s. $^{45}$ She noted different levels of interpretation and conceptualization in movement repertoire and costuming, observing "Authenticity and rights to representation have been a great source of contention within the larger community of Middle Eastern dancers and aficionados" (1991: 28). Beck saw the main differences in approach between those dancers pursuing Middle Eastern folk dances and those performing interpretive and creative versions of cabaret (1991: 29). I have also discovered a split in the American belly dance community, as Beck did, but I feel the most significant distinction is between cabaret and tribal-style dancers.

According to my research and experience, the distinction between dancers interested in belly dance as a cultural art and those interested in it as an art art generally reflects a split between cabaret dancers and tribal-style dancers, respectively, in the American belly dance community. For example, the majority of dancers whom I spoke with who express interest in learning Arabic language, traveling to the East, understanding more about Arabic music and learning more about Eastern culture in general described themselves as cabaret soloists. Additionally, all of these women identify as white Americans.

According to Maira's research, only non-white women involved in the American belly dance community showed sincere interest in Arab culture (2008: 328). In my research, I have found evidence that directly confronts Maira's supposition; that is to say I spoke with many white American women in the belly dance community who expressed

${ }^{45}$ A recent Internet search for Rakkasah described it as a "Middle Eastern Folk Festival and Fantasy Bazaar.” 
a sincere and abiding interest in learning and understanding as much as they could about historic and modern Arab culture. One of these woman, cabaret dancer Ellen, told me, "The more I learn about music, the more I realize that belly dance is, in its traditional, pure form, an expression of music from a culture." Ellen expressed great self-awareness about her performance of belly dance and the history of Orientalist discourse affecting perception of the dance and said, "Our responsibility to educate people is to not show it as a sex dance. To get rid of hundreds of years of Orientalist bullshit- which is a big burden [laughs].”

I find this insight ironic because although these women learn more about the context of Eastern culture in the practice of belly dance, and in fact realize that this dance is generally viewed as immoral in Eastern societies, they continue to pursue this dance form and dedicate themselves to greater knowledge about its cultures of origin. It is also problematic that performers who strive for authentic cultural representations often share the same stage with dancers who seek their own individualized, artistic approaches (Sellers-Young 1992: 147 and personal observation). Additionally, many dancers may feel social pressure to alter "authentic" dances in order to make them "suitable" for Western stage and audience.

On the other hand, tribal dancers I spoke with expressed more interest in the potential for artistic expression and unique creative approaches to the dance. Tribal-style dancer Jill observed of other tribal dancers:

Art has saturated their lives. That is what I wanted....I was in art school....They did nothing mainstream, nothing regular.... I loved their attachment to the antique...their repurposing of objects....There so much progressive thought in what they did. 
The main objective of tribal dance appears to be co-creative expression. This dance focuses on the individual in dialogue with others within the framework of a formulaic group structure. Cabaret dancer and dance scholar Cynthia said of tribal-style belly dance, "It becomes one-dimensional; it's just about your self-expression, that's it. It has nothing to do with participating in a dialogue with this history and this culture and opening into this other world of difference." And this form of self-expression, sometimes cloaked as Middle Eastern dance, can be very disturbing, if not offensive to Arab and Arab American audiences. Egyptian American belly dancer Julie felt tribalstyle was a "competition for attention." For many American women, this competition for attention may seem a worthwhile goal in the context of belly dance as a pursuit of New Liberation or improved body image with its ultimate goal of public exhibition of the body.

As many dancers search for the authentic roots of belly dance and some of them acknowledge the effects of Orientalist discourse and cultural imperialism on the expression and reception this dance form, belly dancers are rediscovering Oriental dance in a new Occidental light. Deagon notes, "Oriental dancers have increasingly embraced a historicism that correctly situates the artistic goals of modern Western artists in the light of Eastern traditions" (2005: 270). I would emphasize that for many modern American belly dancers this embrace includes an acknowledgement of the aspects of modern belly dance that articulate with colonial and imperial legacies. Erdman states, "Dance is integral to its times and is conceived in the context of its times. No communicative art can be made or performed in a vacuum; nor is dance anywhere merely an art for art's sake" (1996: 298). Just below the shimmering surface of the modern, Western belly 
dance performance, behind the vibration of a hip shimmy, the glitter of a sequin, chinkaching of the finger cymbals, is suspended a deep history of the joyous celebration and likewise the binding oppression of the lives of Eastern women as translated by the American Orientalist apparatus. ${ }^{46}$

While many American belly dancers strive for a more authentic approach to belly dance, they are expanding their awareness of the historical and political implications of dance as a feminist project. I agree with Villa that this feminist epistemology embraces the plurality encouraged by Said as an anti-Orientalist approach, moving along web-like channels of knowledge rather than accepting a false hegemony of Western discourse:

One of the challenges for feminist epistemology is to create a global, nonappropriative genealogy of women's knowledge that forms a web (rather than a pyramid) of cultural histories and influences to collectively construct a new paradigm of knowledge that rejects the strategic monovision of Eurocentric historiography (2006: 41).

For some modern American belly dancers, an increased feminist awareness rejects old fantasies of the exotic and/or adopts emergent forms of expression that acknowledge the unique "American-ness" of American Orientalism. Acknowledging the heterogeneity of the American belly dance community leads to a greater possibility of accurately defining the context of this community and creating change within it. In the following section, I

\footnotetext{
${ }^{46}$ This phenomenon seems to be unique to American Orientalism. For example, North African-born dancer Nancy related that her experiences as a dancer in the U.S. were quite different from her experiences living the U.K. She felt that her work as a dancer in Europe was more respected and honored as an art form, whereas in the American belly dance community she felt isolated because of her cultural difference, treated as a exotic novelty, appropriated for bits and pieces of her culture. Similarly, Suraya Hillal, Cairoborn dancer, teacher, choreographer and recipient of the Greater London Arts Dance Award in 1986, stated that she found England to be a more receptive audience for her art. When she came to America to dance she reports she was "subjected to a ludicrous degree of caricature" (quoted by Lorius 1990: 13).
} 
explore internal conflicts surrounding standardization, respectability, and accountability to further demonstrate this community's diversity.

\section{Internal Conflict Within the American Belly Dance Community}

Within the American belly dance community, many dancers struggle with the links between Oriental dance and erotica, male voyeurism, disreputability in the East, and the trivialization of or joke-making about female sexuality. While some American belly dancers strive to be taken seriously as performance artists and wish to emphasize the origins of this art form as part of an authentic Eastern cultural tradition, other dancers embrace belly dance as a parody of the female form in sensual movement, exploiting the Orientalist imagery that has historically been linked to this dance as a spectacle intended for tawdry entertainment (Shay 2008: 144-145). In an interview on the YIP podcast, Carolena Nericcio explains that belly dance often falls into the category of something to be made fun of in American popular culture. Belly dancing often evokes images of James Bond or Charles Angels movies and dancing girls in tasseled pasties and chiffon "harem" pants being ogled by lecherous men wearing fez. Monty suggests in his 1986 dissertation, "Americans have never fully accepted Near Eastern dance as an art form, despite its long standing presence" (1986:1). Based on my interviews and research of the West Coast American belly dance community, dancers continue to feel that their art is misunderstood not only by the general public, but also by fellow dancers within the community.

Many dancers whom I interviewed connect the standardization of dance classes

and performances with respectability of belly dance and its perception as an art form. For example, Natalie shared with me: 
Honestly, it has made me really intimidated over the years to stand and talk about what I believe about this dance for fear of really being vilified. I think there should be standards, technique, and cultural relevance. I don't think those who have been in class for three months should be in a costume performing anywhere in public [laughs]. That is really not shared by a lot of the community in [West Coast city]. If you set limits and raise expectations, then you are becoming exclusionary rather than inclusionary. And this dance is about being inclusive, so you can't do that.

Ellen expressed a similar sentiment:

I would like this dance to be as respected as ballet. But we don't have the same training standards... we don't have any recognizable foundation or terminology for people to adhere to, we don't have any schools of music...I don't think we are ever going to get there, because as soon as we have put a barrier on something, an expectation, there is exclusion and we have offended everybody.

Many dancers I spoke with were aware that the attraction many American women have to the belly dance community is related to a sense of being welcomed and supported, regardless of age, body type or ability. A basic premise of these tenets of American belly dance is that all are welcome because the dance is assumed to be a women's dance on a fundamental and primeval level. This dance is derived from folk traditions and has no formal, classical foundation in Eastern cultures; there is no tradition of standardization in movement, stylization, or presentation mode. Because of its informal history and because belly dance practice in the West encourages all women to participate and even perform, often without regard to set standards or guidelines, many dancers within this community are concerned that belly dance suffers from an "everyone is welcome" or "everything goes" reputation. As one informant stated: "If everything goes, then at some point you will compromise respectability."

In the West, particularly in the U.S., many belly dancers may not necessarily associate dance practice with modern Eastern cultures, instead viewing belly dance as 
part of a more nebulous, ancient Eastern tradition. Because these dancers practice belly dance inside this "empty location," they may feel free to experiment with elements of the dance, cultural references, or personal creative license at will. At the same time other dancers within this community observe this phenomenon with a critical eye. Ellen offered, "I think a lot of people come into this for acceptance, but when you perform you are doing a great disservice to your community if you don't honor the roots of that. I totally think it's from the Middle East." While some dancers disapprove of what other dancers do, seeing their performances as unprofessional at best, culturally disrespectful at worse, they often feel unable to express their concerns because of the "open welcome" of the American belly dance tradition.

Many dancers I interviewed expressed their dismay, disapproval, and even anger and disgust about what other dancers were doing in the belly dance community. Ellen offered some particularly poignant insights on this topic:

We don't really have a history of this dance form, so we have a hard time taking critique from each other. I think that if belly dance is to be taken seriously we need to be able to critique what is happening in our community and accept the critique and not have it be a threat to our sisterhood.

Ellen went on to express her frustrations about the cultural eclecticism and exotic pastiche ${ }^{47}$ in stylization, movement, music and narrative currently so popular in many belly dance circles in the U.S. and internationally:

The thing that really bothers me is an outfit that just looks really weird. Not even looking like a take on a costume- you know camouflage pants and a ripped up tshirt. The music comes on and it's industrial heavy metal. That combination offends me greatly. If I wanted to see this I would go to another event...That

${ }^{47}$ Many Western belly dancers are for example, wearing eclectic costuming, adding hip hop, Flamenco, burlesque and Bollywood movements to their dancing and incorporating theatrical elements such as narrative into performances. 
combination of complete removal [from Eastern cultural roots] makes me think I really wish they had some tact. I think its really selfish to want to present your art so much that you really can't take a look at it and say, 'Is this appropriate for the venue I am in?

What I really wanted to say is you [to those dancers who are experimenting heavily with fusion] are not belly dance. Whatever you are presenting out there, it's loud, it's obnoxious, it's not very well executed and it goes on for too long...This is not the 'whatever goes' club...but I couldn't say it because I have a lot of friends in these other circles. I know a lot of other dancers feel this way.

In fact, over half of the women I interviewed expressed concern about the quality of American belly dance. Many of these interviewees specifically mentioned national belly dance festivals as unfortunate epicenters of the "everything goes" phenomenon:

When you go to a belly dance festival now, I would be surprised if half the dancers actually use belly dance music or costumes. It really makes me sad because that is its foundation. If you are performing something for a group of belly dancers and most of them couldn't figure out why you were at that event, then perhaps you should rethink what you are doing (Ellen).

It was awful! We are sitting there [at a West Coast belly dance festival] and we are going, 'Really?!' It was so dumbed down, so utterly bad. If you have a gimmick, if you are doing what's popular or trendy then people will like you? They had no idea how to belly dance! It was awful! I had gone two years before that and the whole thing was about gimmick...it was like an infomercial...We decided we are not going back to [this festival]. We felt like it was ridiculous (Jessica).

Dancers' conflicts within the American belly dance community has, in some cases, led to serious arguments and sometimes fractioning within the community. For example, some dancers explained to me that an Oregon dance guild was so entrenched in a conflict concerning freedom of expression and cultural authenticity that they hired a mediator to help them resolve these issues. Because this guild's by-laws state that they promote greater understanding of Middle Eastern culture, many members felt it was inappropriate 
for some members to present vaudeville, or gothic influenced belly dance performances in public settings.

There are some cases where belly dance teachers ${ }^{48}$ have attempted to improve the reputation of belly dance by imposing standards upon dance classes and performances, for example, developing movement repertoire, class curriculums, benchmarks for student progress and guidelines for public performance (who performs, how they perform and where they perform.) Many teachers in the U.S. are concerned that lack of standardization in teaching techniques is creating a tradition of mediocrity and tastelessness in American belly dance. In Turkey, for example, belly dance teachers who cater to an increasingly urban and gentrified clientele, attempt to dissociate the dance from its immoral implications in Turkish culture. They are sanitizing belly dance practice by placing emphasis on standardization of movements and proper venues for performance (Potuoglu-Cook 2006: 634-643). For American dancers, standardization is often erratic, partially due to some dancers' lack of accountability to cultural tradition based on a belief that belly dance is detached from modern Eastern cultural traditions.

Some belly dance teachers may be perpetuating misinformation within the community and also inferiority in technique and performance standards. For example, Ellen was concerned that some teachers tell their students, "You can be a belly wonder in two months!" Some dancers I interviewed speculate that many teachers may make up their own standards or history about the dance, "to suit their marketing and their own lack of education." In the American context, many belly dance teachers created classes as a

\footnotetext{
${ }^{48}$ Suhaila Salimpour's certification program is a good example of instituted standardization within the belly dance community.
} 
type of cottage industry, teaching an amalgamation of steps from a myriad of regions (Shay 2008: 143-145). In keeping with the American history of belly dance, today's fledgling students were often encouraged to go out and perform publicly. Assuming the stage, for many belly dance students, is an initiation process; crossing the threshold into a realm where performance is nearly synonymous with a type of group therapy. Performance permits the dancer to express her individual creativity and then receive positive support from the audience (often mostly belly dancers) (Dox 2006:59; SellersYoung 2005: 290).

One interviewee remarked, "Seems like one of the only dance forms where people encourage you to perform when you have only been in class for six months." After students acquire basic steps, they are often encouraged to make a costume and then perform at a student show or local restaurant. In contrast to other Asian classical dance traditions, "Belly dancers can sometimes begin dancing professionally with only a modicum of training and technique, especially if they are considered attractive" (Shay and Sellers-Young 2003: 25). From the beginning of the modern era of American belly dance in the 1960s, integral to belly dance training was the student's participation in public cabaret-styled shows (Monty 1986: 244). Many professional dancers I spoke with resent that some inexperienced dancers are performing in public, while other dancers work very hard to master technique, stage presence, and spend large sums on expensive costuming in order to achieve a polished, professional presentation. 
The student recital or halfa $^{49}$ is a principle venue for student performance that often takes place in public. These events frequently require a purchased ticket or an entrance fee, leading some members of the public to expect a professional show. Again, many dancers I interviewed were very self- conscious of the implications of charging the public to come see student belly dance shows:

Should everybody be performing this dance on stage? Everything goes? Let's include everyone? I don't agree with that. There should be venues for student dancers. I feel that this is an art form and it's important to maintain that excellence (Cynthia).

It's always called a student recital, it's called a RECITAL. When I did tap we called it a recital, when I did African dance we called it a recital. We didn't charge people at the door to come and see this....In some ways is seems disingenuous to expect the public to accept this! (Megan).

Dancers I spoke with were also concerned that inexperienced dancers are being hired as professionals for low rates and are catering to derogatory public expectations of belly dancers. These dancers seem to comply in order to obtain performance experience and some monetary compensation. Kristie and Maria talked to me about dancing in restaurants: "There is an expectation of youth, beauty and dancing sexy especially for his [restaurant owner's] friends and they [the restaurant owners] wanted that. We can do that, but that is only one part." Ellen expressed her despair that low quality performances would always compromise the respectability of American belly dance, saying, "As long as people are willing to pay low rates for low quality entertainment, that will be where we [belly dancers in general] always lie. We will never get up there, never."

Characteristic of the American belly dance community is not only the penchants that many teachers have for sending students out to perform in public venues, but also the

${ }^{49}$ Arabic word for dance party. 
marked interiority of the belly dance community. In many ways, the belly dance community is a self-sustaining economic system. Outside of restaurant performances, belly dancers often make up the audience majority at theater shows and festivals. For example, in the 2009 documentary, Belly, Amy Sigil of troupe Unmata explains that American belly dance is a self-supportive community. She states that if the public somehow went away, she would still be able to make a living from dance performances and teaching workshops. The interiority of the belly dance community, economically and creatively, permits dancers to experiment with artistic and cultural motifs without being accountable to the larger society for this experimentation. A source of and reaction to many of the internal conflicts of American belly dance, is the evolution of new exotics or emergent types. In the following section, I examine three new designations within American belly dance and their controversies within the dance community.

\section{The Evolution of Occidental Dance, a Closer Look at Emergent Types}

\section{Burlesque Belly Dance}

In the classic American belly dance publication, Earth Dancing: Mother Nature's Oldest Rite, Gioseffi traces the origins of belly dance from a tourist spectacle on the Barbary Coast to the "Victorian pornography" of Little Egypt dancing at the World's Fair, to burlesque and then the striptease (1980: 37-39). Jarmakani suggests that, "the cooch as erotic dance and the Oriental dance of the 1970s feminism are actually two sides of the same belly dance coin" (2006: 155). Although women tend to dissociate their participation in modern versions of these dance forms from their historically lower class origins, in recent years burlesque-styled belly dance has become increasingly popular. In 
fact, there is a growing interest in burlesque outside the belly dance community, as well. In Ferreday's study of what she calls "the new burlesque," historical performances are reconstructed by modern performers, exhibiting a nostalgia for an alternative mode of femininity that burlesque represents for its participants (2008: 47-49). Burlesque, in the modern context, is a signifier for sexual liberation and a sense of community, celebrating a hyperbolized femininity in its voluptuousness and glamorousness, similar to American belly dance. Belly dance and burlesque share a common subversive agenda challenging patriarchal constraints as well as mainstream feminism by underscoring the power of feminine sexual allure.

Many dancers believe that belly dance is wrongfully incorporated into strip tease and other erotic dance forms (Helland 2001: 135). Most of the dancers I interviewed were quick to distinguish their dance style as different from erotic dances such as burlesque or striptease. At the same time many of these same dancers clarify their comments, saying they do not judge women who choose to perform these erotic dances and realize some of them may incorporate belly dance elements to escape the stigma of their profession. History shows us that the relationship between belly dance and American erotic dance moves in both directions: first, America's fascination with what was perceived as the bawdy hootchy-cootchy from the East morphing into burlesque and vaudeville and second, burlesque and strip tease dancers adopting belly dance aesthetics to either lessen the stigmatization of their profession or exploit the exotic fantasies of their audiences. My suspicion is that the latter is a more viable explanation and many American belly dancers neglect to recognize this reality. In the documentary Belly, some dancers interviewed suggest that other belly dancers should renounce their judgments of 
erotic dancers, since strippers often make good money (2009). This sentiment implies the view that as long as significant money is being made allowing a woman to gain financial independence, it is an acceptable line of work. In other words: don't be judgmental towards a financially independent woman regardless of her profession.

I spoke with the performer, Princess Farhana,${ }^{50}$ an attractive and well-spoken fifty year old woman, who is well-known for her burlesque dancing as well as belly dancing within the American belly dance community. Her burlesque has inspired other American belly dancers to experiment with this genre of dance. Princess Farhana explained to me that her use of burlesque is widely misunderstood by other belly dancers. She said, "I don't mix belly dance with burlesque; that is a big misconception about me... Whenever I do that it is never billed as belly dance and always in a theatrical context. I would never do it at a private party or club or restaurant where they expect belly dance.” Princess Farhana also acknowledges the historical connections between belly dance and burlesque, although she maintains that the two must be distinct because she sees belly dance as borrowed cultural tradition whereas burlesque is not. She states:

People say that burlesque has nothing to do with belly dancing, but in this country it clearly does. So many burlesque dancers at the turn of the century appropriated the name Little Egypt because there was an Orientalist fad going on at the time. The three-piece belly dancing costume [bra, belt and skirt] from the Middle East that we call traditional was directly lifted from burlesque dancers' costumes and Hollywood movies with harem girls. Until then they wore baladi ${ }^{51}$ dresses. It was directly appropriated from Hollywood. There are so many gray areas in this whole thing.

As mentioned in earlier, not all dancers appreciate their fellow belly dancers' explorations of burlesque in belly dance. Joan, a middle-aged dancer stated:

${ }^{50}$ Princess Farhana gave me permission to use her name for this project.

${ }^{51}$ An Arabic word that means "native." 
I have tried for twenty years to make sure that everyone looks at belly dance as classy. My sole purpose here is to make it as classy as ballet. But us Americans keep wanting to trash it up! So as long as you want to trash it up I can't go there. You can blame it on men as much as you want, but it's you dancers who are trashing it up!... People are trying to make it sex, sex, sex. They are ruining everything that we worked up to. We dance at a family place, we are not going to have burlesque there! I have had to correct a couple of the girls. You can be very sensual and not be nasty. There is nothing wrong with burlesque, there is nothing wrong with pole dancing. But when they are mixing it with belly dancing then they are giving that image.

Sarah, another seasoned belly dancer and feminist, told me:

Burlesque is cheap and easy attention and money. It's a rejection of feminism. That being said I also think that the younger generation, the same ones that say, 'I am not a feminist' are probably absorbing burlesque for several different things. But unfortunately I think it's cheap and easy. If you exploit your young sexual being, you can get a lot of positive attention. Especially from young men and older men with money. Not to say that that's bad but I don't necessarily think that that's the reasons I think art should be promoted. I am not promoting belly dance for getting approval from men and money.

As evident in these quotes, many belly dancers desire to dissociate from American erotic dances, especially those of an older generation who struggled to associate belly dance with 1960s and 70s feminism, while at the same time maintaining a non-judgmental stance towards erotic dancers. Some belly dancers are incorporating burlesque elements into performance without much thought about its larger implications, but other dancers, like Princess Farhana, have educated themselves about the history of American belly dance and are exploring the connections between belly dance and burlesque in an informed way. Burlesque permits many of the dancers in this latter camp to traverse a new exoticism firmly rooted in American culture.

Gothic- The Modern Vamp 
In early twentieth century Hollywood, the Vamp was an incarnation of the New Woman. She had dark, kohl-heavy eyes and wore clothing that resonated with the Oriental fashions of the time. The Vamp wielded her sexual power over men and upturned the normative gender hierarchy. She came to symbolize the passionate decadence and moral disorder of the East as represented by Orientalist discourse. Theda Bara, an actress and celebrity in her time, was the quintessential Hollywood Vamp. (Her pseudonym spells out Arab Death.) She combined both aloofness with allure and mystery associating her with Oriental mystique (Studlar 1997: 115-116). In an era of Vamps and Salomania, many American women explored their own identity in the empty location of the "exotic."

In Oscar Wilde's play, Salome kisses the severed head of John the Baptist. Deagon suggests that the confrontation with the head is not what modern dancers desire (Deagon 2005: 271). I disagree. Many modern belly dancers find the gothic and macabre aesthetic attractive, and they assume the persona of modern vamps by wearing black costuming, heavy black make-up, and an expression of cold detachment, and dancing sinisterly with swords, daggers, and cauldrons spewing with dry ice "smoke." In a recent Internet search using the keyword "gothic belly dance," I discovered dozens of websites featuring gothic dancers, online discussion groups, events, music sources, costuming and articles. Many of these sites contain descriptions with such terms as "dancing darkly," "morbid outlook," and "raks gothique." ${ }^{52}$ Many of these websites seem to laud gothic belly dance as a rebellious form within the belly dance community. For example, on a website selling belly dance themed posters, one poster for sale featured two gothic belly

${ }^{52}$ Raks is an Arabic word for "dance." 
dancers and words such as, "Sister, must we conform?" "Sister, must you judge?"

"travesty, not art," "cultural nonsense," "not authentic" and "God-awful tattoos." Judging from this poster, many gothic belly dancers seem to pride themselves as the misunderstood, repressed minority of the belly dance community and therefore take pride in maintaining a subversive-ness in the eyes of the greater society as well as the belly dance community.

It would seem the rest of the belly dance community does criticize gothic belly dance. For example, Rebecca told me:

I don't believe that gothic tribal belly dance exists. There are so many subcultures; it defeats the purpose of tribal being alternative. Tribal is an escape from the cabaret. She can have tattoos and piercings. Why do we need gothic? We already have black eyeliner. They are trying to be all spooky and they have their shoulder up to their ears and they lean forward. I am not against it. I just think it's funny.

Cabaret belly dancer Denise stated: "People tend to want to listen and dance to the gothic dark music and I almost feel that it has lost some of the joy and it makes me sad. I see these- they are great routines and they look beautiful and dark and yummy, but there's a passion, a joy that is kind of lost."

Overall, gothic belly dance is viewed by its critics and even by most of its practitioners as a complete departure from the Eastern roots of Oriental dance. As Joan illustrates, for many its purpose is just for fun: "I danced to the song, Voodoo. I dressed all tribal, I had a voodoo doll and I had a skull in my hand and did the whole thing to the song, and it was belly dancing. That is tribal fusion, that was fun.” But as gothic belly dance represents an extreme case of belly dance as art art, those expecting a culturally informed presentation may risk offense at a gothic belly dance show. 


\section{Cultural Fusion: Inventing New Exotics}

As American belly dancers continue to explore the imperial privilege of pastiche while fusing cultural fragments and fantasies into dance practice and performance, the heterogeneity of the belly dance community is increasingly evident as some belly dancers critique this trend. Erdman reminds us that arts flourish when their histories are known: "Artists need to be able to quote and cite their antecedents, to partake of or modify or rebel against known traditions, to innovate consciously in a genre or create a new tradition knowing their works are a departure" (1996: 292). Many dancers I interviewed complained that some dancers are fusing elements without understanding those elements' origins:

There are people who know what they are doing and are fusing things on purpose. Then there are people who been dancing for less than a year and they have no idea what they are doing (Princess Farhana).

Fusion is a deep background in two or more dance styles...We owe it to these art forms to have that kind of integrity when we approach them. [Fusion] it's fantasy, it has nothing to do with an active investigation of the cultural form itself or the roots of that (Cynthia).

I see a lot of these people coming to belly dance and it is completely stripped of the costuming, music, history, and tradition of this dance form coming out of the Middle East in some form. I think I would rather watch an innovative fusion dancer who has studied their roots and is choosing to move pass them than someone who just doesn't know what they are doing and has made up a fancy name for it- which is unfortunately very prevalent (Ellen).

Tribal Fusion is the 'garbage can' classification (Katie).

Newbies want to just start with where Rachel [Rachel Brice a very popular Tribal Fusion performer] is at. That is not where she started but her arrival point (Jill). 
Many of the belly dance teachers and professionals I interviewed believe that many beginning belly dancers are becoming lax in obtaining adequate training before taking liberties to combine cultural references or theatrical elements and are therefore producing mediocre performances.

But for many dancers, present and future fusions under the rubric of "belly dance" are just a continuation of the perceived process of cultural appropriation upon which this dance is historically based. Carrie explained this perspective:

Belly dance didn't come from one culture, belly dance came from women. I think it's a fusion of folk dances, it's a fusion of movements. The Gypsies probably carried it around a little bit and then people traveled and brought bits of different things from different places and it evolved in pockets of feminine movement. I don't think it came from one place. It came from women. That's really the only thing that is for sure.

Regardless of whether American belly dancers engage in fusion coming from an informed position or haphazardly fuse references and influences, they agree that some aspects of the dance are subject to personal artistic exploration and that postmodernity entitles them to that exploration. For example, in the Tribal Revolution DVD, Tribal Fusions troupe Ultra Gypsy describes themselves thus: “We are Gypsies for today's world, wandering in a maze of modernity. We are a myriad of cultures, old and new, picking up what we need and defying taboos that bind us. We are modern and primitive, urban and tribal, medusa and machine." I posit that this sentiment exists not only because belly dance is perceived to occupy an empty location because of its association with Orientalist motifs, but also because its practitioners react to a modern world compelled by the influences of mass communications, technology, transnationalism and globalization. Additionally, many American belly dancers assume that universalized feminine 
principles are the basis of this dance. The degree to which the individual dancer acknowledges the historical context of this dance form, including its colonial history, its absorption by American Orientalism, and its continued appropriation by imperial forces determines heterogeneity within this community.

The potential that practitioners of this dance form could recognize themselves as a unique, modern American tradition, without reference to Eastern cultures, universalized femininity or uninterrupted ancient lineage grows as some American belly dancers continue to dismantle Orientalist fantasies about this dance tradition. Practitioners could receive empowerment from this. But as long as some women reap benefits from a perception of belly dance as a tradition that seamlessly unites them with all females (denying men's historical connection to this dance), globally and anachronistically (ignoring political influences on this dance and disregarding the implications of race, religion and class on its practice and reception), the possibility that American belly dancers will abandon the invented tradition of belly dance seems doubtful.

\section{Conclusion}

Studlar writes of the New Women's experimentation in identity construction in the early twentieth century America:

In such a world of oriental chaos, women might imagine themselves to be more than harem dancing girls. They might become 'the Eternal Salome' acting out 'all the forbidden adjectives' associated with antique exoticism, but also with the New Women in her search for meaningful transformation in the modern world (1997: 125).

The invention of exoticism in the American belly dance community has not changed. This time around, the "Eternal Salome" does not bother to assign herself historicity or 
location; she reverberates with the global, the transnational and the culturally messiness of postmodernity. Since the 1940s, political events such as the Arab-Israeli war of 1948, the Arab-Israeli conflict of 1967, the 1975 civil war in Lebanon, the Intifada uprising in Palestine of 1988, the Persian Gulf Ward of 1991 and 2003, September $11^{\text {th }}$ and the ongoing occupations of Iraq and Afghanistan, have challenged the notion of a benign, mysterious, and sensual exoticism of the East (Rasmussen 2005: 195). In the "oriental chaos" of modern global politics with its wars, occupations, and terrorist acts, the "new exotic dancing girl" references a historical echo of American Orientalism and her own eclectic fantasies. Rather than temporally occupying the empty location of the Other while donning the mask of Salome, many modern American belly dancers are drawing from pastiche and personal fantasies to create a more permanent exotic Self. Many American women use belly dance as a palimpsest upon which to write a new story of what they find most beautiful, exotic, empowering and beguiling. 


\section{Chapter 6 \\ Conclusions}

\section{Summary of Main Arguments}

American belly dance relies on the discourse of latent Orientalism to secure the empty location from which to explore identity, meaning and the challenges of Western society. The interplay of Orientalist tropes exported East, by such means as Hollywood film, and then imported back West reveals that purely Occidental constructions comprise many aspects of this dance. Oriental dance is Occidental dance. The perceived malleability of exotic tropes has permitted American women to explore issues of liberation, spirituality, modernity, cultural authenticity, and emergent forms anchored in the notion of invented tradition.

Belly dance provides a formulaic structure to voice the concerns, needs and desires that white, middle-class American women otherwise find difficult to express. As one informant stated, "It gives you the license to play with a feminine side that is negated or ignored or you are advised not to show in our society." Another informant related, "You are dancing your worries and concerns and freeing them from your body because you can't talk about them in your daily life." In a way, the invented tradition of belly dance exploits the Orientalist tropes associated with it to sanction socially uncomfortable communication in the West and in the East.

Although women have derived positive benefit from their experiences, this practice masks social realities such as imperialism, cultural appropriation, and the concerns of non-Western women who live in the countries where belly dance originated. This invented tradition exists because it meets the unique concerns of Western women. 
Dox states, "Ironically, Western belly dancing's overrepresentations of the East...compensates not for Orientalists' inability to see the East, but for Western women's sense of being invisible in Western culture" (2006: 59). Joan's story, ${ }^{53}$ speaking about her love for ancient Egypt, but repugnance towards modern Egyptian social complexities, illustrates the ways belly dance can affect individual identity construction while simultaneously deny realization of current global concerns.

The belly dance community is neither homogeneous nor static and is highly reflexive. This largely socially conscious, well-educated, creative community of women is well-intentioned in their quest for greater meaning and connection in their lives. Although some dancers express interest in exploring dance as an art art, a personal creative endeavor, other dancers see belly dance as a gateway to learning more about Eastern cultures. Furthermore, belly dance did not come from one culture and many dancers recognize that fact. Glossing all American belly dance as homogeneous further essentializes the East by supporting Orientalist dichotomies. Disrupting the assumption of homogeneity in this dance community, with the messy complications of complexity, in my opinion, posits questions of greater interest for future research. For example, will the diversity of this community splinter it into different factions or will it remain socially cohesive? How does the diversity within the American belly dance community influence the international spread of Oriental dance?

${ }^{53}$ See Introduction. 
Many of the dancers I interviewed acknowledged Orientalism ${ }^{54}$ but did not avoid it because they need it to carry the message of alternative femininity, spearhead the quest for community and provide an alternative to mainstream consumerism. Shay and SellersYoung also observed that although Orientalism may lead to disrespectful misrepresentation, dancers participate because of their deep love for the dance (2003: 26). Belly dance permits practitioners to pursue subversive projects, thereby defining the social body by occupying this marginal position. Yet the corset of the expectations of mass media representation, consumerism, and social ideals still binds many American women. Although many women want to celebrate alternative feminine identities, explore alternative modes of consumerism and gain membership to an all-inclusive community of women, internal conflicts persist. "Backstage" belly dancers may adhere, for example, to mainstream ideals in terms of body type. Additionally, the entrepreneurial efforts of performers, instructors and vendors who depend upon the class privilege of middle-class women who have the expendable income to spend on belly dance products and events largely drives the belly dance community.

In the East, most women learn the rules of belly dance while dancing with friends and family members in private homes. In the West, belly dancers learn a form largely based on Orientalist reconstructions and the performances of professional dancers, undoubtedly stigmatized for their dancing in the East. American belly dance, historically disconnected from its original domestic and ritual context, is an Occidentalized version of

\footnotetext{
${ }^{54}$ Many informants brought up the concept of Orientalism during my research interviews. Belly dancers know of Orientalism; in fact many belly dance magazines such as Habibi feature articles by dance scholars (PhDs) addressing topics such as the history of the dance, Orientalism and the social implications of American belly dance.
} 
Oriental dance. In the East, women who dance in the home share common criteria of what constitutes a "good" dancer, for example, modesty and demure movements. Dancers who stray from the rules are considered deviant. Many Arabs and Arab Americans consider Western belly dance a deviant version of an Arabic dance. Deaver suggests that "deviance compounded and perpetuated is cultural change" (1978: 17). As American belly dancers continue to explore their art form in a more reflective and self-conscious way, will American belly dance no longer reference Eastern cultures?

I wish to underscore that a study of American belly dance reveals much about linkages between gender and alterity and dance's reflection of the larger society. A certain functionality inherent in Orientalist discourse exposes the concerns, anxieties and desires of the Occident. The invented tradition of American belly dance exists because it fills a cultural vacancy in American society and must continually engage in a dialectic of reevaluation and revision by its participants to remain relevant. As belly dancers continue to educate themselves, draw from a global inventory of inspirations and influences, and experiment with heterodox forms, they move away from direct connections to the exotic Orient and delving deeper into the exotic Occident. I disagree with authors such as Maira (2008) and Desmond (1991) who suggest that white American belly dancers "try on" different ethnicities. ${ }^{55}$ In the constant quest for exoticism, dancers discover the exotic Self.

\section{Implications of this Research}

${ }^{55}$ This may have been true for American belly dancers in earlier decades, but I argue is less true now and current trends suggest an increasing distance from this supposition. 
In contemplation of how belly dance provides an outlet of expression for the predominantly white, middle-class American women who participate in this dance form, I pose the question: Can the white woman speak? ${ }^{56}$ I acknowledge that much of the belly dance phenomenon stems from Orientalist discourse and the imperialist privilege of consuming cultural fragments for often, ephemeral creative pursuits. But I believe there is something deeper here than just imperialism. Many white women experience utter dissatisfaction with mainstream culture and rely upon such alternative outlets, as belly dance, to express parts of themselves they feel are repressed by normative social formations. This study makes an important contribution to cultural anthropology and feminist theory because it demonstrates that although many American women reinforce racial stereotypes, their actions still empower them as feminists. This study also broadens understanding of identity politics and agency. Many American belly dancers are aware of the potentially negative implications of Orientalism, yet they continue to navigate this discourse in order to pursue identity. Similar to the Sri Lankan factory workers Lynch describes as "Juki Girls," American belly dancers are agents who creatively and strategically utilize discursive motifs to accomplish social and personal goals (2007).

The perpetuation of the myth of Orientalism and American associations between fantasies of the exotic female Other and belly dance persist. For example, in the 2001 text Moving History/Dancing Cultures: A Dance History Reader, the chapter on belly dance opens with the statement that belly dance "has a history as rich and mysterious as the countries of the Far East from which it originates" (Helland 2001: 128). This chapter goes on to make dubious claims: the dance originated from the "free-spirited wild

${ }^{56}$ Here I reference Gayatri Spivak’s famous question, “Can the subaltern speak?” (1985). 
mannered lifestyle" of the Ghawazee; the dances of Ruth St. Denis were "based on authentic oriental movement;" and in the 1970s "Hollywood begins to use real belly dancers and genuine Arabic music" (Helland 2001: 129-135). According to my research and that of others, all of these statements, written for a 2001 text designed for universitylevel dance students, utilize Orientalist inaccuracies that I have investigated and debunked throughout this study. The salience and convenience of Orientalist discourse prevails, perpetuating the polarity between $u$ s and them.

But does the polarity of Orientalism hold any accuracy? For example, the East stereotypically imagines the Western world as consumption-obsessed, materialistic and driven by greedy capitalism. But are Western cultures the only ones who desire certain brand names or associate certain consumer products with social status?

Orientalist/Occidentalist dichotomies provide the framework in which to explore perceptions of Self by comparison with the Other. My analytical dissatisfaction with Orientalism in the study of American belly dance arises from the pervading popularity of belly dance and the ubiquity of Orientalist fantasies about the exotic feminine in the practice of belly dance. In other words, why does the Arab female Other permit such a powerful identity construction for white American women? The Arab female Other, perceived as so distant, so remote, so ensnared in an anachronistic geography, provides an empty location for identity construction. The continued salience of Orientalist tropes in American culture, especially those concerning the Arab female Other, remains an important topic for future research.

As I study American belly dancers' struggles with issues of cultural appropriation, artistic license, standardization, respectability, identity, community, inclusion, and 
accountability I ask these provocative questions: Do American dancers ultimately want belly dance to be an art form; an empowering practice making performance irrelevant; a statement against bourgeois art; a political statement about unity and/or an ethnographic study to promote cross-cultural understanding? Are not most modern art forms collections or conglomerations of various influences? The evolution of modern American belly dance appears to imply a trajectory moving away from the Oriental and towards a reflection of the American experience in a postmodern context. In the future, can belly dance to become "its own thing" without reference to cultural appropriation or bastardization? Can American dancers embrace their exotic Selves? Furthermore, one informant suggested, "Belly dancers are going to save the world, because the dance belongs to the world." American belly dancers view themselves in the context of an internationally expanding community of dancers engaged in a global dialogue that transcends political boundaries and hopes to illuminate the unifying elements of this ever evolving dance form.

\section{Future Research}

In addition to the above questions regarding the future stability of the belly dance community and the future meaning of Self and exoticism in belly dance, I believe that fruitful avenues for future research of American belly dance concern the expanding role of technology and Internet in the globalization of the belly dance phenomenon. Does technology have an equalizing force in terms of class access? Will mass cultural diffusion continue through the Internet? In a tribal fusion performance DVD I analyzed, collections of cultural references and theatrical elements are packaged as global and cutting edge, 
and are marketed to the international dance community. My observations included the following:

She wears a little top hat perched saucily atop her head. A vest with a coin bra and chest tattoos underneath. She has a red and black lacy petticoat short enough to show stocking covered legs and heels. She wears a striped and black satin overskirt that she quickly discards early in the performance. She dances to Balkan flavored music, women singers execute intricate and wandering harmonies. All the while, the dancer makes the facial expressions of a surprised and coy babydoll, looking particularly shocked as she choreographically discards her overskirt (Katie Kay performance, Tribal Revolution DVD, 2008).

Will the international belly dance community respond differently than the American dancers to such performances?

Desmond suggests the need for future research on tourism and ways that tourists interpret their travel experiences. She encourages alternative modes of tourism that incite tourists' interest in cultural histories (1999: 258-260). Based on my preliminary research experiences in Morocco, belly dance tourism presents a rich area for future study, and specifically studies concerning the response of the tourist economy to the presence of belly dance tourists and the interpretations and experiences of belly dance tourists. These types of investigation could reveal insights into the mass global pop-culturization of belly dance, spread by the international influence of such groups as the Belly Dance Superstars, as well as the Internet. This study could further reveal the effects of postmodernization on local culture and illustrate ways individual agents participate in, avoid, resist, or justify social flux. 


\section{References}

Abu-Lughod, Lila

1990 The Romance of Resistance: Tracing Transformations of Power Through Bedouin Women. American Ethnologist 17(1): 41-55.

1986 Veiled Sentiments: Honor and Poetry In A Bedouin Society. Berkeley: University of California Press.

Al Faruqi, Lois Ibsen

1976 Dance of Muslim Peoples. Dance Scope 11(10): 43-51.

Alloula, Malek

1986 The Colonial Harem. Minneapolis: University of Minnesota Press.

Al-Rawi, Rosina-Fawzia

1999 Grandmother's Secrets: The Ancient Rituals and Healing Power of Belly Dancing. New York: Interlink Books.

AlZayer, Penni

2004 World of Dance: Middle Eastern Dance. Philadelphia: Chelsea House Publishers.

Anderson, Benedict

1991 Imagined Communities: Reflections on the Origin and Spread of Nationalism. London and New York: Verso.

Bahrani, Zainab

1998 Conjuring Mesopotamia: Imaginative Geography and a World Past. In Archeology Under Fire: Nationalism, Politics and Heritage in the Eastern Mediterranean and Middle East. Lynn Meskell, ed. Pp. 159-174. London: Routledge.

Beck, Elizabeth

1991 Rakkasah- An American Middle Eastern Dance Festival: Exoticism and Orientalism in the Twentieth Century. UCLA Journal of Dance Ethnology 15: 26-32.

Bellydance Superstars

2009 Tribal Fusion Fundamentals. 122 minutes. Vivendi Entertainment.

2008 Tribal Revolution: Tribal Fusion Bellydance Performance. 70 minutes. Hollywood Music Center.

2005 American Bellydancer. 88 minutes. Ark 21. Miles Copeland.

Briggs, David 
2008 Belly dancing as a vehicle for spiritual exploration. National Catholic Reporter. January 19: 12.

Bourdieu, Pierre

1994 Structure, Habitus, Power: Basis for a Theory of Symbolic Power. In Culture/ Power/ History: A Reader in Contemporary Social Theory. Nicholas B. Dirks, Geoff Eley, and Sherry B. Ortner, eds. Pp. 155-199. Princeton: Princeton University Press.

Brubaker, Rogers and Frederick Cooper

2000 Beyond "Identity." Theory and Society 29: 1-47.

Buonaventura, Wendy

2003 Something in the Way She Moves: Dancing Women from Salome to Madonna. United Kingdom: Da Capo Press.

1998 Serpent of the Nile: Women and Dance in the Arab World. New York: Interlink Books.

1983 BellyDancing: The Serpent and the Sphinx. London: Virago Press.

Carlton, Donna

1994 Looking for Little Egypt. Bloomington, Indiana: IDD Books.

Christopher, Z-Helen

2000 The Emergence of the New Sacred Temple Priestess. Habibi 18(2): 46-51.

Copeland, Suzanne Shakti

2000 The Serpent Dance Journey. In The Belly Dance Book: Rediscovering the Oldest Dance. Tazz Richard, ed. Pp. 72-73. Concord, CA: Backbeat Press.

Crobsy, Janice

2000 The Goddess Dances: Spirituality and American Women's Interpretations of Middle Eastern Dance. In Daughters of the Goddess: Studies of Healing, Identity and Empowerment. Wendy Griffin, ed. Pp. 166-182.

New York: Rowman \& LittleField Publishers.

Croutier, Alev Lytle

1989 Harem: The World Behind the Veil. New York: Abbeville Press.

Davies, Kristian

2005 The Orientalists: Western Artists in Arabia, The Sahara, Persia \& India.

New York: Laynfaroh.

Deagon, Andrea

2005 The Dance of the Seven Veils: The Revision of Revelation in the Oriental Dance Community. In Belly Dance: Orientalism, Transnationalism and 
Harem Fantasy. Anthony Shay and Barbara Sellers-Young, eds. Pp. 243275. Costa Mesa, California: Mazda Publishers.

Deaver, Sherri

1978 Concealment vs. Display: The Modern Saudi Woman. Dance Research Journal 10(2): 14-18.

Desmond, Jane

1999 Staging Tourism: Bodies on Display from Waikiki to Sea World. Chicago: The University of Chicago Press.

1991 Dancing Out the Difference: Cultural Imperialism and Ruth St. Denis's Radha of 1906. Signs: Journal of Women in Culture and Society 17(1): 28-49.

Diallo-Huisman, "Shahrazad" C.

2002 The Rebirth of the Sacred Dancer. Habibi 19(2): 46-55.

Djoumahna, Kajira

2003 The Tribal Bible: Exploring the Phenomenon That is American Tribal Bellydance. Santa Rosa: Kajira Djoumahna.

2000 Belly Dance- In Brief. In The Belly Dance Book: Rediscovering the Oldest Dance. Tazz Richards, ed. Pp. 10-13. Concord, CA: Backbeat Press.

Dougherty, Roberta

2005 Dance and the Dancer in Egyptian Films. In Belly Dance: Orientalism, Transnationalism and Harem Fantasy. Anthony Shay and Barbara SellersYoung, eds. Pp. 145-171. Costa Mesa, California: Mazda Publishers.

Dox, Donalee

2006 Dancing Around Orientalism. The Drama Review 50(4): 52-71.

2005 Spirit from the Body: Belly Dance as a Spiritual Practice. In Belly Dance: Orientalism, Transnationalism and Harem Fantasy. Anthony Shay and Barbara Sellers-Young, eds. Pp. 303-340. Costa Mesa, California: Mazda Publishers.

Edwards, Brian T.

2005 Morocco Bound: Disorienting America's Maghreb, From Casablanca to the Marrakech Express. Durham and London: Duke University Press.

Edwards, Holly

2000 Noble Dreams, Wicked Pleasures: Orientalism in American, 1879-1930.

Princeton: Princeton University Press in Association with the Sterling and Francine Clark Art Institute. 
Elder, Lee Erica

2008 Belly Dance. Dance Spirit 12(2): 68-72.

Erdman, Joan L.

1996 Dance Discourses: Rethinking the History of the 'Oriental Dance.' In Moving Words: Rewriting Dance. Gay Morris, ed. London and New York: Routledge.

Ferreday, Debra

2008 'Showing the girl': The new burlesque. Feminist Theory 9(1): 47-65.

Finney, Gail

1998 Demythologizing the Femme Fatale: Wilde's Salome. In The Routledge Reader in Gender and Performance. Lizbeth Goodman and Jane de Gay, eds. Pp. 182-186. London and New York: Routledge.

Fraser, Kathleen

1993 Aesthetic Explorations of the Egyptian Oriental Dance Among Egyptian Canadians. UCLA Journal of Dance Ethnology 17: 58-66.

Friedlander, Jonathan

2009 America's North Africa: An Exhibition of Pop Culture Literature and Artifacts. Powell Library Rotunda, UCLA. March 2009.

Gioseffi, Daniela

1980 Earth Dancing: Mother Nature's Oldest Rite. Harrisburg, PA: Stackpole Books.

Gupta, Akhil and James Ferguson

1992 Beyond 'Culture': Space, Identity and the Politics of Difference. Cultural Anthropology 7(1):6-23.

Hall, Stuart

1992 The Question of Cultural Identity. In Modernity and Its Futures. Stuart Hall, D. Held, and T. McGrew, eds. Pp. 274-325. Cambridge: The Open University.

Helland, Shawna

2001 The Belly Dance: Ancient Ritual to Cabaret Performance. In Moving History/Dancing Cultures: A Dance History Reader. Ann Dils and Ann Cooper Albright, eds. Pp. 128-135. Middletown, Connecticut: Wesleyan University Press.

Hobin, Tina

2003 Belly Dance: The Dance of Mother Earth. London: Marion Boyars. 
Hobsbawm, Eric

1983 Introduction: Inventing Traditions. In The Invention of Tradition. Eric Hobsbawm and Terence Ranger, eds. Pp. 1-14. Cambridge: Cambridge University Press.

Holland, Samantha

2004 Alternative Feminities: Body, Age, and Identity. Oxford: Berg.

Hollows, Joanne

2000 Feminism, Femininity and Popular Culture. New York: Manchester University Press.

Jarmakani, Amira

2008 Imaging Arab Womanhood: The Cultural Mythology of Veils, Harems and Belly Dancers in the U.S. New York: Palgrave MacMillan.

2006 Belly Dancing for Liberation: A Critical Interpretation of Reclamation Rhetoric in the American Belly Dance Community. In Arabs in the Americas: Interdisciplinary Essays on the Arab Diaspora. Darcy A. Zabel, ed. Pp. 145-168. New York: Peter Lang.

Kamal-Eldin, Tania

1999 Hollywood Harems. 24 min. Women Make Movies Distributors. Egypt.

Kapchan, Deborah A.

1994 Moroccan Female Performers Defining the Social Body. The Journal of American Folklore 107(423): 82-105.

Karayanni, Stavros Stavrou

2005 Dismissal Veiling Desire: Kuchuk Hanem and Imperial Masculinity. In Belly Dance: Orientalism, Transnationalism and Harem Fantasy. Anthony Shay and Barbara Sellers-Young, eds. Pp. 114-143. Costa Mesa, California: Mazda Publishers.

2004 Dancing Fear \& Desire: Race, Sexuality \& Imperial Politics in Middle Eastern Dance. Waterloo, Ontario, Canada: Wilfrid Laurier University Press.

Lorius, Cassandra

1996a Desire and Gaze: Spectacular Bodies in Cairene Elite Weddings. Women's Studies International Forum 19(5): 513-523.

$1996 b$ 'On Boy, You Salt of the Earth': Outwitting Patriarchy in Raqs Baladi. Popular Music 15(3): 285-298.

1990 Raqs Sharqi: a re-Evaluation of Egypt's Art Dance. Dance Theatre Journal 8(3): 10-13. 
Lynch, Caitrin

2007 Juki Girls, Good Girls: Gender and Cultural Politics in Sri Lanka’s Global Garment Industry. Ithaca: ILR Press/Cornell University Press.

MacKenzie, John M.

1995 Orientalism: History, Theory and the Arts. Manchester: Manchester University Press.

Maira, Sunaina

2008 Belly Dancing: Arab-Face, Orientalist Feminism, and U.S. Empire. American Quarterly 317-345.

2000 Henna and Hip Hop: The Politics of Cultural Production and the Work of Cultural Studies. Journal of Asian American Studies. October, 329-369.

Mernissi, Fatema

2001 Scheherazade Goes West: Different Cultures, Different Harems. New York: Washington Square Press.

1994 Dreams of Trespass: Tales of a Harem Girlhood. Reading, Mass.:

Addison-Wesley Publishing Company.

1987 Beyond the Veil: Male-Female Dynamics in Modern Muslim Society. Bloomington and Indianapolis: Indiana University Press.

Meskell, Lynn

1998 Introduction: Archaeology Matters. In Archeology Under Fire:

Nationalism, Politics and Heritage in the Eastern Mediterranean and

Middle East. Lynn Meskell, ed. Pp. 1-12. London: Routledge.

Mishkin, Julie Russo and Marta Schill

1973 The Compleat Belly Dancer. New York: Doubleday and Company, Inc.

Mohanty, Chandra Talpade

2003 Feminism Without Borders: Decolonizing Theory, Practicing Solidarity. Durham \& London: Duke University Press.

Monty, Paul Eugene

1986 Serena, Ruth St. Denis and the Evolution of Belly Dance in America (1876-1976). Ph. D. dissertation, Department of Education, Health, Nursing and Arts Profession, New York University.

Mourat, Elizabeth Artemis

2000 Dance of Ancient Egypt In The Belly Dance Book: Rediscovering the

Oldest Dance. Tazz Richard, ed. Pp. 42-51. Concord, CA: Backbeat Press.

Najwa, Adra 
2005 Belly Dance: an Urban Folk Genre. In Belly Dance: Orientalism, Transnationalism and Harem Fantasy. Anthony Shay and Barbara SellersYoung, eds. Pp. 28-50. Costa Mesa, California: Mazda Publishers.

Ortner, Sherry B.

2006 Identities: The Hidden Life of Class. In Anthropology and Social Theory. Pp. 63-79. Durham: Duke University Press.

Perez, Nissan N.

1988 Focus East: Early Photography in the Near East (1839-1885). New York: Harry N. Abrams, Inc., Publishers.

Potuoglu-Cook, Okyu

2006 Beyond the Glitter: Belly Dance and Neoliberal Gentrification in Istanbul. Cultural Anthropology 21(4): 633-660.

Rasmussen, Anne

2005 An Evening in the Orient. In Belly Dance: Orientalism, Transnationalism and Harem Fantasy. Anthony Shay and Barbara Sellers-Young, eds. Pp. 172-206. Costa Mesa, California: Mazda Publishers.

Rinn, Cecelia and Chad Rinn

2009 Belly. Full length. Full Tilt Boogie L.L.C. Boise, Idaho.

Rubidge, Sarah

1993 Modern Movement and Traditional Tales. Dance Theater Journal 10(3): 32-37.

Rutyer, Nancy Lee

2005 La Meri and Middle Eastern Dance. In Belly Dance: Orientalism, Transnationalism and Harem Fantasy. Anthony Shay and Barbara SellersYoung, eds. Pp. 207-220. Costa Mesa, California: Mazda Publishers.

Said, Edward

2000 Reflections on Exile and Other Essays. Cambridge, Mass.: Harvard University Press.

1978 Orientalism. New York: Vintage Books.

Savigliano, Marta E.

1995 Tango and the Political Economy of Passion. Boston: Westview Press.

Seigel, Marcia B.

1995 On Multiculturality and Authenticity: A Critical Call to Arms. In Looking Out: Perspectives on Dance and Criticism in a Multicultural World. David Gere, ed. Pp. 223-231. New York: Schirmer Books. 
Sellers-Young, Barbara

2005 Body, Image, Identity: American Tribal Belly Dance. In Belly Dance: Orientalism, Transnationalism and Harem Fantasy. Anthony Shay and Barbara Sellers-Young, eds. Pp. 277-303. Costa Mesa, California: Mazda Publishers.

1992 Raks El Sharki: Transculturation of a Folk Form. Journal of Popular Culture 26(2): 141-152.

Shaheen, Jack G.

2001 Reel Bad Arabs: How Hollywood Vilifies a People. New York: Olive Branch Press.

1984 The TV Arab. Bowling Green, Ohio: Bowling Green State University Popular Press.

Shay, Anthony

2008 Dancing Across Borders: The American Fascination with Exotic Dance Forms. Jefferson, NC: McFarland \&Company.

2006 Choreographing Identities: Folk Dance, Ethnicity and Festival in North America. Jefferson, NC: McFarland \& Company.

2005a Dance and Jurisprudence in the Islamic Middle East. In Belly Dance: Orientalism, Transnationalism and Harem Fantasy. Anthony Shay and Barbara Sellers-Young, eds. Pp. 85-113. Costa Mesa, California: Mazda Publishers.

2005b The Male Oriental Dancer. In Belly Dance: Orientalism, Transnationalism and Harem Fantasy. Anthony Shay and Barbara Sellers-Young, eds. Pp. 51-84. Costa Mesa, California: Mazda Publishers.

Shay, Anthony and Barbara Sellers-Young

2005 Introduction. In Belly Dance: Orientalism, Transnationalism and Harem Fantasy. Anthony Shay and Barbara Sellers-Young, eds. Pp. 1-27. Costa Mesa, California: Mazda Publishers.

2003 Belly Dance: Orientalism: Exoticism: Self-Exoticism. Dance Research Journal. 35(1): 13-37.

Spivak, Gayatri Chakravorty

1985 Can the Subaltern Speak? Speculations on Widow Sacrifice. Wedge 7/8: 120-130.

Stewart, Iris

2000 Sacred Women, Sacred Dance: Awakening Spirituality Through Movement \& Ritual. Rochester, Vermont: Inner Traditions.

Studlar, Gaylyn 
1997 "Out- Salomeing Salome": Dance, the New Woman, and Fan Magazine Orientalism. In Visions of the East: Orientalism in Film. Matthew Bernstein and Gaylyn Studlar, eds. Pp. 99-129. New Brunswick, New Jersey: Rutger University Press.

Thornton, Lynne

1994 Women As Portrayed In Orientalist Painting. Paris: ACR PocheCouleur.

Van Nieuwkerk, Karin

2001 Changing Images and Shifting Identities: Female Performers in Egypt. In Moving History/Dancing Cultures: A Dance History Reader. Ann Dils and Ann Cooper Albright, eds. Pp. 136-143. Middletown, Connecticut. Wesleyan University Press.

1995 A Trade Like Any Other: Female Singers and Dancers in Egypt. Austin: University of Texas Press.

Villa, Elena M.

2006 Eloquent Flesh: Cross-Cultural Figurations of the Dancer in Nineteenthand Twentieth-Century Literature. Ph. D. dissertation, Department of Comparative Literature, University of Oregon.

Wilson, Serena and Alan

1972 The Serena Technique of Belly Dancing: The Fun Way To a Trim Shape. New York: Drake Publishers Inc.

Wood, Leona and Anthony Shay

1976 Danse du Ventre: A Fresh Appraisal. Dance Research Journal 8(2): 18-30. 